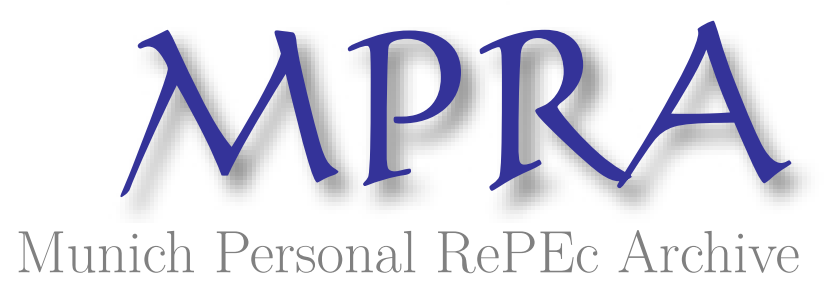

\title{
What happens if in the principal component analysis the Pearsonian is replaced by the Brownian coefficient of correlation?
}

Mishra, Sudhanshu K

North-eastern Hill University, Shillong, India

29 June 2014

Online at https://mpra.ub.uni-muenchen.de/56861/

MPRA Paper No. 56861, posted 28 Jun 2014 05:49 UTC 


\title{
What happens if in the Principal Component Analysis the Pearsonian is replaced by the Brownian coefficient of correlation?
}

\author{
Sudhanshu K. Mishra \\ Department of Economics \\ North-Eastern Hill University, Shillong (India) \\ Contact: mishrasknehu@yahoo.com
}

\begin{abstract}
The Brownian correlation has been recently introduced by Székely et al. (2007; 2009), which has an attractive property that when it is zero, it guarantees independence. This paper investigates into the effects and advantages, if any, of replacement of the Pearsonian coefficient of correlation ( $r$ ) by the Brownian coefficient of correlation (say, $\rho$ ), other things remaining the same. Such a replacement and analysis of its effects have been made by the Host-Parasite Coevolutionary algorithm of global optimization applied on six datasets.
\end{abstract}

Keywords: Brownian correlation, Principal Component Analysis, Global Optimization, HostParasite Co-evolutionary algorithm, Iris Flower Dataset, 1985 Auto Imports Database, Levy distribution, outliers.

JEL Classification: C13, C43, C45, C61, C63, C87 


\section{Introduction}

Principal Component Analysis (PCA) is a statistical analysis of fundamental importance when dimensionality reduction of the multivariate data or construction of best representative composite indices is needed. It finds its application in almost any branch of science ranging from anthropology to zoology. Given a dataset $\mathrm{X}(\mathrm{m})$ in $\mathrm{n}$ observations on $\mathrm{m}$ variables, it obtains a set of composite variables $\mathrm{Z}\left(\mathrm{m}_{1}\right) ; \mathrm{m}_{1} \leq \mathrm{m}$ such that:

(1) $Z_{k}$ is a linear combination of original variables, $X_{j} ; j=1, m$, that is, $Z_{k}=\Sigma_{j} X_{j} \cdot a_{j, k} ; k=1$, $\mathrm{m}_{1}$, where $\mathrm{m}_{1} \leq \mathrm{m}$.

(2) The sum of squared (Pearsonian) coefficients of correlation between a given composite variable $Z_{k}$ and all original variables $X_{j} ; j=1, m$, that is, $\Sigma_{j} r^{2}\left(X_{j}, Z_{k}\right) ; k=1, m_{1}$, is maximized. Each $\mathrm{Z}_{\mathrm{k}}$ is associated with a local optimum, although one of them (practically, almost always) attains a unique global optimum.

(3) Any two composite variables, $\mathrm{Z}_{\mathrm{k}}$ and $\mathrm{Z}_{\mathrm{k}}$; $\mathrm{k}, \mathrm{k}^{\prime}=1, \mathrm{~m}_{1} ; \mathrm{k} \neq \mathrm{k}^{\prime}$ are orthogonal to each other, that is, the dot product $Z_{\mathrm{k}} Z_{\mathrm{k}}$, $=0$.

This paper investigates into the question as to replacement of the Pearsonian coefficient of correlation (r) by the Brownian coefficient of correlation (say, $\rho$ ), other things remaining the same.

\section{The Brownian Coefficient of Correlation}

The Pearsonian coeffient of correlation needs no introduction, but the Brownian coefficient of correlation (also known as the distance correlation) was introduced in 2005 by G.J. Székely in his lectures and later published by him and his coauthors (Székely et al., 2007; Székely and Rizzo, 2009). It was shown that the Brownian correlation is a generalization of the Pearsonian correlation in the sense that the former is applicable to the relationship between two sets of variables of the same or different dimensions, equal to or larger than one, while the latter is limited to two sets of variable each being a singleton. Secondly, as it is well known, the Pearsonian correlation is limited to the linear relationship between two variables and, therefore, Pearsonian uncorrelatedness $(\mathrm{r}=0)$ does not imply independence. The Brownian correlation addresses this problem such that $\rho=0$ implies independence and the relationship among the variables need not be linear. However, while the Pearsonian coefficient of correlation ranges between $[-1,1]$, the Brownian coefficient of correlation ranges between $[0,1]$. In this aspect, it behaves much like the squared value of Pearsonian coefficient of correlation.

Fig.1. Plot of Eckerle and NIST Data

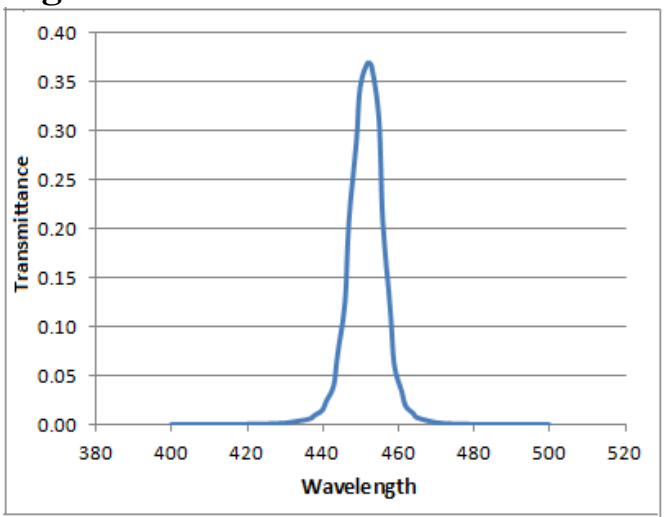

In severely nonlinear data when the Pearsonian coefficient of correlation may be near zero, the Brownian coefficient of correlation may be quite large. Székely and Rizzo (2009) cite a case from Eckerle and NIST (1979) where the Pearsonian coefficient of correlation (r) between wavelength (x) and transmittance (y) is 0.0356 , statistically showing linear independence of $\mathrm{y}$ with $\mathrm{x}$. However, the Brownian coefficient of correlation $(\rho)$ is 0.4275431 , showing significant dependence of $y$ on $\mathrm{x}$. We have obtained $\mathrm{r}=0.03844$ and $\rho=0.42744$ from the data (35 observations) provided by Eckerle and NIST (1979). 
The computational steps of the Brownian coefficient of correlation are given below.

i. Let $X$ and $Y$ be two sets of $p$ and $q$ number of variables (respectively), each in $n$ observations, such that $x_{i, j} \in X ; i=1, n ; j=1, p$ and $y_{i, j} \in Y ; i=1, n ; j=1, q$. Moreover, $p, q \geq 1$.

ii. Compute

$$
\begin{aligned}
& a_{i, j} \in A: a_{i, \mathrm{j}}=\left\|X_{i} \cdot-X_{j} \cdot\right\|=\left(\sum_{k=1}^{p}\left(x_{i, k}-x_{j, k}\right)^{2}\right)^{1 / 2} ; i, j=1, n . \\
& b_{i, \mathrm{j}} \in B: b_{i, \mathrm{j}}=\left\|Y_{i} \cdot-Y_{j} \cdot\right\|=\left(\sum_{k=1}^{q}\left(y_{i, k}-y_{j, k}\right)^{2}\right)^{1 / 2} ; i, j=1, n . \\
& \bar{a}_{i}=\sum_{j=1}^{n} a_{i, j} / n ; \bar{b}_{i}=\sum_{j=1}^{n} b_{i, j} / n ; \quad \bar{a}_{j}=\sum_{i=1}^{n} a_{i, j} / n ; \bar{b}_{j}=\sum_{i=1}^{n} b_{i, j} / n \\
& \bar{a}=\sum_{i=1}^{n} \bar{a}_{i} / n=\sum_{j=1}^{n} \bar{a}_{j} / n ; \quad \bar{b}=\sum_{i=1}^{n} \bar{b}_{i} / n=\sum_{j=1}^{n} \bar{b}_{j} / n
\end{aligned}
$$

iii. Centralize $A$ to $A^{\prime}$ and $B$ to $B^{\prime}$ such that

$$
a_{i, j}^{\prime}=a_{i, j}-\left(\bar{a}_{i}+\bar{a}_{j}\right)+\bar{a} \text { and } b_{i, j}^{\prime}=b_{i, j}-\left(\bar{b}_{i}+\bar{b}_{j}\right)+\bar{b}
$$

iv. Compute $\operatorname{cov}(\mathrm{X}, \mathrm{Y}), \operatorname{var}(\mathrm{X})$ and $\operatorname{var}(\mathrm{Y})$, the last two $(\operatorname{var}(\mathrm{X})$ and $\operatorname{var}(\mathrm{Y}))$ being the special cases of the first $(\operatorname{cov}(\mathrm{X}, \mathrm{Y}))$.

$$
\begin{aligned}
& \operatorname{Cov}(X, Y)=\left(\left(1 / n^{2}\right) \sum_{i=1}^{n} \sum_{j=1}^{n} a_{i, j}^{\prime} b_{i, j}^{\prime}\right)^{0.5} \quad ; \quad \operatorname{Var}(X)=\left(\left(1 / n^{2}\right) \sum_{i=1}^{n} \sum_{j=1}^{n} a_{i, j}^{\prime} a_{i, j}^{\prime}\right)^{0.5} \\
& \operatorname{Var}(Y)=\left(\left(1 / n^{2}\right) \sum_{i=1}^{n} \sum_{j=1}^{n} b_{i, j}^{\prime} b_{i, j}^{\prime}\right)^{0.5}
\end{aligned}
$$

v. Compute the Brownian coefficient of correlation $\rho(X, Y)$

$$
\rho(X, Y)=\operatorname{Cov}(X, Y) /(\operatorname{Var}(X) \cdot \operatorname{Var}(Y))^{0.5}
$$

\section{Principal Component Analysis based on Brownian correlation}

For simplicity, let $X$ be a set of $m(m \geq 1)$ subsets of variables, or $\mathrm{X}=\left[X_{1}, X_{2}, \ldots, X_{m}\right]$. Let every $X_{j} ; j=1, m$ be one-dimensional and having $n$ observations (replicates). Thus, $X_{j}=X_{j}(n, 1) \forall j=1, m$. Our objective is to find $\mathrm{Z}(\mathrm{n}, 1)=Z_{1}=\sum_{j=1}^{m} X_{j} w_{j, 1}$. That is, $Z_{1}$ (the first principal component scores associated with the global optimum) is a linear combination (weighted sum) of $X_{j} ; j=1, m$. We have to obtain $w_{1}=\left[w_{1,1}, w_{2,1} \ldots, w_{m, 1}\right]$ such that $\sum_{j=1}^{m} \rho^{2}\left(Z_{1}, X_{j}\right)$ is maximized. It may be noted that $\rho^{2}\left(Z_{1}, X_{j}\right)$ is the squared Brownian coefficient of correlation between $Z_{1}$ and $X_{j}$. 


\section{Optimization of sum of squared Brownian correlation among $Z_{1}$ and $X_{j}$}

As formulated in the preceding section, our task is to find the (global) maximum of $\sum_{j=1}^{m} \rho^{2}\left(Z_{1}, X_{j}\right)$ with $w_{1}=\left[w_{1,1}, w_{2,1} \ldots, w_{m, 1}\right]$ as the decision variables. This may be accomplished by a suitable method of global optimization (such as the Genetic algorithm, Particle Swarm, the Differential Evolution, Host-Parasite Co-evolutionary algorithm, etc.). If, subsequently, other principal component scores are to be obtained, additional decision variables $w_{j}=\left[w_{1, j}, w_{2, j}, \ldots, w_{m, j}\right] ; j \neq 1$ and an independence constraint $\rho\left(Z_{1}, Z_{j}\right)=0$ may be incorporated in the optimization problem. Presently, we keep the issue of subsequent principal components scores ( $Z_{2}, Z_{3}$ etc.) and orthogonality (or independence) among them in abeyance.

\section{Materials and Methods}

In this investigation we have tested the effects of replacement of the Pearsonian correlation by the Brownian correlation in constructing the leading PC or the Principal Component scores $\left(\mathrm{Z}_{1}\right)$ on six datasets. These datasets are: (i) Iris flower dataset, (ii) Motor Car dataset, (iii) Sinusoidal dataset, (iv) Crime Incidence in India - 2011 dataset, (v) the dataset with outliers in variables, and (vi) Lévy Distributed Probability Density Function dataset.

For obtaining the leading PC scores we have used the Host-Parasite Coevolutionary algorithm of global optimization (Mishra, 2013) to directly work out the weight vector with which $Z_{1 P}$ (the leading Pearsonian PC scores) is computed as $Z_{i, 1 P}=\sum_{j=1}^{m} X_{i, j} w_{j, 1 P} ; i=1,2, \ldots, n$ and $\sum_{j=1}^{m} r^{2}\left(Z_{1 P}, X_{i, j}\right)$ is maximized for the Pearsonian correlation, r). The results are identical to the ones that we get using the SPSS package software that applies the traditional method (of eigen-decomposition of the Pearsonian correlation matrix among the variables, $X$ ). Similarly, we have computed $Z_{1 B}$ (the

leading Brownian PC scores) as $Z_{i, 1 B}=\sum_{j=1}^{m} X_{i, j} w_{j, 1 P} ; i=1,2, \ldots, n$ and $\sum_{j=1}^{m} \rho^{2}\left(Z_{1 B}, X_{i, j}\right)$ is maximized for the Brownian correlation, $\rho$ ). But, these results (based on the Brownian correlation) have no counterpart to be compared with, since there is no software or alternative algorithm to be used for this purpose. We have developed our own (Fortran) program for this purpose.

We have compared the performance of the leading PC scores based on the Brownian correlation with the leading PC scores based on the Pearsonian correlation. We have also presented the correlation matrices (both Pearsonian and Brownian) and their eigenvectors and eigenvalues with our observations on them. Wherever necessary or facilitating, we have given illustrative graphical presentation.

\section{Findings}

For the different datasets our findings are presented below.

6.1. Iris Flower Dataset: Anderson (1936) and Fisher (1936) collected and analyzed the data relating to the flowers of different species of Iris. Since Fisher applied his (linear) discriminant analysis on this dataset, it has been used by many researchers and now it is considered as a classic dataset. 
Description of Data: $\mathrm{X}_{1}=$ sepal length, $\mathrm{X}_{2}=$ sepal width, $\mathrm{X}_{3}=$ petal length, $\mathrm{X}_{4}=$ petal width. Flowers of different species of Iris. No. of observations: Iris setosa (50), Iris versicolor (50), Iris virginica (50); total no. of observation: 150 .

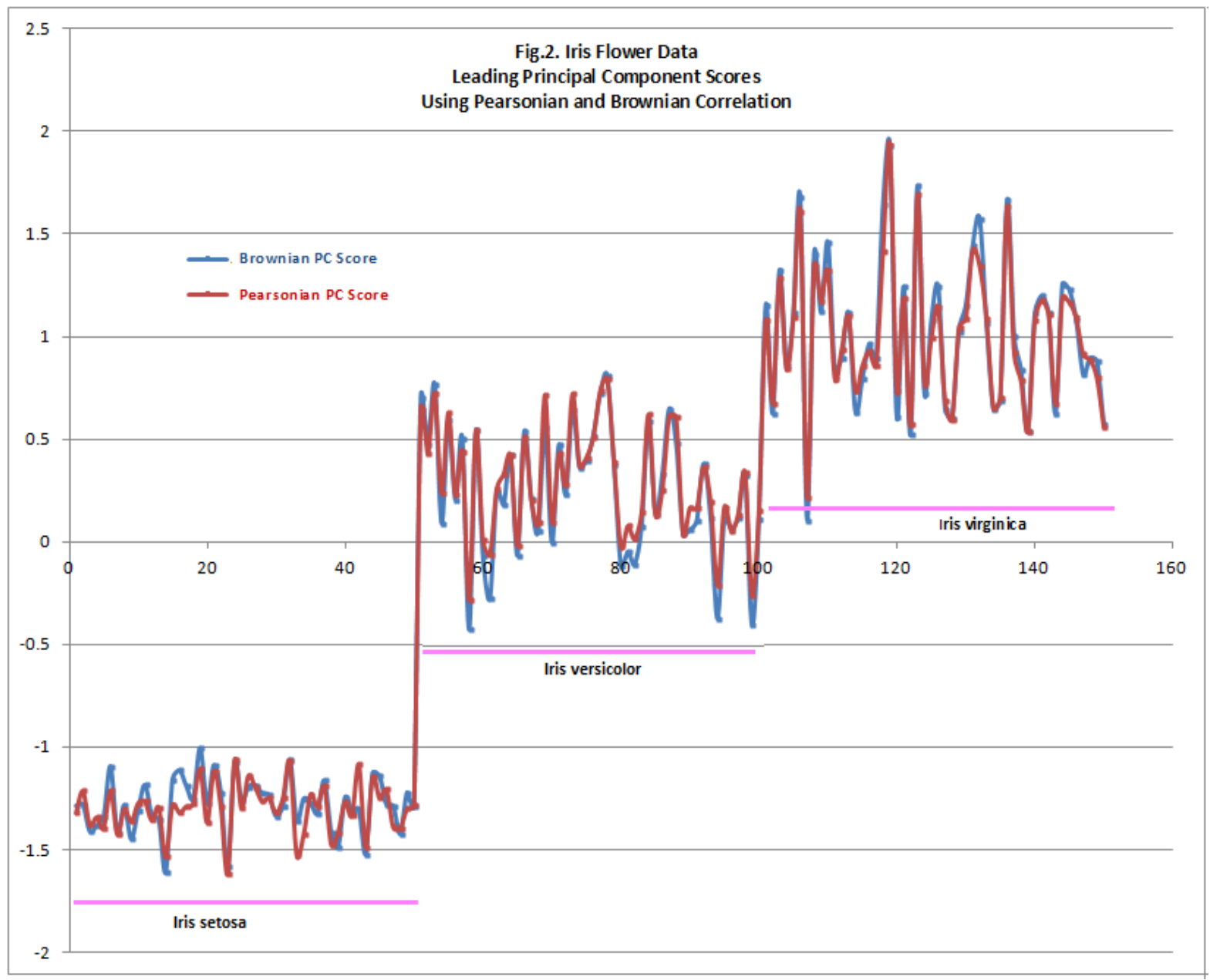

Findings: There is not much difference between the Brownian and Pearsonian leading PC scores. The coefficients of correlation ( $r$ and $\rho$ ) between them are $(0.99699,0.99727)$ respectively (see Table.1.1 and Table.1.2). However, the Brownian PC scores have relatively larger variance. They have been plotted in Fig.2. We observe that the three clusters of (the species of) Iris are clearly discernible. The details are given in Table.A1 in the appendix.

\begin{tabular}{|l|c|c|c|c|c|c|}
\hline \multicolumn{7}{|c|}{ Table.1.1. Pearsonian Correlation matrix of Iris Flower Dataset } \\
\hline Measures & Sepal length & Sepal width & Petal length & Petal width & Score(Brown) & Score(Pearson) \\
\hline Sepal length & 1.00000 & -0.11757 & 0.87175 & 0.81794 & 0.91406 & 0.89017 \\
\hline Sepal width & -0.11757 & 1.00000 & -0.42844 & -0.36613 & -0.39130 & -0.46014 \\
\hline Petal length & 0.87175 & -0.42844 & 1.00000 & 0.96287 & 0.99214 & 0.99156 \\
\hline Petal width & 0.81794 & -0.36613 & 0.96287 & 1.00000 & 0.96608 & 0.96498 \\
\hline Score(Brown) & 0.91406 & -0.39130 & 0.99214 & 0.96608 & 1.00000 & 0.99699 \\
\hline S core(Pearson) & 0.89017 & -0.46014 & 0.99156 & 0.96498 & 0.99699 & 1.00000 \\
\hline
\end{tabular}


The eigenvalues $(\lambda)$ and the associated eigenvectors $(V)$ of the Pearsonian and the Brownian correlation matrices (of X1 through X4) are given in Table.1.3 and Table.1.4. The Pearsonian leading PC scores explain $72.963 \%$ of the total variance in the data and it is commensurate with $72.963=100(\lambda 1 / 4)$. However, the Brownian leading PC scores explain $75.483 \%$ of the total variance in the data while 76.936 $=100(\lambda 1 / 4)$ is larger than that. This is a discrepancy which will be discussed at the end of this paper.

\begin{tabular}{|l|c|c|c|c|c|c|}
\hline \multicolumn{7}{|c|}{ Table.1.2. Brownian Correlation matrix of Iris Flower Dataset } \\
\hline Measures & Sepal length & Sepal width & Petal length & Petal width & Score(Brown) & Score(Pearson) \\
\hline Sepal length & 1.00000 & 0.31053 & 0.85852 & 0.82660 & 0.90101 & 0.87966 \\
\hline Sepal width & 0.31053 & 1.00000 & 0.54157 & 0.51300 & 0.52353 & 0.55212 \\
\hline Petal length & 0.85852 & 0.54157 & 1.00000 & 0.97363 & 0.99236 & 0.99208 \\
\hline Petal width & 0.82660 & 0.51300 & 0.97363 & 1.00000 & 0.97399 & 0.97297 \\
\hline Score(Brown) & 0.90101 & 0.52353 & 0.99236 & 0.97399 & 1.00000 & 0.99727 \\
\hline S core(Pearson) & 0.87966 & 0.55212 & 0.99208 & 0.97297 & 0.99727 & 1.00000 \\
\hline
\end{tabular}

\begin{tabular}{|c|c|c|c|c|}
\hline \multicolumn{5}{|c|}{ Table.1.3. Eigenvalues and Eigenvectors of } \\
Pearsonian Correlation matrix of Iris Flower Dataset \\
\hline Measures & $\lambda_{1}$ & $\lambda_{2}$ & $\lambda_{3}$ & $\lambda_{4}$ \\
\hline$\lambda$ & 2.918499 & 0.914030 & 0.146758 & 0.020713 \\
\hline$\lambda / 4$ & 0.729625 & 0.228507 & 0.036690 & 0.005178 \\
\hline $\mathrm{V}$ & $\mathrm{V}_{1}$ & $\mathrm{~V}_{2}$ & $\mathrm{~V}_{3}$ & $\mathrm{~V}_{4}$ \\
\hline 1 & 0.521065 & 0.377420 & -0.719575 & 0.261262 \\
\hline 2 & -0.269349 & 0.923295 & 0.244389 & -0.123500 \\
\hline 3 & 0.580413 & 0.024493 & 0.142153 & -0.801444 \\
\hline 4 & 0.564857 & 0.066940 & 0.634254 & 0.523619 \\
\hline
\end{tabular}

\begin{tabular}{|c|c|c|c|c|}
\hline \multicolumn{5}{|c|}{ Table.1.4. Eigenvalues and Eigenvectors of } \\
Brownian Correlation matrix of Iris Flower Dataset \\
\hline Measures & $\lambda_{1}$ & $\lambda_{2}$ & $\lambda_{3}$ & $\lambda_{4}$ \\
\hline$\lambda$ & 3.077445 & 0.738238 & 0.161808 & 0.022509 \\
\hline$\lambda / 4$ & 0.769361 & 0.184560 & 0.040452 & 0.005627 \\
\hline $\mathrm{V}$ & $\mathrm{V}_{1}$ & $\mathrm{~V}_{2}$ & $\mathrm{~V}_{3}$ & $\mathrm{~V}_{4}$ \\
\hline 1 & 0.504328 & -0.413653 & -0.748353 & 0.120470 \\
\hline 2 & 0.357569 & 0.898947 & -0.247231 & 0.053989 \\
\hline 3 & 0.560082 & -0.092801 & 0.305698 & -0.764359 \\
\hline 4 & 0.551458 & -0.110331 & 0.534222 & 0.631132 \\
\hline
\end{tabular}

6.2. Motor Car Dataset: The " 1985 Auto Imports Database" was compiled by J.C. Schlimmer from various sources such as (1) 1985 Model Import Car and Truck Specifications, 1985, Ward's Automotive Yearbook; (2) Personal Auto Manuals, Insurance Services Office, 160 Water Street, New York, (3) Insurance Collision Report, Insurance Institute for Highway Safety, Watergate 600 , Washington. The data pertains to 26 attributes of 205 models of automobile of different makes, with some information missing in case of some models. The dataset is archived on the website of Donald Bren School of Information and Computer Sciences (1996). A subset of this 
dataset was used by Kibler et al. (1989) to predict price of car using all numeric and Boolean attributes. In the present study we use only a smaller subset of data for 195 models - for which the complete numerical information on body and engine characteristics (13 variables) is available. These 13 variables are used for constructing the leading principal component scores with Pearsonian and Brownian correlation. The dataset also has information on price of car, which we use for regression analysis.

Description of Data: $\mathrm{X}_{1}=$ Wheelbase; $\mathrm{X}_{2}=$ Length; $\mathrm{X}_{3}=$ Width; $\mathrm{X}_{4}=$ Height; $\mathrm{X}_{5}=$ Curb height; $\mathrm{X}_{6}=$ Engine size; $\mathrm{X}_{7}=$ Bore; $\mathrm{X}_{8}=$ Stroke; $\mathrm{X}_{9}=$ Compression ratio; $\mathrm{X}_{10}=$ Horse power; $\mathrm{X}_{11}=$ Peak rpm; $\mathrm{X}_{12}=$ City mpg; $\mathrm{X}_{13}=$ Highway mpg. Also, $\mathrm{P}=$ price of car (of a particular model/make). Total no. observations: 195.

\begin{tabular}{|c|c|c|c|c|c|c|c|c|c|c|c|c|c|c|c|}
\hline \multicolumn{16}{|c|}{ Table.2.1. Pearsonian Correlation matrix of Motor Car Dataset } \\
\hline & $\mathrm{x} 1$ & $x 2$ & $\mathrm{x} 3$ & $\mathrm{X} 4$ & $\mathrm{X} 5$ & $\mathrm{x} 6$ & $\mathrm{X7}$ & $\mathrm{x} 8$ & X9 & $\mathrm{x} 10$ & $\mathrm{X} 11$ & $\mathrm{X} 12$ & $\mathrm{X} 13$ & SB & SP \\
\hline$x_{1}$ & 1.0000 & 0.8792 & 0.8190 & 0.5925 & 0.7827 & 0.5697 & 0.4982 & 0.1717 & 0.2477 & 0.3755 & -0.3523 & -0.4991 & -0.5664 & 0.8115 & 0.8063 \\
\hline $\mathrm{X} 2$ & 0.8792 & 1.0000 & 0.8581 & 0.4962 & 0.8817 & 0.6875 & 0.6094 & 0.1187 & 0.1602 & 0.5838 & -0.2810 & -0.6897 & -0.7193 & 0.9210 & 0.9136 \\
\hline X3 & 0.8190 & 0.8581 & 1.0000 & 0.3158 & 0.8673 & 0.7403 & 0.5443 & 0.1864 & 0.1910 & 0.6168 & -0.2516 & -0.6471 & -0.6922 & 0.8942 & 0.8907 \\
\hline $\mathrm{X} 4$ & 0.5925 & 0.4962 & 0.3158 & 1.0000 & 0.3077 & 0.0313 & 0.1893 & -0.0555 & 0.2612 & -0.0844 & -0.2641 & -0.1024 & -0.1512 & 0.3275 & 0.3260 \\
\hline$x 5$ & 0.7827 & 0.8817 & 0.8673 & 0.3077 & 1.0000 & 0.8576 & 0.6458 & 0.1728 & 0.1554 & 0.7603 & -0.2789 & -0.7722 & -0.8127 & 0.9680 & 0.9649 \\
\hline X6 & 0.5697 & 0.6875 & 0.7403 & 0.0313 & 0.8576 & 1.0000 & 0.5831 & 0.2120 & 0.0246 & 0.8427 & -0.2190 & -0.7106 & -0.7321 & 0.8582 & 0.8645 \\
\hline$x 7$ & 0.4982 & 0.6094 & 0.5443 & 0.1893 & 0.6458 & 0.5831 & 1.0000 & -0.0668 & 0.0031 & 0.5685 & -0.2777 & -0.5920 & -0.6000 & 0.7089 & 0.7201 \\
\hline $\mathrm{X8}$ & 0.1717 & 0.1187 & 0.1864 & -0.0555 & 0.1728 & 0.2120 & -0.0668 & 1.0000 & 0.1999 & 0.1000 & -0.0683 & -0.0276 & -0.0365 & 0.1469 & 0.1477 \\
\hline X9 & 0.2477 & 0.1602 & 0.1910 & 0.2612 & 0.1554 & 0.0246 & 0.0031 & 0.1999 & 1.0000 & -0.2144 & -0.4446 & 0.3314 & 0.2679 & 0.0706 & 0.0382 \\
\hline $\mathrm{X} 10$ & 0.3755 & 0.5838 & 0.6168 & -0.0844 & 0.7603 & 0.8427 & 0.5685 & 0.1000 & -0.2144 & 1.0000 & 0.1057 & -0.8341 & -0.8129 & 0.7862 & 0.7996 \\
\hline $\mathrm{X} 11$ & -0.3523 & -0.2810 & -0.2516 & -0.2641 & -0.2789 & -0.2190 & -0.2777 & -0.0683 & -0.4446 & 0.1057 & 1.0000 & -0.0695 & -0.0170 & -0.2451 & -0.2378 \\
\hline $\mathrm{X} 12$ & -0.4991 & -0.6897 & -0.6471 & -0.1024 & -0.7722 & -0.7106 & -0.5920 & -0.0276 & 0.3314 & -0.8341 & -0.0695 & 1.0000 & 0.9723 & -0.8467 & -0.8497 \\
\hline $\mathrm{X} 13$ & -0.5664 & -0.7193 & -0.6922 & -0.1512 & -0.8127 & -0.7321 & -0.6000 & -0.0365 & 0.2679 & -0.8129 & -0.0170 & 0.9723 & 1.0000 & -0.8764 & -0.8793 \\
\hline SB & 0.8115 & 0.9210 & 0.8942 & 0.3275 & 0.9680 & 0.8582 & 0.7089 & 0.1469 & 0.0706 & 0.7862 & -0.2451 & -0.8467 & -0.8764 & 1.0000 & 0.9987 \\
\hline SP & 0.8063 & 0.9136 & 0.8907 & 0.3260 & 0.9649 & 0.8645 & 0.7201 & 0.1477 & 0.0382 & 0.7996 & -0.2378 & -0.8497 & -0.8793 & 0.9987 & 1.0000 \\
\hline
\end{tabular}

\begin{tabular}{|c|c|c|c|c|c|c|c|c|c|c|c|c|c|c|c|}
\hline & & & & & & & & & & & & & & & \\
\hline $\mathrm{X} 1$ & 1.0000 & 0.8833 & 0.8363 & 0.6077 & 0.7777 & 0.6208 & 0.5305 & 0.2415 & 0.3077 & 0.4897 & 0.3260 & 0.5231 & 0.5777 & 0.8124 & 0.8057 \\
\hline $\mathrm{X} 2$ & 0.8833 & 1.0000 & 0.8711 & 0.5566 & 0.8614 & 0.7044 & 0.6187 & 0.2287 & 0.2260 & 0.6200 & 0.2758 & 0.6632 & 0.6934 & 0.8971 & 0.8886 \\
\hline$x 3$ & 0.8363 & 0.8711 & 1.0000 & 0.4319 & 0.8599 & 0.7475 & 0.5913 & 0.2644 & 0.2746 & 0.6442 & 0.2525 & 0.6573 & 0.6939 & 0.8934 & 0.8877 \\
\hline $\mathrm{X} 4$ & 0.6077 & 0.5566 & 0.4319 & 1.0000 & 0.3979 & 0.2358 & 0.2663 & 0.1639 & 0.2865 & 0.2031 & 0.2849 & 0.2267 & 0.2553 & 0.4051 & 0.4034 \\
\hline X5 & 0.7777 & 0.8614 & 0.8599 & 0.3979 & 1.0000 & 0.8642 & 0.6725 & 0.2314 & 0.2538 & 0.7830 & 0.2612 & 0.7973 & 0.8305 & 0.9655 & 0.9600 \\
\hline X6 & 0.6208 & 0.7044 & 0.7475 & 0.2358 & 0.8642 & 1.0000 & 0.6670 & 0.2943 & 0.1880 & 0.8407 & 0.2472 & 0.7604 & 0.7680 & 0.8749 & 0.8774 \\
\hline $\mathrm{X7}$ & 0.5305 & 0.6187 & 0.5913 & 0.2663 & 0.6725 & 0.6670 & 1.0000 & 0.3232 & 0.1623 & 0.5982 & 0.3262 & 0.6126 & 0.6269 & 0.7296 & 0.7387 \\
\hline $\mathrm{X} 8$ & 0.2415 & 0.2287 & 0.2644 & 0.1639 & 0.2314 & 0.2943 & 0.3232 & 1.0000 & 0.3230 & 0.2349 & 0.2553 & 0.2014 & 0.2105 & 0.2342 & 0.2336 \\
\hline X9 & 0.3077 & 0.2260 & 0.2746 & 0.2865 & 0.2538 & 0.1880 & 0.1623 & 0.3230 & 1.0000 & 0.2460 & 0.4866 & 0.3341 & 0.2886 & 0.2136 & 0.2018 \\
\hline X10 & 0.4897 & 0.6200 & 0.6442 & 0.2031 & 0.7830 & 0.8407 & 0.5982 & 0.2349 & 0.2460 & 1.0000 & 0.1838 & 0.8835 & 0.8572 & 0.8098 & 0.8180 \\
\hline X11 & 0.3260 & 0.2758 & 0.2525 & 0.2849 & 0.2612 & 0.2472 & 0.3262 & 0.2553 & 0.4866 & 0.1838 & 1.0000 & 0.1765 & 0.1507 & 0.2385 & 0.2310 \\
\hline $\mathrm{X} 12$ & 0.5231 & 0.6632 & 0.6573 & 0.2267 & 0.7973 & 0.7604 & 0.6126 & 0.2014 & 0.3341 & 0.8835 & 0.1765 & 1.0000 & 0.9622 & 0.8443 & 0.8473 \\
\hline X13 & 0.5777 & 0.6934 & 0.6939 & 0.2553 & 0.8305 & 0.7680 & 0.6269 & 0.2105 & 0.2886 & 0.8572 & 0.1507 & 0.9622 & 1.0000 & 0.8692 & 0.8720 \\
\hline SB & 0.8124 & 0.8971 & 0.8934 & 0.4051 & 0.9655 & 0.8749 & 0.7296 & 0.2342 & 0.2136 & 0.8098 & 0.2385 & 0.8443 & 0.8692 & 1.0000 & 0.9983 \\
\hline SP & 0.8057 & 0.8886 & 0.8877 & 0.4034 & 0.9600 & 0.8774 & 0.7387 & 0.2336 & 0.2018 & 0.8180 & 0.2310 & 0.8473 & 0.8720 & 0.9983 & 1.0000 \\
\hline
\end{tabular}

Findings: There is not much difference between the Brownian and Pearsonian leading PC scores. The coefficients of correlation $(r$ and $\rho$ ) between them are $(0.9987,0.9983)$ respectively (see Table.2.1 and Table.2.2). However, the Brownian PC scores have slightly larger variance. They have been plotted in Fig.3. The details are given in Table.A2 in the appendix.

The eigenvalues $(\lambda)$ and the associated eigenvectors $(V)$ of the Pearsonian and the Brownian correlation matrices (of X1 through X13) are given in Table.2.3 and Table.2.4. The Pearsonian leading PC scores explain $52.275 \%$ of the total variance in the data and it is commensurate with $52.275=100(\lambda 1 / 13)$. 
However, the Brownian leading PC scores explain 53.372\% of the total variance in the data while 56.24= $100(\lambda 1 / 13)$ is larger than that. We will discuss this issue in due course.

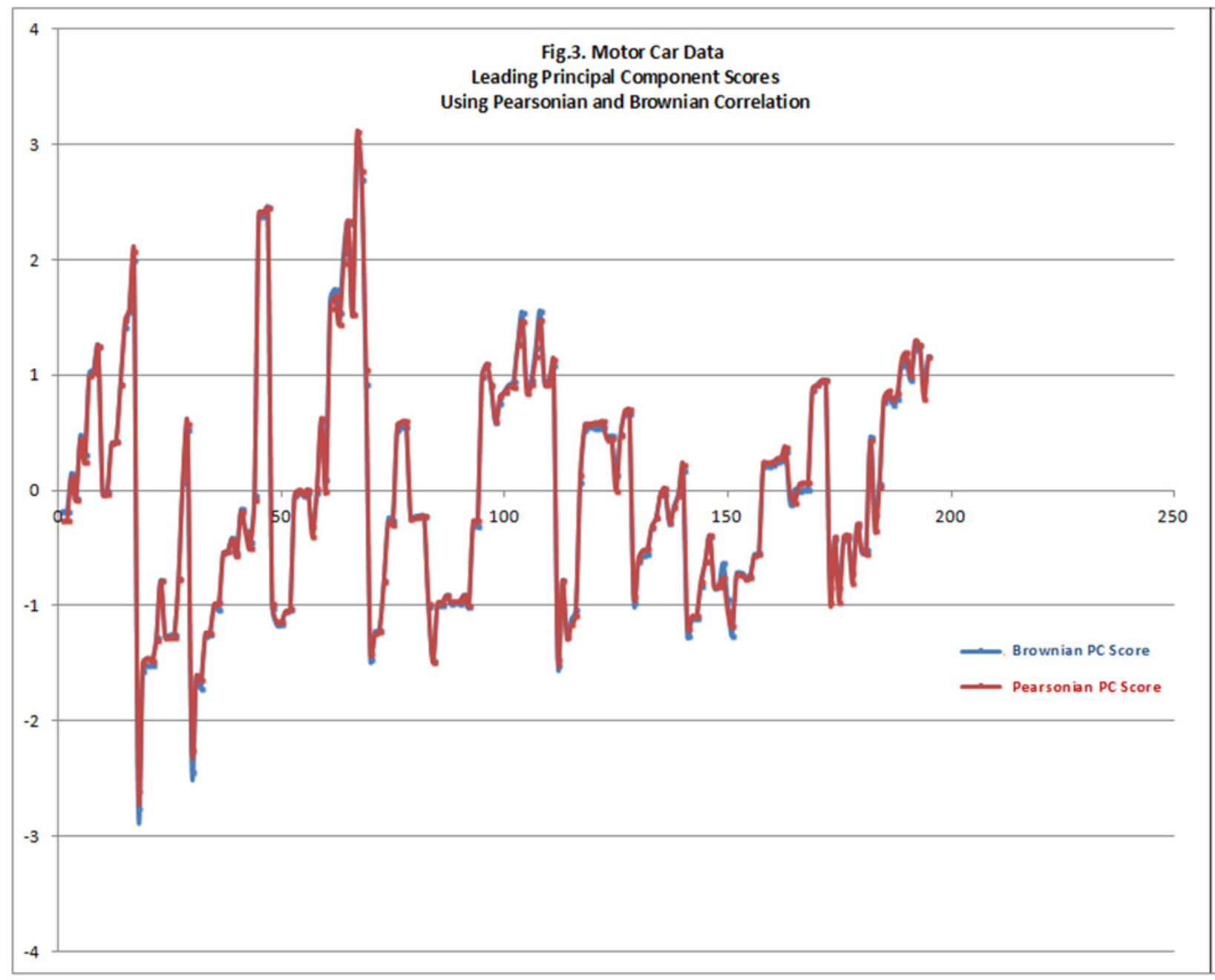

\begin{tabular}{|c|c|c|c|c|c|c|c|c|c|c|c|c|c|}
\hline & & & & $\begin{array}{l}\text { Tab } \\
\text { rsoni }\end{array}$ & $\begin{array}{l}3.1 \\
\text { or }\end{array}$ & $\begin{array}{l}\text { nval } \\
\text { ion }\end{array}$ & $\begin{array}{l}\text { S and } \\
\text { atrix }\end{array}$ & $\begin{array}{l}\text { gen } \\
\text { hot }\end{array}$ & $\begin{array}{l}\text { tors of } \\
\text { Car Da }\end{array}$ & set & & & \\
\hline & $\lambda_{1}$ & $\lambda_{2}$ & $\lambda_{3}$ & $\lambda_{4}$ & $\lambda_{5}$ & $\lambda_{6}$ & $\lambda_{7}$ & $\lambda_{8}$ & $\lambda_{9}$ & $\lambda_{10}$ & $\lambda_{11}$ & $\lambda_{12}$ & $\lambda_{13}$ \\
\hline$\lambda$ & 6.79575 & 2.26793 & 1.19702 & 0.90126 & 0.54167 & 0.41122 & 0.29691 & 0.23572 & 0.11800 & 0.09561 & 0.06642 & 0.05221 & 0.02026 \\
\hline$\lambda / 13$ & 0.52275 & 0.17446 & 0.09208 & 0.06933 & 0.04167 & 0.03163 & 0.02284 & 0.01813 & 0.00908 & 0.00735 & 0.00511 & 0.00402 & 0.00156 \\
\hline $\mathrm{V}$ & $\mathrm{V}_{1}$ & $V_{2}$ & $V_{3}$ & $V_{4}$ & $V_{5}$ & $V_{6}$ & $V_{7}$ & $\mathrm{~V}_{8}$ & $V_{9}$ & $V_{10}$ & $V_{11}$ & $V_{12}$ & $V_{13}$ \\
\hline 1 & 0.30931 & -0.27976 & -0.11059 & 0.23657 & 0.03915 & 0.10455 & 0.40046 & 0.10371 & -0.44033 & -0.38093 & 0.45934 & -0.12544 & 0.09249 \\
\hline 2 & 0.35044 & -0.14973 & -0.10612 & 0.13945 & -0.03890 & 0.03488 & 0.18606 & -0.04672 & -0.33081 & 0.72326 & -0.31254 & -0.17013 & -0.15925 \\
\hline 3 & 0.34168 & -0.11574 & 0.06598 & 0.08612 & -0.19615 & 0.18832 & 0.45207 & 0.00794 & 0.75923 & -0.00905 & -0.04267 & -0.03559 & 0.01070 \\
\hline 4 & 0.12507 & -0.39131 & -0.47143 & 0.42114 & 0.14273 & -0.16432 & -0.50627 & 0.24956 & 0.25027 & -0.03532 & -0.03790 & -0.01831 & 0.00417 \\
\hline 5 & 0.37014 & -0.05089 & 0.06846 & -0.02685 & -0.11576 & 0.07599 & -0.10589 & -0.01229 & -0.12722 & -0.01652 & -0.07715 & 0.88890 & 0.10913 \\
\hline 6 & 0.33161 & 0.08570 & 0.25140 & -0.19342 & -0.09412 & 0.16752 & -0.19349 & 0.54041 & -0.13587 & -0.31785 & -0.47013 & -0.27144 & 0.03864 \\
\hline 7 & 0.27624 & 0.01574 & -0.15412 & -0.41893 & 0.20758 & -0.78729 & 0.22161 & 0.04549 & 0.05254 & -0.07175 & -0.04562 & 0.00915 & -0.00382 \\
\hline 8 & 0.05666 & -0.11483 & 0.74402 & 0.42011 & 0.42772 & -0.25259 & -0.04029 & -0.04268 & 0.04290 & 0.03531 & -0.00466 & 0.00535 & -0.01493 \\
\hline 9 & 0.01466 & -0.52734 & 0.25505 & -0.15205 & -0.61057 & -0.22257 & -0.23903 & -0.34131 & -0.05589 & -0.07921 & 0.02831 & -0.16395 & 0.02218 \\
\hline 10 & 0.30674 & 0.30925 & 0.15195 & -0.09647 & -0.18850 & -0.04820 & -0.31050 & 0.27819 & 0.09012 & 0.32844 & 0.65737 & -0.08987 & -0.10008 \\
\hline 11 & -0.09120 & 0.44412 & -0.05086 & 0.55528 & -0.51295 & -0.38361 & 0.14712 & 0.09715 & -0.08360 & -0.10860 & -0.14690 & 0.04078 & 0.01169 \\
\hline 12 & -0.32596 & -0.28694 & 0.08301 & -0.06516 & -0.10462 & -0.04639 & 0.19544 & 0.45282 & -0.01066 & 0.01041 & 0.04496 & 0.21963 & -0.70246 \\
\hline 13 & -0.33730 & -0.23692 & 0.08421 & -0.06844 & -0.08616 & -0.08213 & 0.17766 & 0.46932 & 0.00389 & 0.31098 & 0.04953 & 0.07023 & 0.66949 \\
\hline
\end{tabular}




\begin{tabular}{|c|c|c|c|c|c|c|c|c|c|c|c|c|c|}
\hline \multicolumn{14}{|c|}{$\begin{array}{l}\text { Table.2.4. Eigenvalues and Eigenvectors of } \\
\text { Brownian Correlation matrix of Motor Car Dataset }\end{array}$} \\
\hline & $\lambda_{1}$ & $\lambda_{2}$ & $\lambda_{3}$ & $\lambda_{4}$ & $\lambda_{5}$ & $\lambda_{6}$ & $\lambda_{7}$ & $\lambda_{8}$ & $\lambda_{9}$ & $\lambda_{10}$ & $\lambda_{11}$ & $\lambda_{12}$ & $\lambda_{13}$ \\
\hline$\lambda$ & 7.3118 & 1.5780 & 1.1786 & 0.8022 & 0.6626 & 0.4610 & 0.3460 & 0.2306 & 0.1255 & 0.1133 & 0.0943 & 0.0677 & 0.0285 \\
\hline$\lambda / 13$ & 0.5624 & 0.1214 & 0.0907 & 0.0617 & 0.0510 & 0.0355 & 0.0266 & 0.0177 & 0.0097 & 0.0087 & 0.0073 & 0.0052 & 0.0022 \\
\hline V & $V_{1}$ & $V_{2}$ & $V_{3}$ & $V_{4}$ & $V_{5}$ & $V_{6}$ & $V_{7}$ & $V_{8}$ & $V_{9}$ & $V_{10}$ & $V_{11}$ & $V_{12}$ & $V_{13}$ \\
\hline 1 & 0.3035 & -0.1934 & -0.3604 & 0.0499 & 0.0275 & -0.2785 & 0.0976 & -0.1050 & 0.5287 & -0.3602 & -0.4486 & -0.1274 & -0.1120 \\
\hline 2 & 0.3294 & -0.0520 & -0.3082 & 0.0600 & -0.0102 & -0.1461 & 0.0648 & -0.2434 & 0.0703 & -0.1577 & 0.7391 & 0.3238 & 0.1565 \\
\hline 3 & 0.3271 & -0.0180 & -0.2060 & 0.0751 & 0.0265 & -0.4147 & 0.0718 & 0.0260 & -0.7677 & 0.0227 & -0.2672 & 0.0680 & -0.0146 \\
\hline 4 & 0.1768 & -0.4051 & -0.4587 & -0.0550 & 0.2472 & 0.6533 & -0.2087 & 0.1591 & -0.1277 & 0.1147 & -0.0639 & 0.0277 & -0.0116 \\
\hline 5 & 0.3493 & 0.0957 & -0.0872 & -0.0099 & -0.0412 & -0.1432 & -0.0583 & 0.0884 & 0.1161 & 0.5368 & 0.2455 & -0.6699 & -0.1303 \\
\hline 6 & 0.3237 & 0.1768 & 0.0993 & 0.1007 & -0.1371 & -0.1134 & -0.3184 & 0.5923 & 0.2476 & 0.2150 & -0.0988 & 0.4921 & 0.0261 \\
\hline 7 & 0.2771 & 0.0391 & 0.1070 & 0.2743 & -0.4411 & 0.3907 & 0.6700 & 0.1734 & -0.0390 & -0.0743 & -0.0254 & -0.0352 & -0.0007 \\
\hline 8 & 0.1291 & -0.3006 & 0.4047 & 0.7557 & 0.3258 & -0.0033 & -0.1486 & -0.1644 & 0.0136 & 0.0249 & 0.0158 & -0.0348 & -0.0237 \\
\hline 9 & 0.1404 & -0.4720 & 0.3830 & -0.4397 & 0.3729 & -0.1783 & 0.3655 & 0.3078 & 0.0401 & -0.0039 & 0.1126 & 0.0197 & 0.0608 \\
\hline 10 & 0.3105 & 0.2521 & 0.2287 & -0.1121 & 0.0550 & 0.1609 & -0.3371 & 0.1964 & -0.1466 & -0.6547 & 0.1114 & -0.3441 & 0.1147 \\
\hline 11 & 0.1343 & -0.5199 & 0.2471 & -0.2013 & -0.6526 & -0.0192 & -0.3358 & -0.2565 & -0.0550 & 0.0274 & -0.0374 & 0.0026 & 0.0118 \\
\hline 12 & 0.3184 & 0.2288 & 0.2170 & -0.2301 & 0.1536 & 0.1841 & 0.0136 & -0.3485 & -0.0061 & 0.0459 & -0.0375 & 0.2384 & -0.7118 \\
\hline 13 & 0.3246 & 0.2328 & 0.1500 & -0.1711 & 0.1567 & 0.1562 & 0.0419 & -0.4093 & 0.0851 & 0.2444 & -0.2797 & 0.0667 & 0.6486 \\
\hline
\end{tabular}

Relationship between motor car price and the car's engine and body characteristics: If we use car price as the dependent variable and the leading principal component score as an explanatory variable in a linear regression model, we obtain

$$
\begin{aligned}
& \hat{P}=13248.014+6768.322 \mathrm{~S}_{\mathrm{B}} ; \mathrm{R}^{2}=701 \quad ; \quad \hat{P}=13248.014+6768.322 \mathrm{~S}_{\mathrm{P}}: \mathrm{R}^{2}=0.706 \\
& \text { (316.162) (316.162) (313.730) (314.538) }
\end{aligned}
$$

for Brownian and Pearsonian principal component scores, respectively. The figures in the parentheses are standard error of estimates of the regression coefficients. It appears that the two are statistically indistinguishable. However, a lower value of $\mathrm{R}^{2}$ in case of the Brownian regression equation may be due to its proneness to incorporate nonlinearity in the explanatory variable, $\mathrm{S}_{\mathrm{B}}$.

6.3. Sinusoidal Data: The sinusoidal data ( 9 variables: $X_{1}$ through $X_{9}$ ) have been generated by us to introduce severe nonlinearities in the dataset. They are different sine or cosine functions of basic variable (1, 2, 3, through 50) perturbed by (uniformly distributed) random numbers between 0 and unity. Their movement along the horizontal axis (1 through 50) has been presented in Fig.4(a).

Findings: There is not much difference between the Brownian and Pearsonian leading PC scores. The coefficients of correlation $(r$ and $\rho$ ) between them are $(0.9987,0.9983)$ respectively (see Table.4.1 and Table.3.2). However, the Brownian PC scores have slightly smaller variance. They have been plotted in Fig.4(b). The details are given in Table.A3 in the appendix.

The eigenvalues $(\lambda)$ and the associated eigenvectors (V) of the Pearsonian and the Brownian correlation matrices (of X1 through X9) are given in Table.3.3 and Table.3.4. The Pearsonian leading PC scores explain $22.949 \%$ of the total variance in the data and it is commensurate with $22.949=100(\lambda 1 / 9)$. However, the Brownian leading PC scores explain $22.404 \%$ of the total variance in the data while $32.986=100(\lambda 1 / 9)$ is substantially larger than that. The possible explanation of this observed discrepancy will be given in due course. 


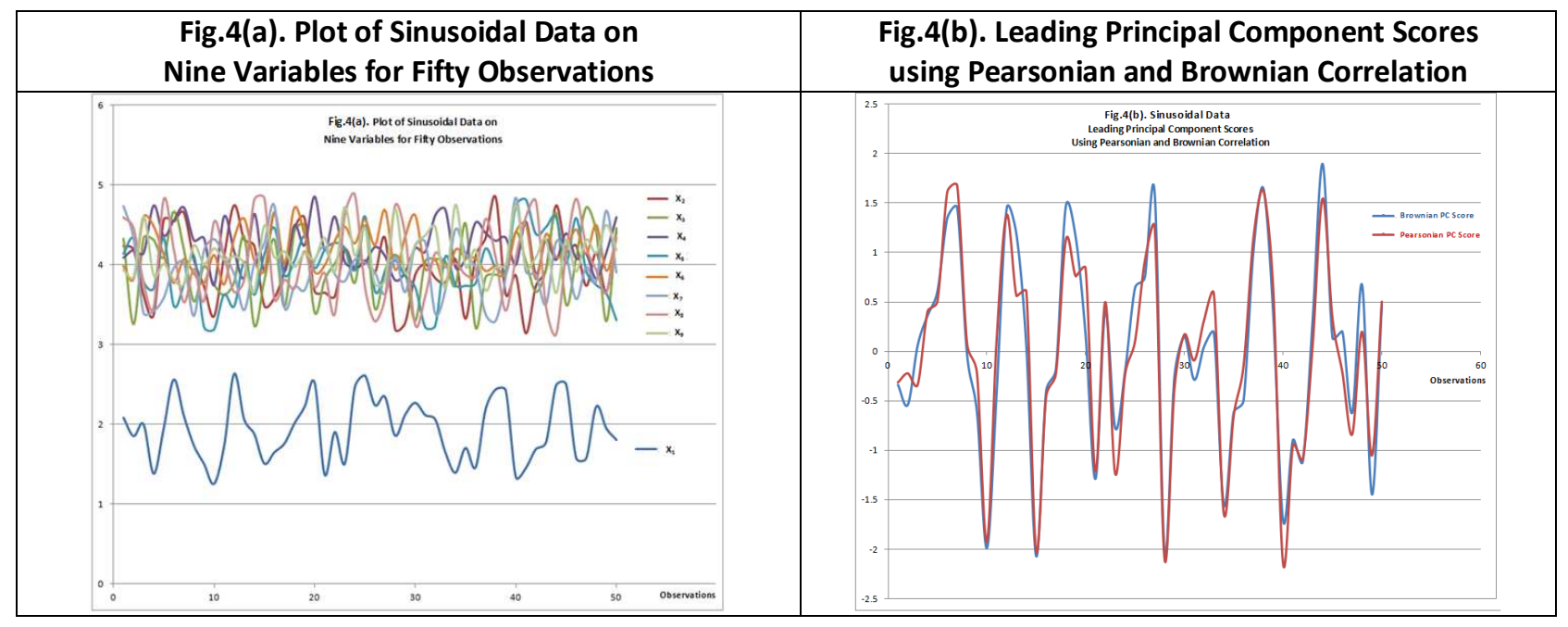

\begin{tabular}{|l|c|c|c|c|c|c|c|c|r|r|r|}
\hline \multicolumn{10}{|c|}{ Table.3.1. Pearsonian Correlation matrix of Sinusoidal Dataset } \\
\hline & $\mathrm{X} 1$ & $\mathrm{X} 2$ & $\mathrm{X} 3$ & $\mathrm{X} 4$ & $\mathrm{X} 5$ & $\mathrm{X} 6$ & $\mathrm{X} 7$ & $\mathrm{X} 8$ & $\mathrm{X} 9$ & \multicolumn{1}{|c|}{ SB } & \multicolumn{1}{|c|}{ SP } \\
\hline X1 & 1.000000 & 0.477999 & 0.036105 & 0.054236 & -0.075043 & 0.055156 & -0.169786 & -0.252138 & -0.284375 & 0.691472 & 0.692272 \\
\hline X2 & 0.477999 & 1.000000 & 0.121609 & 0.117210 & 0.009134 & 0.029593 & -0.195106 & -0.048875 & -0.283840 & 0.706035 & 0.663524 \\
\hline X3 & 0.036105 & 0.121609 & 1.000000 & -0.073124 & 0.183494 & 0.336459 & -0.064162 & -0.046778 & 0.021822 & 0.264908 & 0.085322 \\
\hline X4 & 0.054236 & 0.117210 & -0.073124 & 1.000000 & -0.104353 & -0.125137 & -0.138354 & -0.242769 & -0.390480 & 0.339441 & 0.515656 \\
\hline X5 & -0.075043 & 0.009134 & 0.183494 & -0.104353 & 1.000000 & 0.252031 & 0.026387 & 0.162591 & -0.009649 & 0.000100 & -0.136356 \\
\hline X6 & 0.055156 & 0.029593 & 0.336459 & -0.125137 & 0.252031 & 1.000000 & -0.145654 & -0.211004 & 0.139617 & 0.259056 & 0.042260 \\
\hline X7 & -0.169786 & -0.195106 & -0.064162 & -0.138354 & 0.026387 & -0.145654 & 1.000000 & -0.015072 & 0.239745 & -0.518213 & -0.462006 \\
\hline X8 & -0.252138 & -0.048875 & -0.046778 & -0.242769 & 0.162591 & -0.211004 & -0.015072 & 1.000000 & 0.108076 & -0.402119 & -0.407898 \\
\hline X9 & -0.284375 & -0.283840 & 0.021822 & -0.390480 & -0.009649 & 0.139617 & 0.239745 & 0.108076 & 1.000000 & -0.600414 & -0.687379 \\
\hline SB & 0.691472 & 0.706035 & 0.264908 & 0.339441 & 0.000100 & 0.259056 & -0.518213 & -0.402119 & -0.600414 & 1.000000 & 0.954728 \\
\hline SP & 0.692272 & 0.663524 & 0.085322 & 0.515656 & -0.136356 & 0.042260 & -0.462006 & -0.407898 & -0.687379 & 0.954728 & 1.000000 \\
\hline
\end{tabular}

\begin{tabular}{|l|c|c|c|c|c|c|c|c|c|c|c|c|}
\hline \multicolumn{10}{|c|}{ Table.3.2. Brownian Correlation matrix of Sinusoidal Dataset } \\
\hline & $\mathrm{X} 1$ & $\mathrm{X} 2$ & $\mathrm{X} 3$ & $\mathrm{X} 4$ & $\mathrm{X} 5$ & $\mathrm{X} 6$ & $\mathrm{X} 7$ & $\mathrm{X} 8$ & $\mathrm{X} 9$ & $\mathrm{SB}$ & $\mathrm{SP}$ \\
\hline $\mathrm{X} 1$ & 1.000000 & 0.445287 & 0.187440 & 0.176104 & 0.226644 & 0.175839 & 0.247937 & 0.274121 & 0.289344 & 0.671368 & 0.662206 \\
\hline $\mathrm{X} 2$ & 0.445287 & 1.000000 & 0.275675 & 0.228791 & 0.157907 & 0.170978 & 0.240721 & 0.233906 & 0.344412 & 0.678935 & 0.634896 \\
\hline $\mathrm{X} 3$ & 0.187440 & 0.275675 & 1.000000 & 0.206049 & 0.271758 & 0.415916 & 0.251077 & 0.196363 & 0.185312 & 0.314755 & 0.197056 \\
\hline $\mathrm{X} 4$ & 0.176104 & 0.228791 & 0.206049 & 1.000000 & 0.215051 & 0.190766 & 0.244889 & 0.278645 & 0.390223 & 0.390847 & 0.520346 \\
\hline $\mathrm{X} 5$ & 0.226644 & 0.157907 & 0.271758 & 0.215051 & 1.000000 & 0.288959 & 0.228980 & 0.279306 & 0.166121 & 0.170292 & 0.206381 \\
\hline $\mathrm{X} 6$ & 0.175839 & 0.170978 & 0.415916 & 0.190766 & 0.288959 & 1.000000 & 0.287810 & 0.246804 & 0.195513 & 0.290597 & 0.164029 \\
\hline $\mathrm{X} 7$ & 0.247937 & 0.240721 & 0.251077 & 0.244889 & 0.228980 & 0.287810 & 1.000000 & 0.147723 & 0.276358 & 0.538614 & 0.460901 \\
\hline $\mathrm{X} 8$ & 0.274121 & 0.233906 & 0.196363 & 0.278645 & 0.279306 & 0.246804 & 0.147723 & 1.000000 & 0.206043 & 0.376501 & 0.389649 \\
\hline $\mathrm{X} 9$ & 0.289344 & 0.344412 & 0.185312 & 0.390223 & 0.166121 & 0.195513 & 0.276358 & 0.206043 & 1.000000 & 0.548356 & 0.632674 \\
\hline SB & 0.671368 & 0.678935 & 0.314755 & 0.390847 & 0.170292 & 0.290597 & 0.538614 & 0.376501 & 0.548356 & 1.000000 & 0.936263 \\
\hline SP & 0.662206 & 0.634896 & 0.197056 & 0.520346 & 0.206381 & 0.164029 & 0.460901 & 0.389649 & 0.632674 & 0.936263 & 1.000000 \\
\hline
\end{tabular}

\begin{tabular}{|c|c|c|c|c|c|c|c|c|c|}
\hline \multicolumn{1}{|c|}{ Table.3.3. Eigenvalues and Eigenvectors of } \\
\hline \multicolumn{10}{|c|}{ Pearsonian Correlation matrix of Sinusoidal Dataset } \\
\hline & $\lambda_{1}$ & $\lambda_{2}$ & $\lambda_{3}$ & $\lambda_{4}$ & $\lambda_{5}$ & $\lambda_{6}$ & $\lambda_{7}$ & $\lambda_{8}$ & $\lambda_{9}$ \\
\hline$\lambda$ & 2.065385 & 1.624454 & 1.167268 & 1.053080 & 0.898750 & 0.753980 & 0.567224 & 0.455192 & 0.414667 \\
\hline$\lambda / 9$ & 0.229487 & 0.180495 & 0.129696 & 0.117009 & 0.099861 & 0.083776 & 0.063025 & 0.050577 & 0.046074 \\
\hline$V$ & $V_{1}$ & $V_{2}$ & $V_{3}$ & $V_{4}$ & $V_{5}$ & $V_{6}$ & $V_{7}$ & $V_{8}$ & $V_{9}$ \\
\hline 1 & 0.481700 & -0.097258 & -0.010123 & -0.501194 & -0.112449 & -0.198313 & -0.216908 & -0.305350 & 0.561202 \\
\hline 2 & 0.461696 & -0.135288 & 0.275504 & -0.370222 & -0.156784 & 0.136067 & 0.554838 & 0.195259 & -0.408045 \\
\hline 3 & 0.059369 & -0.542656 & -0.036833 & 0.111104 & -0.060755 & 0.776374 & -0.206298 & -0.196039 & 0.029332 \\
\hline 4 & 0.358806 & 0.275228 & -0.157660 & 0.572991 & -0.134996 & 0.142654 & 0.487445 & -0.148183 & 0.379734 \\
\hline 5 & -0.094880 & -0.423166 & 0.362276 & 0.332175 & -0.486778 & -0.436820 & 0.019075 & -0.355257 & -0.126525 \\
\hline 6 & 0.029406 & -0.615632 & -0.278844 & 0.121941 & 0.175223 & -0.273148 & 0.171769 & 0.559849 & 0.281532 \\
\hline 7 & -0.321475 & 0.126998 & -0.261257 & -0.221793 & -0.788456 & 0.150370 & 0.038844 & 0.298574 & 0.167774 \\
\hline 8 & -0.283825 & 0.050795 & 0.754032 & -0.031100 & 0.110092 & 0.176117 & 0.124520 & 0.219820 & 0.490273 \\
\hline 9 & -0.478295 & -0.158839 & -0.227958 & -0.309368 & 0.198545 & -0.000714 & 0.563970 & -0.480770 & 0.098531 \\
\hline
\end{tabular}




\begin{tabular}{|c|c|c|c|c|c|c|c|c|c|}
\hline \multicolumn{1}{|c|}{ Table.3.4. Eigenvalues and Eigenvectors of } \\
\hline & $\lambda_{1}$ & $\lambda_{2}$ & $\lambda_{3}$ & $\lambda_{4}$ & $\lambda_{5}$ & $\lambda_{6}$ & $\lambda_{7}$ & $\lambda_{8}$ & $\lambda_{9}$ \\
\hline$\lambda$ & 2.968768 & 1.120953 & 0.924676 & 0.902607 & 0.763621 & 0.675246 & 0.604829 & 0.538365 & 0.500935 \\
\hline$\lambda / 9$ & 0.329863 & 0.124550 & 0.102742 & 0.100290 & 0.084847 & 0.075027 & 0.067203 & 0.059818 & 0.055659 \\
\hline$V$ & $V_{1}$ & $V_{2}$ & $V_{3}$ & $V_{4}$ & $V_{5}$ & $V_{6}$ & $V_{7}$ & $V_{8}$ & $V_{9}$ \\
\hline 1 & 0.343545 & 0.357240 & 0.486353 & -0.132822 & -0.183718 & -0.028951 & 0.139495 & 0.525209 & 0.412651 \\
\hline 2 & 0.355119 & 0.392337 & 0.393442 & 0.097039 & 0.223422 & 0.138632 & -0.221430 & -0.198575 & -0.630991 \\
\hline 3 & 0.335935 & -0.412562 & 0.184455 & 0.240025 & 0.455300 & 0.232231 & -0.350501 & -0.151213 & 0.467288 \\
\hline 4 & 0.327793 & 0.159618 & -0.665199 & -0.044539 & 0.141665 & 0.117187 & -0.346207 & 0.508743 & -0.100596 \\
\hline 5 & 0.311297 & -0.344173 & -0.005012 & -0.377014 & -0.504023 & 0.595395 & 0.057406 & -0.115834 & -0.131254 \\
\hline 6 & 0.332048 & -0.511669 & 0.048284 & 0.147949 & 0.196355 & -0.274964 & 0.517824 & 0.314518 & -0.349993 \\
\hline 7 & 0.327597 & -0.065431 & -0.067013 & 0.480012 & -0.607502 & -0.419401 & -0.286512 & -0.161431 & 0.019820 \\
\hline 8 & 0.316668 & -0.020031 & -0.071905 & -0.688139 & 0.138912 & -0.529933 & -0.101519 & -0.321002 & 0.084505 \\
\hline 9 & 0.347572 & 0.371245 & -0.346602 & 0.213006 & 0.089518 & 0.159539 & 0.570059 & -0.401992 & 0.236295 \\
\hline
\end{tabular}

6.4. Crime Incidents in India 2011 Data: The dataset is provided by the National Crime Records Bureau, Ministry of Home Affairs, Govt. of India on its website.

Description of variables: This dataset has seven variables (each in 35 observations for the states and union territories of India). $\mathrm{X}_{1}=$ Murder; $\mathrm{X}_{2}=$ Attempt to Commit Murder; $\mathrm{X}_{3}=$ Culpable Homicide Not Amounting to Murder; $\mathrm{X}_{4}=$ Rape; $\mathrm{X}_{5}=$ Kidnapping \& Abduction; $\mathrm{X}_{6}=$ Dacoity; $\mathrm{X}_{7}=$ Preparation \& Assembly For Dacoity.

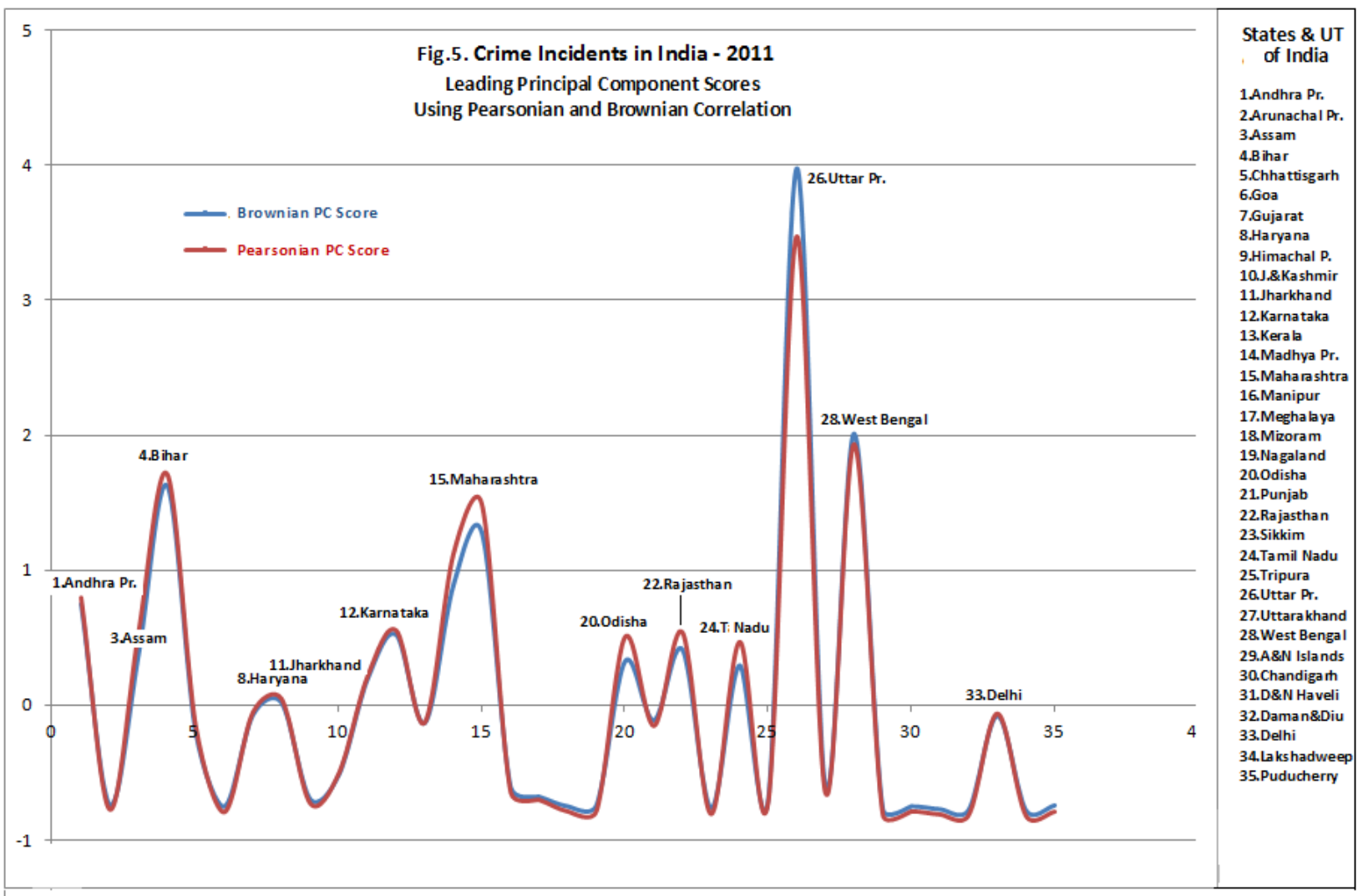




\begin{tabular}{|l|c|c|c|c|c|c|c|c|c|}
\hline \multicolumn{8}{|c|}{ Table.4.1. Pearsonian Correlation matrix of Crime Incidence Dataset } \\
\hline & $\mathrm{X} 1$ & $\mathrm{X} 2$ & $\mathrm{X} 3$ & $\mathrm{X} 4$ & $\mathrm{X} 5$ & $\mathrm{X} 6$ & $\mathrm{X} 7$ & $\mathrm{SB}$ & $\mathrm{SP}$ \\
\hline $\mathrm{X} 1$ & 1.000000 & 0.952748 & 0.762417 & 0.768416 & 0.817072 & 0.750916 & 0.322254 & 0.951722 & 0.965378 \\
\hline $\mathrm{X} 2$ & 0.952748 & 1.000000 & 0.752003 & 0.715526 & 0.797357 & 0.650701 & 0.354426 & 0.925068 & 0.937870 \\
\hline $\mathrm{X} 3$ & 0.762417 & 0.752003 & 1.000000 & 0.505564 & 0.843174 & 0.428564 & 0.265564 & 0.881343 & 0.821074 \\
\hline $\mathrm{X} 4$ & 0.768416 & 0.715526 & 0.505564 & 1.000000 & 0.633816 & 0.526476 & 0.470646 & 0.766260 & 0.810667 \\
\hline $\mathrm{X} 5$ & 0.817072 & 0.797357 & 0.843174 & 0.633816 & 1.000000 & 0.540617 & 0.293448 & 0.902621 & 0.886100 \\
\hline $\mathrm{X} 6$ & 0.750916 & 0.650701 & 0.428564 & 0.526476 & 0.540617 & 1.000000 & 0.343141 & 0.702146 & 0.743570 \\
\hline $\mathrm{X} 7$ & 0.322254 & 0.354426 & 0.265564 & 0.470646 & 0.293448 & 0.343141 & 1.000000 & 0.462047 & 0.474430 \\
\hline SB & 0.951722 & 0.925068 & 0.881343 & 0.766260 & 0.902621 & 0.702146 & 0.462047 & 1.000000 & 0.992830 \\
\hline SP & 0.965378 & 0.937870 & 0.821074 & 0.810667 & 0.886100 & 0.743570 & 0.474430 & 0.992830 & 1.000000 \\
\hline
\end{tabular}

\begin{tabular}{|l|c|c|c|c|c|c|c|c|c|}
\hline \multicolumn{10}{|c|}{ Table.4.2. Brownian Correlation matrix of Crime Incidence Dataset } \\
\hline & $\mathrm{X} 1$ & $\mathrm{X} 2$ & $\mathrm{X} 3$ & $\mathrm{X} 4$ & $\mathrm{X} 5$ & $\mathrm{X} 6$ & $\mathrm{X} 7$ & $\mathrm{SB}$ & $\mathrm{SP}$ \\
\hline $\mathrm{X} 1$ & 1.000000 & 0.940148 & 0.761567 & 0.850679 & 0.796399 & 0.820574 & 0.499891 & 0.958803 & 0.963778 \\
\hline $\mathrm{X} 2$ & 0.940148 & 1.000000 & 0.761491 & 0.801443 & 0.770022 & 0.710575 & 0.548970 & 0.926337 & 0.932280 \\
\hline $\mathrm{X} 3$ & 0.761567 & 0.761491 & 1.000000 & 0.675050 & 0.792049 & 0.594823 & 0.523484 & 0.866787 & 0.823615 \\
\hline $\mathrm{X} 4$ & 0.850679 & 0.801443 & 0.675050 & 1.000000 & 0.752195 & 0.694113 & 0.540678 & 0.881868 & 0.896625 \\
\hline $\mathrm{X} 5$ & 0.796399 & 0.770022 & 0.792049 & 0.752195 & 1.000000 & 0.664563 & 0.423464 & 0.865649 & 0.859378 \\
\hline $\mathrm{X} 6$ & 0.820574 & 0.710575 & 0.594823 & 0.694113 & 0.664563 & 1.000000 & 0.500087 & 0.810772 & 0.819527 \\
\hline X7 & 0.499891 & 0.548970 & 0.523484 & 0.540678 & 0.423464 & 0.500087 & 1.000000 & 0.595239 & 0.582965 \\
\hline SB & 0.958803 & 0.926337 & 0.866787 & 0.881868 & 0.865649 & 0.810772 & 0.595239 & 1.000000 & 0.996319 \\
\hline SP & 0.963778 & 0.932280 & 0.823615 & 0.896625 & 0.859378 & 0.819527 & 0.582965 & 0.996319 & 1.000000 \\
\hline
\end{tabular}

\begin{tabular}{|c|c|c|c|c|c|c|c|}
\hline \multicolumn{7}{|c|}{ Table.4.3. Eigenvalues and Eigenvectors of } \\
\hline & $\lambda_{1}$ & $\lambda_{2}$ & $\lambda_{3}$ & $\lambda_{4}$ & $\lambda_{5}$ & $\lambda_{6}$ & $\lambda_{7}$ \\
\hline$\lambda$ & 4.706050 & 0.914373 & 0.611295 & 0.420157 & 0.195834 & 0.128903 & 0.023388 \\
\hline$\lambda / 7$ & 0.672293 & 0.130625 & 0.087328 & 0.060022 & 0.027976 & 0.018415 & 0.003341 \\
\hline$V$ & $V_{1}$ & $V_{2}$ & $V_{3}$ & $V_{4}$ & $V_{5}$ & $V_{6}$ & $V_{7}$ \\
\hline 1 & 0.445009 & 0.118239 & 0.181549 & -0.090992 & 0.286485 & 0.013008 & 0.815171 \\
\hline 2 & 0.432329 & 0.107970 & 0.045497 & -0.081574 & 0.669808 & -0.304322 & -0.501453 \\
\hline 3 & 0.378490 & 0.328745 & -0.463797 & 0.311209 & -0.021786 & 0.649678 & -0.118984 \\
\hline 4 & 0.373692 & -0.250344 & 0.020210 & -0.784371 & -0.298612 & 0.260005 & -0.158949 \\
\hline 5 & 0.408464 & 0.250049 & -0.270028 & 0.105833 & -0.545348 & -0.623624 & 0.014307 \\
\hline 6 & 0.342763 & -0.135306 & 0.743395 & 0.419699 & -0.273098 & 0.153989 & -0.192685 \\
\hline 7 & 0.218697 & -0.850167 & -0.351999 & 0.292625 & 0.087483 & -0.070109 & 0.085359 \\
\hline
\end{tabular}

\begin{tabular}{|c|c|c|c|c|c|c|c|}
\hline \multicolumn{7}{|c|}{ Table.4.4. Eigenvalues and Eigenvectors of } \\
\hline & $\lambda_{1}$ & $\lambda_{2}$ & $\lambda_{3}$ & $\lambda_{4}$ & $\lambda_{5}$ & $\lambda_{6}$ & $\lambda_{7}$ \\
\hline$\lambda$ & 5.174474 & 0.656804 & 0.450269 & 0.295293 & 0.232572 & 0.157547 & 0.033040 \\
\hline$\lambda / 7$ & 0.739211 & 0.093829 & 0.064324 & 0.042185 & 0.033225 & 0.022507 & 0.004720 \\
\hline$V$ & $V_{1}$ & $V_{2}$ & $V_{3}$ & $V_{4}$ & $V_{5}$ & $V_{6}$ & $V_{7}$ \\
\hline 1 & 0.419658 & -0.177682 & -0.201783 & 0.132612 & 0.315844 & 0.048299 & 0.794936 \\
\hline 2 & 0.408761 & -0.080167 & -0.011430 & 0.297761 & 0.568397 & 0.359839 & -0.533982 \\
\hline 3 & 0.375214 & -0.057734 & 0.625572 & -0.348122 & 0.216238 & -0.542567 & -0.047069 \\
\hline 4 & 0.391635 & -0.039225 & -0.137466 & 0.621331 & -0.462217 & -0.453969 & -0.142831 \\
\hline 5 & 0.384349 & -0.291710 & 0.330283 & -0.175593 & -0.550978 & 0.568172 & 0.029418 \\
\hline 6 & 0.365937 & -0.025155 & -0.658475 & -0.596185 & -0.089692 & -0.137390 & -0.222510 \\
\hline 7 & 0.284612 & 0.933490 & 0.078991 & -0.015547 & -0.071711 & 0.161312 & 0.099736 \\
\hline
\end{tabular}

Findings: There is not much difference between the Brownian and Pearsonian leading PC scores. The coefficients of correlation $(r$ and $\rho$ ) between them are $(0.992830,0.996319)$ respectively 
(see Table.4.1 and Table.4.2). However, the Brownian PC scores have lager variance. They have been plotted in Fig.5). The details are given in Table.A4 in the appendix.

The eigenvalues $(\lambda)$ and the associated eigenvectors (V) of the Pearsonian and the Brownian correlation matrices (of X1 through X7) are given in Table.4.3 and Table.4.4. The Pearsonian leading PC scores explain $67.229 \%$ of the total variance in the data and it is commensurate with $67.229=100(\lambda 1 / 7)$. However, the Brownian leading PC scores explain $72.392 \%$ of the total variance in the data while $73.9211=100(\lambda 1 / 7)$ is marginally larger than that. The possible explanation of this observed discrepancy will be given in due course.

6.5. Dataset with Outliers: This dataset contains 7 variables (each one in 35 observations) that are linearly correlated with very large correlation among them, except that each one has a single large (of a magnitude of about 10 times of its cohorts) outlier. We subject this dataset to construction of the leading principal component scores by using Pearsonian and Brownian correlation coefficients.

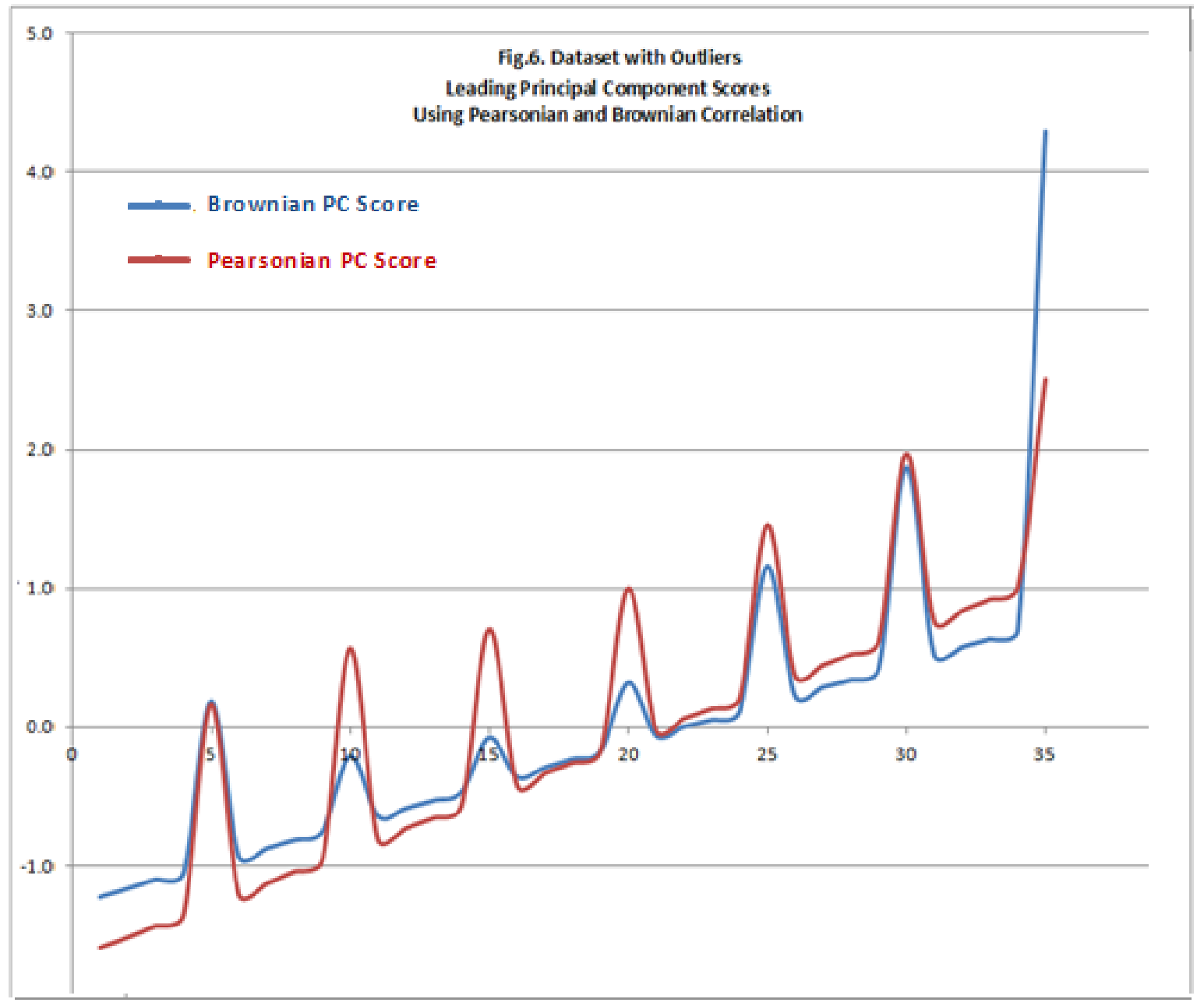

Findings: There is some difference between the Brownian and Pearsonian leading PC scores. The coefficients of correlation ( $r$ and $\rho$ ) between them are $(0.910506,0.949876)$ respectively (Table.5.1 and Table.5.2). They have been plotted in Fig.6. The details are given in Table.A5 in the appendix. The 
Brownian PC scores have lager variance, although it cannot be concluded that they ameliorate the problems due to outliers or they represent the variables (with outliers) better than the Pearsonian leading PC score.

The eigenvalues $(\lambda)$ and the associated eigenvectors $(V)$ of the Pearsonian and the Brownian correlation matrices (of $\mathrm{X} 1$ through $\mathrm{X7}$ ) are given in Table.5.3 and Table.5.4. The Pearsonian leading PC scores explain 30.750 of the total variance in the data and it is commensurate with $30.751=100(\lambda 1 / 7)$. However, the Brownian leading PC scores explain $58.360 \%$ of the total variance in the data while 67.497 $=100(\lambda 1 / 7)$ is considerably larger than that. The possible explanation of this observed discrepancy will be explored in due course.

\begin{tabular}{|l|c|c|c|c|c|c|c|c|c|}
\hline \multicolumn{8}{|c|}{ Table.5.1. Pearsonian Correlation matrix of Dataset with Outliers } \\
\hline & $\mathrm{X} 1$ & $\mathrm{X} 2$ & $\mathrm{X} 3$ & $\mathrm{X} 4$ & $\mathrm{X} 5$ & $\mathrm{X} 6$ & $\mathrm{X} 7$ & $\mathrm{SB}$ & $\mathrm{SP}$ \\
\hline $\mathrm{X} 1$ & 1.000000 & 0.333274 & 0.257309 & 0.246588 & 0.275624 & 0.318127 & 0.360049 & 0.719453 & 0.790055 \\
\hline X2 & 0.333274 & 1.000000 & 0.149002 & 0.145658 & 0.168815 & 0.192087 & 0.223476 & 0.432582 & 0.600698 \\
\hline X3 & 0.257309 & 0.149002 & 1.000000 & 0.103183 & 0.113524 & 0.134531 & 0.151032 & 0.308415 & 0.468284 \\
\hline X4 & 0.246588 & 0.145658 & 0.103183 & 1.000000 & 0.097512 & 0.105096 & 0.118198 & 0.290887 & 0.427888 \\
\hline X5 & 0.275624 & 0.168815 & 0.113524 & 0.097512 & 1.000000 & 0.097911 & 0.106620 & 0.381527 & 0.453212 \\
\hline X6 & 0.318127 & 0.192087 & 0.134531 & 0.105096 & 0.097911 & 1.000000 & 0.104480 & 0.464015 & 0.500756 \\
\hline X7 & 0.360049 & 0.223476 & 0.151032 & 0.118198 & 0.106620 & 0.104480 & 1.000000 & 0.823015 & 0.555852 \\
\hline SB & 0.719453 & 0.432582 & 0.308415 & 0.290887 & 0.381527 & 0.464015 & 0.823015 & 1.000000 & 0.910506 \\
\hline SP & 0.790055 & 0.600698 & 0.468284 & 0.427888 & 0.453212 & 0.500756 & 0.555852 & 0.910506 & 1.000000 \\
\hline
\end{tabular}

\begin{tabular}{|l|c|c|c|c|c|c|c|c|c|}
\hline \multicolumn{10}{|c|}{ Table.5.2. Brownian Correlation matrix of Dataset with Outliers } \\
\hline & $\mathrm{X} 1$ & $\mathrm{X} 2$ & $\mathrm{X} 3$ & $\mathrm{X} 4$ & $\mathrm{X} 5$ & $\mathrm{X} 6$ & $\mathrm{X} 7$ & $\mathrm{SB}$ & SP \\
\hline X1 & 1.000000 & 0.789665 & 0.750109 & 0.703358 & 0.667044 & 0.636991 & 0.612285 & 0.894048 & 0.857865 \\
\hline X2 & 0.789665 & 1.000000 & 0.733230 & 0.685645 & 0.650741 & 0.616587 & 0.592989 & 0.793885 & 0.834236 \\
\hline X3 & 0.750109 & 0.733230 & 1.000000 & 0.649538 & 0.613027 & 0.583419 & 0.557450 & 0.735454 & 0.763273 \\
\hline X4 & 0.703358 & 0.685645 & 0.649538 & 1.000000 & 0.574242 & 0.542829 & 0.519851 & 0.696234 & 0.705768 \\
\hline X5 & 0.667044 & 0.650741 & 0.613027 & 0.574242 & 1.000000 & 0.512619 & 0.491103 & 0.696388 & 0.673816 \\
\hline X6 & 0.636991 & 0.616587 & 0.583419 & 0.542829 & 0.512619 & 1.000000 & 0.467770 & 0.696247 & 0.653841 \\
\hline X7 & 0.612285 & 0.592989 & 0.557450 & 0.519851 & 0.491103 & 0.467770 & 1.000000 & 0.812590 & 0.644645 \\
\hline SB & 0.894048 & 0.793885 & 0.735454 & 0.696234 & 0.696388 & 0.696247 & 0.812590 & 1.000000 & 0.949876 \\
\hline SP & 0.857865 & 0.834236 & 0.763273 & 0.705768 & 0.673816 & 0.653841 & 0.644645 & 0.949876 & 1.000000 \\
\hline
\end{tabular}

\begin{tabular}{|c|c|c|c|c|c|c|c|}
\hline \multicolumn{7}{|c|}{ Table.5.3. Eigenvalues and Eigenvectors of } \\
\hline & $\lambda_{1}$ & $\lambda_{2}$ & $\lambda_{3}$ & $\lambda_{4}$ & $\lambda_{5}$ & $\lambda_{6}$ & $\lambda_{7}$ \\
\hline$\lambda$ & 2.152533 & 0.906245 & 0.905057 & 0.896032 & 0.870888 & 0.753702 & 0.515544 \\
\hline$\lambda / 7$ & 0.307505 & 0.129464 & 0.129294 & 0.128005 & 0.124413 & 0.107672 & 0.073649 \\
\hline$V$ & $V_{1}$ & $V_{2}$ & $V_{3}$ & $V_{4}$ & $V_{5}$ & $V_{6}$ & $V_{7}$ \\
\hline 1 & 0.538493 & 0.014697 & 0.007084 & 0.003407 & -0.068165 & 0.183408 & -0.819428 \\
\hline 2 & 0.409431 & 0.027749 & 0.047809 & 0.038439 & -0.347471 & -0.833329 & 0.112517 \\
\hline 3 & 0.319179 & 0.363108 & 0.034708 & 0.214613 & 0.826841 & -0.148375 & 0.115464 \\
\hline 4 & 0.291645 & -0.624408 & -0.647375 & -0.184998 & 0.216205 & 0.007993 & 0.157895 \\
\hline 5 & 0.308908 & -0.470763 & 0.744400 & -0.205451 & 0.105925 & 0.155698 & 0.226176 \\
\hline 6 & 0.341314 & 0.502643 & -0.125485 & -0.652742 & -0.173306 & 0.260185 & 0.302166 \\
\hline 7 & 0.378867 & 0.054891 & -0.086534 & 0.670780 & -0.320860 & 0.397376 & 0.367634 \\
\hline
\end{tabular}




\begin{tabular}{|c|c|c|c|c|c|c|c|}
\hline \multicolumn{7}{|c|}{ Table.5.4. Eigenvalues and Eigenvectors of } \\
\hline & $\lambda_{1}$ & $\lambda_{2}$ & $\lambda_{3}$ & $\lambda_{4}$ & $\lambda_{5}$ & $\lambda_{6}$ & $\lambda_{7}$ \\
\hline$\lambda$ & 4.724762 & 0.539186 & 0.492721 & 0.427024 & 0.348319 & 0.262176 & 0.205812 \\
\hline$\lambda / 7$ & 0.674966 & 0.077027 & 0.070389 & 0.061003 & 0.049760 & 0.037454 & 0.029402 \\
\hline$V$ & $V_{1}$ & $V_{2}$ & $V_{3}$ & $V_{4}$ & $V_{5}$ & $V_{6}$ & $V_{7}$ \\
\hline 1 & 0.416111 & 0.030670 & -0.045894 & -0.079184 & 0.159636 & 0.320837 & -0.830129 \\
\hline 2 & 0.408857 & 0.039555 & -0.069779 & -0.101422 & 0.229522 & 0.693142 & 0.531968 \\
\hline 3 & 0.393810 & 0.063031 & -0.093190 & -0.186466 & 0.662084 & -0.586447 & 0.123332 \\
\hline 4 & 0.375607 & 0.096218 & -0.193867 & -0.625877 & -0.616283 & -0.188480 & 0.070893 \\
\hline 5 & 0.360742 & 0.164631 & -0.535195 & 0.691006 & -0.240479 & -0.135274 & 0.052057 \\
\hline 6 & 0.347109 & 0.423596 & 0.776229 & 0.236361 & -0.169752 & -0.100441 & 0.052719 \\
\hline 7 & 0.336007 & -0.881889 & 0.240396 & 0.153612 & -0.130501 & -0.093730 & 0.046580 \\
\hline
\end{tabular}

6.6. Lévy Distributed Probability Density Function Dataset: This dataset has 7 variables (Lévy-distributed probability density functions with the same location parameter, $\mu=0$, but varying scale parameters described below.

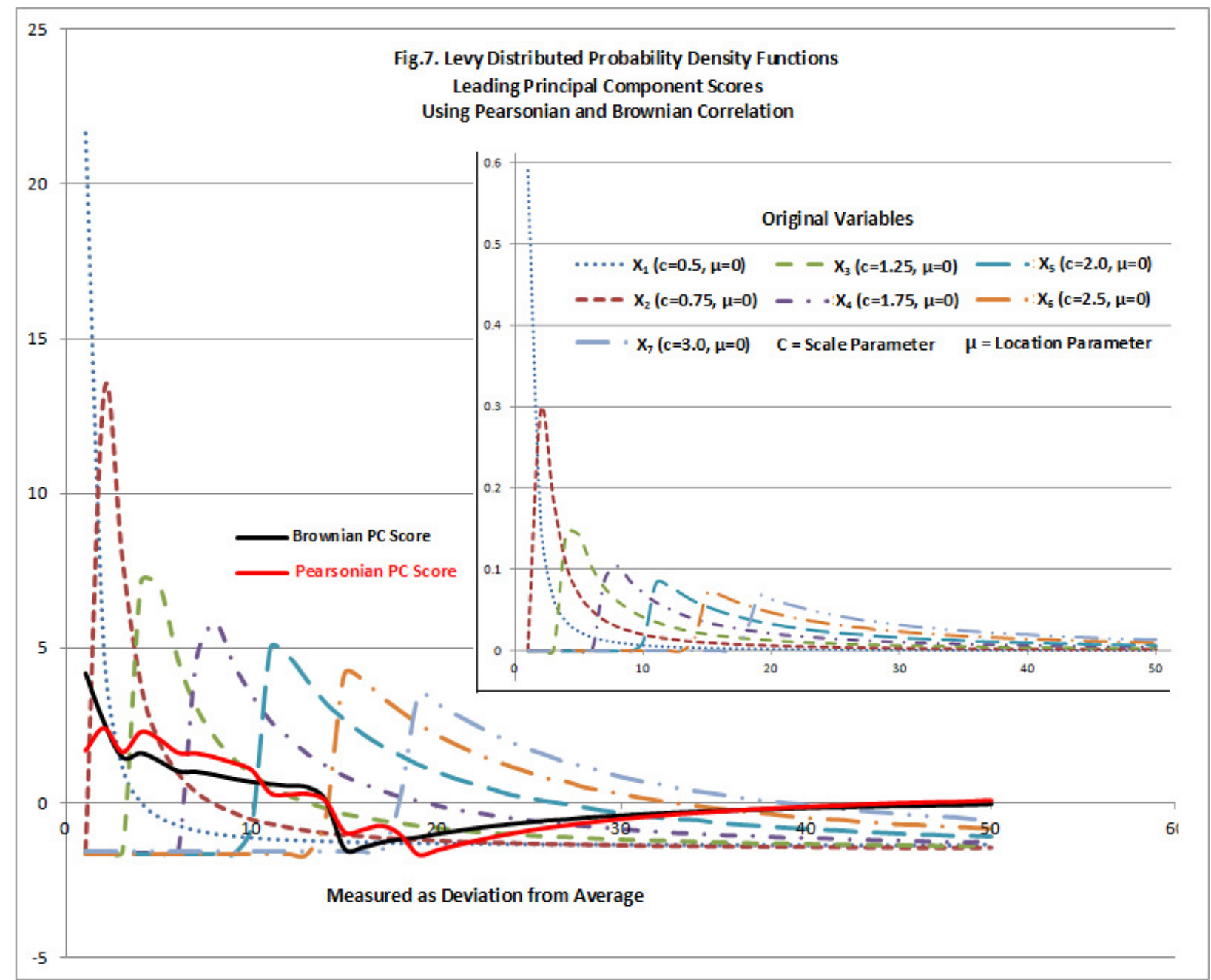


Description: X1=Lévy PDF (c=0.5, $\mu=0) ; \mathrm{X} 2=$ Lévy PDF $(\mathrm{c}=0.75, \mu=0) ; \mathrm{X} 3=$ Lévy PDF $(\mathrm{c}=1.25$, $\mu=0) ; \mathrm{X} 4=$ Lévy PDF (c=1.75, $\mu=0) ; \mathrm{X} 5=$ Lévy PDF $(\mathrm{c}=2.0, \mu=0) ; \mathrm{X} 6=$ Lévy PDF $(\mathrm{c}=2.5, \mu=0)$; X7=Lévy PDF (c=3.0, $\mu=0)$. They all have 50 observations each and plotted in the inset of Fig.7 as 'original variables' against the observation number (1 through 50) in the horizontal axis. Their Brownian and Pearsonian leading principal component scores as well as the transformed (original variables measured as signed deviations from their respective Brownian average) are plotted in Fig.7. It may be noted that the principal component scores are unique up to scale factor; they mean the one and the same up to multiplication by any nonzero $\mathrm{k}$, negative or positive, since they are derived through using the squared values of correlation coefficients.

Findings: There is some difference between the Brownian and Pearsonian leading PC scores. The coefficients of correlation ( $\mathrm{r}$ and $\rho$ ) between them are $(0.885419,0.955735)$ respectively (see Table.6.1 and Table.6.2). The details are given in Table.A6 in the appendix. The Brownian PC scores have lager variance, although it cannot be concluded that they represent the variables better than the Pearsonian leading PC score.

The eigenvalues $(\lambda)$ and the associated eigenvectors (V) of the Pearsonian and the Brownian correlation matrices (of $\mathrm{X}_{1}$ through $\mathrm{X}_{7}$ ) are given in Table.6.3 and Table.6.4. The Pearsonian leading PC scores explain $33.111 \%$ of the total variance in the data and it is commensurate with $33.111=100\left(\lambda_{1} / 7\right)$. However, the Brownian leading PC scores explain $51.582 \%$ of the total variance in the data while $59.32=100\left(\lambda_{1} / 7\right)$ is considerably larger than that. The possible explanation of this observed discrepancy will be explored in due course.

\begin{tabular}{|l|c|c|c|r|r|r|r|r|r|}
\hline \multicolumn{10}{|c|}{ Table.6.1. Pearsonian Correlation matrix of Lévy PDF Dataset } \\
\hline & $\mathrm{X} 1$ & $\mathrm{X} 2$ & $\mathrm{X} 3$ & $\mathrm{X} 4$ & $\mathrm{X} 5$ & $\mathrm{X} 6$ & $\mathrm{X} 7$ & \multicolumn{1}{|c|}{ SB } & SP \\
\hline X1 & 1.000000 & 0.221632 & -0.044305 & -0.142426 & -0.195994 & -0.224126 & -0.230510 & 0.727126 & 0.398615 \\
\hline X2 & 0.221632 & 1.000000 & 0.248500 & -0.083527 & -0.236534 & -0.314331 & -0.343052 & 0.551320 & 0.631029 \\
\hline X3 & -0.044305 & 0.248500 & 1.000000 & 0.281389 & -0.112608 & -0.311533 & -0.402016 & 0.364388 & 0.595124 \\
\hline X4 & -0.142426 & -0.083527 & 0.281389 & 1.000000 & 0.318013 & -0.090133 & -0.295947 & 0.045643 & 0.165073 \\
\hline X5 & -0.195994 & -0.236534 & -0.112608 & 0.318013 & 1.000000 & 0.392853 & 0.016171 & -0.364405 & -0.427726 \\
\hline X6 & -0.224126 & -0.314331 & -0.311533 & -0.090133 & 0.392853 & 1.000000 & 0.503399 & -0.768704 & -0.787706 \\
\hline X7 & -0.230510 & -0.343052 & -0.402016 & -0.295947 & 0.016171 & 0.503399 & 1.000000 & -0.564906 & -0.758809 \\
\hline SB & 0.727126 & 0.551320 & 0.364388 & 0.045643 & -0.364405 & -0.768704 & -0.564906 & 1.000000 & 0.885419 \\
\hline SP & 0.398615 & 0.631029 & 0.595124 & 0.165073 & -0.427726 & -0.787706 & -0.758809 & 0.885419 & 1.000000 \\
\hline
\end{tabular}

\begin{tabular}{|l|c|c|c|c|c|c|c|c|c|}
\hline \multicolumn{9}{|c|}{ Table.6.2. Brownian Correlation matrix Lévy PDF Dataset } \\
\hline & $\mathrm{X} 1$ & $\mathrm{X} 2$ & $\mathrm{X} 3$ & $\mathrm{X} 4$ & $\mathrm{X} 5$ & $\mathrm{X} 6$ & $\mathrm{X} 7$ & $\mathrm{SB}$ & $\mathrm{SP}$ \\
\hline $\mathrm{X} 1$ & 1.000000 & 0.543886 & 0.342699 & 0.314039 & 0.341826 & 0.364742 & 0.363316 & 0.717816 & 0.544026 \\
\hline X2 & 0.543886 & 1.000000 & 0.612421 & 0.463055 & 0.467230 & 0.509518 & 0.521185 & 0.723720 & 0.730972 \\
\hline X3 & 0.342699 & 0.612421 & 1.000000 & 0.646473 & 0.525622 & 0.559687 & 0.589850 & 0.665574 & 0.694461 \\
\hline X4 & 0.314039 & 0.463055 & 0.646473 & 1.000000 & 0.648226 & 0.558311 & 0.574386 & 0.578283 & 0.537635 \\
\hline X5 & 0.341826 & 0.467230 & 0.525622 & 0.648226 & 1.000000 & 0.677774 & 0.554493 & 0.645913 & 0.661594 \\
\hline X6 & 0.364742 & 0.509518 & 0.559687 & 0.558311 & 0.677774 & 1.000000 & 0.722742 & 0.909340 & 0.880468 \\
\hline X7 & 0.363316 & 0.521185 & 0.589850 & 0.574386 & 0.554493 & 0.722742 & 1.000000 & 0.741749 & 0.777842 \\
\hline SB & 0.717816 & 0.723720 & 0.665574 & 0.578283 & 0.645913 & 0.909340 & 0.741749 & 1.000000 & 0.955735 \\
\hline SP & 0.544026 & 0.730972 & 0.694461 & 0.537635 & 0.661594 & 0.880468 & 0.777842 & 0.955735 & 1.000000 \\
\hline
\end{tabular}




\begin{tabular}{|c|c|c|c|c|c|c|c|}
\hline \multicolumn{7}{|c|}{ Table.6.3. Eigenvalues and Eigenvectors of } \\
\hline & $\lambda_{1}$ & $\lambda_{2}$ & $\lambda_{3}$ & $\lambda_{4}$ & $\lambda_{5}$ & $\lambda_{6}$ & $\lambda_{7}$ \\
\hline$\lambda$ & 2.317735 & 1.585835 & 0.937160 & 0.754292 & 0.576703 & 0.484076 & 0.344198 \\
\hline$\lambda / 7$ & 0.331105 & 0.226548 & 0.133880 & 0.107756 & 0.082386 & 0.069154 & 0.049171 \\
\hline$V$ & $V_{1}$ & $V_{2}$ & $V_{3}$ & $V_{4}$ & $V_{5}$ & $V_{6}$ & $V_{7}$ \\
\hline 1 & 0.261831 & -0.334383 & 0.728222 & -0.164964 & 0.479844 & 0.134440 & 0.117420 \\
\hline 2 & 0.414493 & -0.164932 & 0.025601 & 0.785576 & -0.229017 & 0.351670 & 0.084184 \\
\hline 3 & 0.390909 & 0.322387 & -0.407504 & 0.148603 & 0.693660 & -0.203329 & 0.180577 \\
\hline 4 & 0.108429 & 0.656567 & 0.111594 & -0.232877 & -0.025743 & 0.695058 & -0.081911 \\
\hline 5 & -0.280953 & 0.504355 & 0.457731 & 0.314748 & -0.100631 & -0.348247 & 0.476135 \\
\hline 6 & -0.517407 & 0.057659 & 0.109183 & 0.424339 & 0.420538 & 0.096670 & -0.592269 \\
\hline 7 & -0.498426 & -0.261290 & -0.262842 & 0.014600 & 0.220216 & 0.450759 & 0.601931 \\
\hline
\end{tabular}

\begin{tabular}{|c|c|c|c|c|c|c|c|}
\hline \multicolumn{7}{|c|}{ Table.6.4. Eigenvalues and Eigenvectors of } \\
Brownian Correlation matrix of Lévy PDF Dataset \\
\hline & $\lambda_{1}$ & $\lambda_{2}$ & $\lambda_{3}$ & $\lambda_{4}$ & $\lambda_{5}$ & $\lambda_{6}$ & $\lambda_{7}$ \\
\hline$\lambda$ & 4.152402 & 0.880731 & 0.572471 & 0.506443 & 0.383676 & 0.281065 & 0.223213 \\
\hline$\lambda / 7$ & 0.593200 & 0.125819 & 0.081782 & 0.072349 & 0.054811 & 0.040152 & 0.031888 \\
\hline$V$ & $V_{1}$ & $V_{2}$ & $V_{3}$ & $V_{4}$ & $V_{5}$ & $V_{6}$ & $V_{7}$ \\
\hline 1 & 0.280995 & -0.772653 & 0.290840 & -0.284994 & 0.346749 & -0.193698 & 0.022027 \\
\hline 2 & 0.371631 & -0.433004 & -0.316830 & 0.226435 & -0.554737 & 0.453312 & -0.097566 \\
\hline 3 & 0.394281 & 0.059439 & -0.618752 & 0.136276 & 0.076403 & -0.640461 & 0.153481 \\
\hline 4 & 0.388326 & 0.280178 & -0.291196 & -0.487858 & 0.402649 & 0.407779 & -0.345676 \\
\hline 5 & 0.388941 & 0.262628 & 0.301223 & -0.498398 & -0.464776 & -0.076616 & 0.467684 \\
\hline 6 & 0.406687 & 0.202743 & 0.450506 & 0.272035 & -0.147727 & -0.280378 & -0.645063 \\
\hline 7 & 0.400009 & 0.152981 & 0.231713 & 0.537146 & 0.407711 & 0.309892 & 0.460556 \\
\hline
\end{tabular}

\section{On the Issue of Discrepancy Observed in Brownian Correlation based PC Scores}

Throughout the analysis we have found a discrepancy between the explanatory (varianceexplaining) performance of the leading Brownian $\mathrm{PC}$ and $\lambda_{1} / \mathrm{m}$ of the Brownian correlation matrix ( $\mathrm{m}$ being the order of the correlation matrix concerned). The variance-explaining performance of the leading Brownian PC is lower than $\lambda_{1} / \mathrm{m}$, although the magnitude of this gap is different for the different datasets.

This discrepancy may be due to (i) our inability to find a global optimum solution (by the HostParasite Co-evolutionary algorithm used for obtaining the solution), or (ii) inherent decomposability of the Brownian correlation matrix into (orthogonal) eigenvectors and the associated eigenvalues. The plausibility of the first cause is meagre since this procedure (which directly and iteratively optimizes the sum of squared coefficients of correlation between the PC scores and the variables that they are constituted of) always returns the results identical to those that we obtain by the traditional method (proceeding through singular value decomposition of the correlation matrix among the variables, as suggested by Hotelling, 1933). In other words, the results of the traditional method of constructing PC scores are identical to the ones obtained through direct global optimization - without proceeding through the singular value decomposition of the Pearsonian correlation matrix among the variables and using the eigenvector as the weight vector on the variables under consideration. Further, we also find that correlation between the Pearsonian and the Brownian Leading PCs is always very high (greater 
than 0.9). These reasons suggest that the second cause is more plausible. It may be noted that in the eigenvalue decomposition of a matrix $R$, it is presumed that $R$ (Pearsonian correlation matrix) can be decomposed as $R=R_{1}+R_{2}+\ldots+R_{m}$ where $R_{j}=\lambda_{j} V_{j} V_{j}^{\prime}$ or $R_{j}$ is a product of the $\mathrm{j}^{\text {th }}$ eigenvalue and the cross product of the (associated) $\mathrm{j}^{\text {th }}$ eigenvector $\left(V_{j}\right)$ and its transpose $\left(V_{j}^{\prime}\right)$. Since the eigenvectors are mutually orthogonal to each other $\left(V_{j} V_{k ; j \neq k}=0 \forall j, k\right)$, so are their cross product, $R_{j}$. Now, since the Brownian correlation is not a product moment of $X$, but the product moment of the distances among different observations on $X$, the Brownian principal components scores (of variables) may not preserve the orthogonal decomposability properties as the Pearsonian principal component scores do. We have found that the alternative scores (say, $\xi_{1}$ ) obtained by using the eigenvalues and eigenvectors of the Brownian correlation matrix are suboptimal and do not maximize $\sum_{j=1}^{m} \rho^{2}\left(\xi_{1}, X_{j}\right)$, that is, $\sum_{j=1}^{m} \rho^{2}\left(\xi_{1}, X_{j}\right)$ is far less than $\sum_{j=1}^{m} \rho^{2}\left(Z_{1}, X_{j}\right)$.

\section{Leading Principal Component of Transformed variables}

The Brownian correlation is inherently nonlinear and so far we have constructed the leading Principal Component scores by linear aggregation. Now, suppose, we suitably transform the basic variables in such a manner that their product moment matrix is equal to the Brownian correlation matrix, then the possible objection to (illegitimate) mixing up of linear aggregation and nonlinear correlation may be largely addressed. In other words, let $U=f(X)$ be transformation of $X$ such that $[f(X))^{\prime}[f(\mathrm{X})]=[\rho]=\langle U, U\rangle$, where $[\rho]$ is the (symmetric positive semi-definite) Brownian correlation matrix, and $\varepsilon$ is the eigenvectors (properly scaled by the corresponding eigenvalues) of $[\rho]$. The principal component scores are, then, $U \varepsilon$.

Such a transformation is possible. Let $[r]$ be the Pearsonian correlation matrix obtained from $X$. Let $[L]$ and $[E]$ be the eigenvalues of $[r]$. The matrix $[L]$ is diagonal and the eigenvectors in $[E]$ are of unit length. Similarly, $[\lambda]$ and $[\varepsilon]$ be the eigenvalues and eigenvectors of $[\rho]$. Then the transformation $U=X[E][\mathrm{L}]^{-0.5}\left[[\varepsilon][\lambda]^{0.5}\right]^{\prime}$ would provide $[\rho]=\langle U, U\rangle$.

The results of such transformations are provided in tables B1 throght B6 in the appendix. The Pearsonian correlation matrices of the transformed data are the same as the Brownian correlation of the original data. The leading principal component scores $(U \varepsilon)$ obtained by using the Pearsonian correlation matrix derived from $U$ and the leading principal component scores $(X a)$ obtained through the Pearsonian correlation matrix derived from $X$ are almost identical (that is, $U \varepsilon \cong k X a ; k \cong 1)$.

\section{Concluding Remarks}

In this study we attempted to construct the leading principal component scores in which the Brownian correlation is used and compared the results of such endeavor with the traditional principal component scores based on time tested method that uses the Pearsonian correlation. The testing was done on six datasets, some of which contain highly nonlinear variables. Although the leading PC scores based on the Brownian correlation explain somewhat larger proportion of total variation in the data, we found that such a modest improvement does not 
provide sufficient attractive features so that one should replace the traditional one (based on the Pearsonian correlation) by the new one (based on the Brownian correlation). A suitable transformation of data shows that the Brownian correlation based PC scores with transformed variables and pearsonian correlation based PC scores with the original data are almost identical. Therefore, the Brownian correlation is not likely to provide any attractive feature in the Principal Component analysis if we approach the problem through eigen-decomposition.

\section{References}

Anderson, E. (1936). The species problem in Iris. Annals of the Missouri Botanical Garden. 23(3):457-509.

Donald Bren School of Information and Computer Sciences (1996). Machine-learningdatabases/autos. https://archive.ics.uci.edu/ml/machine-learning-databases/autos/. University of California, Irvine.

Eckerle, K. and NIST (1979). Circular Interference Transmittance Study. National Institute of Standards and Technology, US Dept. of Commerce. http://www.itl.nist.gov/div898/strd/nls/data/eckerle4.shtml.

Fisher, R.A. (1936). The use of multiple measurements in taxonomic problems. Annals of Eugenics. 7(2): 179-188.

Hotelling, H. (1933). Analysis of a Complex of Statistical Variables into Principal Components. Journal of Educational Psychology. 24(6): 417-441.

Kibler, D., Aha, D.W. and Albert, M. (1989). Instance-based prediction of real-valued attributes. Computational Intelligence. 5(2): 51-57.

Mishra, S.K. (2013). Global Optimization of Some Difficult Benchmark Functions by HostParasite Coevolutionary Algorithm. Economics Bulletin. 33(1): 1-18.

National Crime Records Bureau (?). Incidence And Rate Of Violent Crimes During 2011. Ministry of Home Affairs, Govt. of India. http://ncrb.nic.in/CD-CII2011/cii2011/Table\%203.1.pdf

Székely, G.J. and Rizzo, M.L. (2009). Brownian distance covariance. The Annals of Applied Statistics. 3(4): 1236-1265.

Székely, G.J., Rizzo, M.L. and Bakirov, N. K. (2007). Measuring and testing independence by correlation of distances. Ann. Statist. 35(6): 2769-2794. 


\section{Appendix}

\begin{tabular}{|c|c|c|c|c|c|c|}
\hline \multicolumn{7}{|c|}{ Table.A1. Iris Flower Dataset } \\
\hline SI no. & Sepal length & Sepal width & Petal length & Petal width & Score(Brown) & Score(Pearson) \\
\hline 1 & 5.1 & 3.5 & 1.4 & 0.2 & -1.28638 & -1.32123 \\
\hline 2 & 4.9 & 3.0 & 1.4 & 0.2 & -1.27942 & -1.21404 \\
\hline 3 & 4.7 & 3.2 & 1.3 & 0.2 & -1.40977 & -1.37930 \\
\hline 4 & 4.6 & 3.1 & 1.5 & 0.2 & -1.38228 & -1.34147 \\
\hline 5 & 5.0 & 3.6 & 1.4 & 0.2 & -1.33949 & -1.39424 \\
\hline 6 & 5.4 & 3.9 & 1.7 & 0.4 & -1.09355 & -1.21093 \\
\hline 7 & 4.6 & 3.4 & 1.4 & 0.3 & -1.41777 & -1.42585 \\
\hline 8 & 5.0 & 3.4 & 1.5 & 0.2 & -1.28303 & -1.30265 \\
\hline 9 & 4.4 & 2.9 & 1.4 & 0.2 & -1.44796 & -1.36203 \\
\hline 10 & 4.9 & 3.1 & 1.5 & 0.1 & -1.30862 & -1.27434 \\
\hline 11 & 5.4 & 3.7 & 1.5 & 0.2 & -1.18377 & -1.26383 \\
\hline 12 & 4.8 & 3.4 & 1.6 & 0.2 & -1.33278 & -1.35707 \\
\hline 13 & 4.8 & 3.0 & 1.4 & 0.1 & -1.35352 & -1.29425 \\
\hline 14 & 4.3 & 3.0 & 1.1 & 0.1 & -1.61060 & -1.53616 \\
\hline 15 & 5.8 & 4.0 & 1.2 & 0.2 & -1.15690 & -1.28275 \\
\hline 16 & 5.7 & 4.4 & 1.5 & 0.4 & -1.11183 & -1.31978 \\
\hline 17 & 5.4 & 3.9 & 1.3 & 0.4 & -1.19006 & -1.28791 \\
\hline 18 & 5.1 & 3.5 & 1.4 & 0.3 & -1.24923 & -1.27785 \\
\hline 19 & 5.7 & 3.8 & 1.7 & 0.3 & -1.00371 & -1.10763 \\
\hline 20 & 5.1 & 3.8 & 1.5 & 0.3 & -1.27361 & -1.36713 \\
\hline 21 & 5.4 & 3.4 & 1.7 & 0.2 & -1.08701 & -1.11682 \\
\hline 22 & 5.1 & 3.7 & 1.5 & 0.4 & -1.22029 & -1.28758 \\
\hline 23 & 4.6 & 3.6 & 1.0 & 0.2 & -1.58377 & -1.61856 \\
\hline 24 & 5.1 & 3.3 & 1.7 & 0.5 & -1.07021 & -1.06102 \\
\hline 25 & 4.8 & 3.4 & 1.9 & 0.2 & -1.26039 & -1.29933 \\
\hline 26 & 5.0 & 3.0 & 1.6 & 0.2 & -1.19423 & -1.13871 \\
\hline 27 & 5.0 & 3.4 & 1.6 & 0.4 & -1.18460 & -1.19665 \\
\hline 28 & 5.2 & 3.5 & 1.5 & 0.2 & -1.22532 & -1.26515 \\
\hline 29 & 5.2 & 3.4 & 1.4 & 0.2 & -1.23328 & -1.24823 \\
\hline 30 & 4.7 & 3.2 & 1.6 & 0.2 & -1.33738 & -1.32156 \\
\hline 31 & 4.8 & 3.1 & 1.6 & 0.2 & -1.28427 & -1.24855 \\
\hline 32 & 5.4 & 3.4 & 1.5 & 0.4 & -1.06096 & -1.06856 \\
\hline 33 & 5.2 & 4.1 & 1.5 & 0.1 & -1.35948 & -1.52557 \\
\hline 34 & 5.5 & 4.2 & 1.4 & 0.2 & -1.25180 & -1.42710 \\
\hline 35 & 4.9 & 3.1 & 1.5 & 0.2 & -1.27146 & -1.23096 \\
\hline 36 & 5.0 & 3.2 & 1.2 & 0.2 & -1.32308 & -1.28804 \\
\hline 37 & 5.5 & 3.5 & 1.3 & 0.2 & -1.16275 & -1.19314 \\
\hline 38 & 4.9 & 3.6 & 1.4 & 0.1 & -1.41359 & -1.47445 \\
\hline 39 & 4.4 & 3.0 & 1.3 & 0.2 & -1.48825 & -1.41745 \\
\hline 40 & 5.1 & 3.4 & 1.5 & 0.2 & -1.24609 & -1.26581 \\
\hline 41 & 5.0 & 3.5 & 1.3 & 0.3 & -1.31030 & -1.33393 \\
\hline 42 & 4.5 & 2.3 & 1.3 & 0.3 & -1.30098 & -1.08403 \\
\hline
\end{tabular}




\begin{tabular}{|c|c|c|c|c|c|c|}
\hline 43 & 4.4 & 3.2 & 1.3 & 0.2 & -1.52059 & -1.48980 \\
\hline 44 & 5.0 & 3.5 & 1.6 & 0.6 & -1.12646 & -1.14606 \\
\hline 45 & 5.1 & 3.8 & 1.9 & 0.4 & -1.13994 & -1.24676 \\
\hline 46 & 4.8 & 3.0 & 1.4 & 0.3 & -1.27921 & -1.20749 \\
\hline 47 & 5.1 & 3.8 & 1.6 & 0.2 & -1.28663 & -1.39126 \\
\hline 48 & 4.6 & 3.2 & 1.4 & 0.2 & -1.42258 & -1.39688 \\
\hline 49 & 5.3 & 3.7 & 1.5 & 0.2 & -1.22071 & -1.30066 \\
\hline 50 & 5.0 & 3.3 & 1.4 & 0.2 & -1.29099 & -1.28572 \\
\hline 51 & 7.0 & 3.2 & 4.7 & 1.4 & 0.70605 & 0.64278 \\
\hline 52 & 6.4 & 3.2 & 4.5 & 1.5 & 0.47331 & 0.42666 \\
\hline 53 & 6.9 & 3.1 & 4.9 & 1.5 & 0.77069 & 0.72399 \\
\hline 54 & 5.5 & 2.3 & 4.0 & 1.3 & 0.09141 & 0.23773 \\
\hline 55 & 6.5 & 2.8 & 4.6 & 1.5 & 0.59905 & 0.62743 \\
\hline 56 & 5.7 & 2.8 & 4.5 & 1.3 & 0.20509 & 0.22676 \\
\hline 57 & 6.3 & 3.3 & 4.7 & 1.6 & 0.50561 & 0.43553 \\
\hline 58 & 4.9 & 2.4 & 3.3 & 1.0 & -0.42675 & -0.28431 \\
\hline 59 & 6.6 & 2.9 & 4.6 & 1.3 & 0.54552 & 0.54134 \\
\hline 60 & 5.2 & 2.7 & 3.9 & 1.4 & -0.07106 & 0.00667 \\
\hline 61 & 5.0 & 2.0 & 3.5 & 1.0 & -0.27688 & -0.06429 \\
\hline 62 & 5.9 & 3.0 & 4.2 & 1.5 & 0.24855 & 0.25710 \\
\hline 63 & 6.0 & 2.2 & 4.0 & 1.0 & 0.18082 & 0.32794 \\
\hline 64 & 6.1 & 2.9 & 4.7 & 1.4 & 0.42210 & 0.41979 \\
\hline 65 & 5.6 & 2.9 & 3.6 & 1.3 & -0.06517 & -0.01946 \\
\hline 66 & 6.7 & 3.1 & 4.4 & 1.4 & 0.53901 & 0.51071 \\
\hline 67 & 5.6 & 3.0 & 4.5 & 1.5 & 0.21012 & 0.20434 \\
\hline 68 & 5.8 & 2.7 & 4.1 & 1.0 & 0.05023 & 0.09265 \\
\hline 69 & 6.2 & 2.2 & 4.5 & 1.5 & 0.56111 & 0.71472 \\
\hline 70 & 5.6 & 2.5 & 3.9 & 1.1 & -0.00242 & 0.09621 \\
\hline 71 & 5.9 & 3.2 & 4.8 & 1.8 & 0.47245 & 0.43037 \\
\hline 72 & 6.1 & 2.8 & 4.0 & 1.3 & 0.23221 & 0.27787 \\
\hline 73 & 6.3 & 2.5 & 4.9 & 1.5 & 0.64606 & 0.72002 \\
\hline 74 & 6.1 & 2.8 & 4.7 & 1.2 & 0.36396 & 0.36921 \\
\hline 75 & 6.4 & 2.9 & 4.3 & 1.3 & 0.39925 & 0.40993 \\
\hline 76 & 6.6 & 3.0 & 4.4 & 1.4 & 0.51824 & 0.51005 \\
\hline 77 & 6.8 & 2.8 & 4.8 & 1.4 & 0.72097 & 0.73305 \\
\hline 78 & 6.7 & 3.0 & 5.0 & 1.7 & 0.81141 & 0.79250 \\
\hline 79 & 6.0 & 2.9 & 4.5 & 1.5 & 0.37405 & 0.38785 \\
\hline 80 & 5.7 & 2.6 & 3.5 & 1.0 & -0.11531 & -0.02349 \\
\hline 81 & 5.5 & 2.4 & 3.8 & 1.1 & -0.04732 & 0.07631 \\
\hline 82 & 5.5 & 2.4 & 3.7 & 1.0 & -0.10860 & 0.01368 \\
\hline 83 & 5.8 & 2.7 & 3.9 & 1.2 & 0.07628 & 0.14091 \\
\hline 84 & 6.0 & 2.7 & 5.1 & 1.6 & 0.58831 & 0.61905 \\
\hline 85 & 5.4 & 3.0 & 4.5 & 1.5 & 0.13624 & 0.13067 \\
\hline 86 & 6.0 & 3.4 & 4.5 & 1.6 & 0.33036 & 0.25036 \\
\hline 87 & 6.7 & 3.1 & 4.7 & 1.5 & 0.64855 & 0.61183 \\
\hline 88 & 6.3 & 2.3 & 4.4 & 1.3 & 0.48345 & 0.60938 \\
\hline
\end{tabular}




\begin{tabular}{|c|c|c|c|c|c|c|}
\hline 89 & 5.6 & 3.0 & 4.1 & 1.3 & 0.03930 & 0.04060 \\
\hline 90 & 5.5 & 2.5 & 4.0 & 1.3 & 0.05907 & 0.16538 \\
\hline 91 & 5.5 & 2.6 & 4.4 & 1.2 & 0.10227 & 0.16281 \\
\hline 92 & 6.1 & 3.0 & 4.6 & 1.4 & 0.38180 & 0.36438 \\
\hline 93 & 5.8 & 2.6 & 4.0 & 1.2 & 0.11658 & 0.19633 \\
\hline 94 & 5.0 & 2.3 & 3.3 & 1.0 & -0.37365 & -0.21130 \\
\hline 95 & 5.6 & 2.7 & 4.2 & 1.3 & 0.11194 & 0.16836 \\
\hline 96 & 5.7 & 3.0 & 4.2 & 1.2 & 0.06322 & 0.05330 \\
\hline 97 & 5.7 & 2.9 & 4.2 & 1.3 & 0.11654 & 0.13285 \\
\hline 98 & 6.2 & 2.9 & 4.3 & 1.3 & 0.32537 & 0.33627 \\
\hline 99 & 5.1 & 2.5 & 3.0 & 1.1 & -0.40428 & -0.26117 \\
\hline 100 & 5.7 & 2.8 & 4.1 & 1.3 & 0.10858 & 0.14978 \\
\hline 101 & 6.3 & 3.3 & 6.0 & 2.5 & 1.15365 & 1.07613 \\
\hline 102 & 5.8 & 2.7 & 5.1 & 1.9 & 0.62588 & 0.67551 \\
\hline 103 & 7.1 & 3.0 & 5.9 & 2.1 & 1.32494 & 1.28656 \\
\hline 104 & 6.3 & 2.9 & 5.6 & 1.8 & 0.86174 & 0.84019 \\
\hline 105 & 6.5 & 3.0 & 5.8 & 2.2 & 1.11632 & 1.08969 \\
\hline 106 & 7.6 & 3.0 & 6.6 & 2.1 & 1.67854 & 1.60545 \\
\hline 107 & 4.9 & 2.5 & 4.5 & 1.7 & 0.10668 & 0.21412 \\
\hline 108 & 7.3 & 2.9 & 6.3 & 1.8 & 1.40004 & 1.34325 \\
\hline 109 & 6.7 & 2.5 & 5.8 & 1.8 & 1.12243 & 1.17071 \\
\hline 110 & 7.2 & 3.6 & 6.1 & 2.5 & 1.46173 & 1.31836 \\
\hline 111 & 6.5 & 3.2 & 5.1 & 2.0 & 0.84078 & 0.79586 \\
\hline 112 & 6.4 & 2.7 & 5.3 & 1.9 & 0.89578 & 0.93501 \\
\hline 113 & 6.8 & 3.0 & 5.5 & 2.1 & 1.11760 & 1.09907 \\
\hline 114 & 5.7 & 2.5 & 5.0 & 2.0 & 0.63430 & 0.73515 \\
\hline 115 & 5.8 & 2.8 & 5.1 & 2.4 & 0.79548 & 0.85623 \\
\hline 116 & 6.4 & 3.2 & 5.3 & 2.3 & 0.96355 & 0.92765 \\
\hline 117 & 6.5 & 3.0 & 5.5 & 1.8 & 0.89532 & 0.85844 \\
\hline 118 & 7.7 & 3.8 & 6.7 & 2.2 & 1.64741 & 1.41553 \\
\hline 119 & 7.7 & 2.6 & 6.9 & 2.3 & 1.92684 & 1.93147 \\
\hline 120 & 6.0 & 2.2 & 5.0 & 1.5 & 0.60787 & 0.73728 \\
\hline 121 & 6.9 & 3.2 & 5.7 & 2.3 & 1.24476 & 1.18881 \\
\hline 122 & 5.6 & 2.8 & 4.9 & 2.0 & 0.52473 & 0.57056 \\
\hline 123 & 7.7 & 2.8 & 6.7 & 2.0 & 1.73479 & 1.69050 \\
\hline 124 & 6.3 & 2.7 & 4.9 & 1.8 & 0.72518 & 0.77781 \\
\hline 125 & 6.7 & 3.3 & 5.7 & 2.1 & 1.08041 & 0.99221 \\
\hline 126 & 7.2 & 3.2 & 6.0 & 1.8 & 1.24221 & 1.14016 \\
\hline 127 & 6.2 & 2.8 & 4.8 & 1.8 & 0.64794 & 0.68556 \\
\hline 128 & 6.1 & 3.0 & 4.9 & 1.8 & 0.60279 & 0.59562 \\
\hline 129 & 6.4 & 2.8 & 5.6 & 2.1 & 1.02630 & 1.04333 \\
\hline 130 & 7.2 & 3.0 & 5.8 & 1.6 & 1.15199 & 1.08726 \\
\hline 131 & 7.4 & 2.8 & 6.1 & 1.9 & 1.44205 & 1.42114 \\
\hline 132 & 7.9 & 3.8 & 6.4 & 2.0 & 1.57460 & 1.34470 \\
\hline 133 & 6.4 & 2.8 & 5.6 & 2.2 & 1.06346 & 1.08671 \\
\hline 134 & 6.3 & 2.8 & 5.1 & 1.5 & 0.64581 & 0.65000 \\
\hline
\end{tabular}




\begin{tabular}{|r|r|r|r|r|r|l|}
\hline 135 & 6.1 & 2.6 & 5.6 & 1.4 & 0.68776 & 0.70153 \\
\hline 136 & 7.7 & 3.0 & 6.1 & 2.3 & 1.66914 & 1.63281 \\
\hline 137 & 6.3 & 3.4 & 5.6 & 2.4 & 1.00381 & 0.91959 \\
\hline 138 & 6.4 & 3.1 & 5.5 & 1.8 & 0.84222 & 0.78543 \\
\hline 139 & 6.0 & 3.0 & 4.8 & 1.8 & 0.54172 & 0.53955 \\
\hline 140 & 6.9 & 3.1 & 5.4 & 2.1 & 1.11424 & 1.08049 \\
\hline 141 & 6.7 & 3.1 & 5.6 & 2.4 & 1.20008 & 1.17544 \\
\hline 142 & 6.9 & 3.1 & 5.1 & 2.3 & 1.11616 & 1.10950 \\
\hline 143 & 5.8 & 2.7 & 5.1 & 1.9 & 0.62588 & 0.67551 \\
\hline 144 & 6.8 & 3.2 & 5.9 & 2.3 & 1.25608 & 1.19047 \\
\hline 145 & 6.7 & 3.3 & 5.7 & 2.5 & 1.22902 & 1.16572 \\
\hline 146 & 6.7 & 3.0 & 5.2 & 2.3 & 1.08258 & 1.09126 \\
\hline 147 & 6.3 & 2.5 & 5.0 & 1.9 & 0.81879 & 0.91278 \\
\hline 148 & 6.5 & 3.0 & 5.2 & 2.0 & 0.89724 & 0.88745 \\
\hline 149 & 6.2 & 3.4 & 5.4 & 2.3 & 0.88146 & 0.80089 \\
\hline 150 & 5.9 & 3.0 & 5.1 & 1.8 & 0.57717 & 0.56045 \\
\hline
\end{tabular}

\section{Table.A2. Motor Car Dataset}

\begin{tabular}{|c|c|c|c|c|c|c|c|c|c|c|c|c|c|c|c|}
\hline $\mathrm{SI}$ & $\mathrm{X}_{1}$ & $x_{2}$ & $X_{3}$ & $X_{4}$ & $X_{5}$ & $X_{6}$ & $x_{7}$ & $X_{8}$ & $X_{9}$ & $\mathrm{X}_{10}$ & $X_{11}$ & $X_{12}$ & $X_{13}$ & Score(Br.) & Score(Pear) \\
\hline 1 & 88.6 & 168.8 & 64.1 & 48.8 & 2548 & 130 & 3.47 & 2.68 & 9.00 & 111 & 5000 & 21 & 27 & -0.17394 & -0.26243 \\
\hline 2 & 88.6 & 168.8 & 64.1 & 48.8 & 2548 & 130 & 3.47 & 2.68 & 9.00 & 111 & 5000 & 21 & 27 & -0.17394 & -0.26243 \\
\hline 3 & 94.5 & 171.2 & 65.5 & 52.4 & 2823 & 152 & 2.68 & 3.47 & 9.00 & 154 & 5000 & 19 & 26 & 0.15419 & 0.11602 \\
\hline 4 & 99.8 & 176.6 & 66.2 & 54.3 & 2337 & 109 & 3.19 & 3.40 & 10.00 & 102 & 5500 & 24 & 30 & -0.05990 & -0.08275 \\
\hline 5 & 99.4 & 176.6 & 66.4 & 54.3 & 2824 & 136 & 3.19 & 3.40 & 8.00 & 115 & 5500 & 18 & 22 & 0.48040 & 0.44286 \\
\hline 6 & 99.8 & 177.3 & 66.3 & 53.1 & 2507 & 136 & 3.19 & 3.40 & 8.50 & 110 & 5500 & 19 & 25 & 0.31033 & 0.25098 \\
\hline 7 & 105.8 & 192.7 & 71.4 & 55.7 & 2844 & 136 & 3.19 & 3.40 & 8.50 & 110 & 5500 & 19 & 25 & 1.02202 & 0.98971 \\
\hline 8 & 105.8 & 192.7 & 71.4 & 55.7 & 2954 & 136 & 3.19 & 3.40 & 8.50 & 110 & 5500 & 19 & 25 & 1.05217 & 1.01947 \\
\hline 9 & 105.8 & 192.7 & 71.4 & 55.9 & 3086 & 131 & 3.13 & 3.40 & 8.30 & 140 & 5500 & 17 & 20 & 1.24919 & 1.24719 \\
\hline 11 & 101.2 & 176.8 & 64.8 & 54.3 & 2395 & 108 & 3.50 & 2.80 & 8.80 & 101 & 5800 & 23 & 29 & -0.00804 & -0.03633 \\
\hline \begin{tabular}{l|l|}
12 & \\
\end{tabular} & \begin{tabular}{|l|l}
101.2 \\
\end{tabular} & 176.8 & 64.8 & 54.3 & 2395 & 108 & 3.50 & 2.80 & 8.80 & 101 & 5800 & 23 & 29 & -0.00804 & -0.03633 \\
\hline 13 & 101.2 & 176.8 & 64.8 & 54.3 & 2710 & 164 & 3.31 & 3.19 & 9.00 & 121 & 4250 & 21 & 28 & 0.41612 & 0.41001 \\
\hline 14 & 101.2 & 176.8 & 64.8 & 54.3 & 2765 & 164 & 3.31 & 3.19 & 9.00 & 121 & 4250 & 21 & 28 & 0.43120 & 0.42489 \\
\hline 15 & 103.5 & 189.0 & 66.9 & 55.7 & 3055 & 164 & 3.31 & 3.19 & 9.00 & 121 & 4250 & 20 & 25 & 0.92785 & 0.91278 \\
\hline 16 & 103.5 & 189.0 & 66.9 & 55.7 & 3230 & 209 & 3.62 & 3.39 & 8.00 & 182 & 5400 & 16 & 22 & 1.41723 & 1.47016 \\
\hline 17 & 103.5 & 193.8 & 67.9 & 53.7 & 3380 & 209 & 3.62 & 3.39 & 8.00 & 182 & 5400 & 16 & 22 & 1.55909 & 1.58389 \\
\hline 18 & 110.0 & 197.0 & 70.9 & 56.3 & 3505 & 209 & 3.62 & 3.39 & 8.00 & 182 & 5400 & 15 & 20 & 2.00732 & 2.07183 \\
\hline 19 & 88.4 & 141.1 & 60.3 & 53.2 & 1488 & 61 & 2.91 & 3.03 & 9.50 & 48 & 5100 & 47 & 53 & -2.75293 & -2.60594 \\
\hline 20 & 94.5 & 155.9 & 63.6 & 52.0 & 1874 & 90 & 3.03 & 3.11 & 9.60 & 70 & 5400 & 38 & 43 & -1.56155 & -1.49250 \\
\hline 21 & 94.5 & 158.8 & 63.6 & 52.0 & 1909 & 90 & 3.03 & 3.11 & 9.60 & 70 & 5400 & 38 & 43 & -1.51252 & -1.45179 \\
\hline 22 & 93.7 & 157.3 & 63.8 & 50.8 & 1876 & 90 & 2.97 & 3.23 & 9.41 & 68 & 5500 & 37 & 41 & -1.51745 & -1.47569 \\
\hline 23 & 93.7 & 157.3 & 63.8 & 50.8 & 1876 & 90 & 2.97 & 3.23 & 9.40 & 68 & 5500 & 31 & 38 & -1.27717 & -1.30167 \\
\hline 24 & 93.7 & 157.3 & 63.8 & 50.8 & 2128 & 98 & 3.03 & 3.39 & 7.60 & 102 & 5500 & 24 & 30 & -0.77313 & -0.78301 \\
\hline 25 & 93.7 & 157.3 & 63.8 & 50.6 & 1967 & 90 & 2.97 & 3.23 & 9.40 & 68 & 5500 & 31 & 38 & -1.25410 & -1.28105 \\
\hline 26 & 93.7 & 157.3 & 63.8 & 50.6 & 1989 & 90 & 2.97 & 3.23 & 9.40 & 68 & 5500 & 31 & 38 & -1.24807 & -1.27510 \\
\hline 27 & 93.7 & 157.3 & 63.8 & 50.6 & 1989 & 90 & 2.97 & 3.23 & 9.40 & 68 & 5500 & 31 & 38 & -1.24807 & -1.27510 \\
\hline 28 & 93.7 & 157.3 & 63.8 & 50.6 & 2191 & 98 & 3.03 & 3.39 & 7.60 & 102 & 5500 & 24 & 30 & -0.75775 & -0.76997 \\
\hline 29 & 103.3 & 174.6 & 64.6 & 59.8 & 2535 & 122 & 3.34 & 3.46 & 8.50 & 88 & 5000 & 24 & 30 & 0.06945 & 0.12306 \\
\hline 30 & 95.9 & 173.2 & 66.3 & 50.2 & 2811 & 156 & 3.60 & 3.90 & 7.00 & 145 & 5000 & 19 & 24 & 0.52781 & 0.57434 \\
\hline 31 & 86.6 & 144.6 & 63.9 & 50.8 & 1713 & 92 & 2.91 & 3.41 & 9.60 & 58 & 4800 & 49 & 54 & -2.43666 & -2.25186 \\
\hline 32 & 86.6 & 144.6 & 63.9 & 50.8 & 1819 & 92 & 2.91 & 3.41 & 9.20 & 76 & 6000 & 31 & 38 & -1.61318 & -1.60274 \\
\hline 33 & 93.7 & 150.0 & 64.0 & 52.6 & 1837 & 79 & 2.91 & 3.07 & 10.10 & 60 & 5500 & 38 & 42 & -1.71020 & -1.64719 \\
\hline 34 & 93.7 & 150.0 & 64.0 & 52.6 & 1940 & 92 & 2.91 & 3.41 & 9.20 & 76 & 6000 & 30 & 34 & -1.25625 & -1.23694 \\
\hline 35 & 93.7 & 150.0 & 64.0 & 52.6 & 1956 & 92 & 2.91 & 3.41 & 9.20 & 76 & 6000 & 30 & 34 & -1.25187 & -1.23261 \\
\hline 36 & 96.5 & 163.4 & 64.0 & 54.5 & 2010 & 92 & 2.91 & 3.41 & 9.20 & 76 & 6000 & 30 & 34 & -0.98625 & -0.98140 \\
\hline 37 & 96.5 & 157.1 & 63.9 & 58.3 & 2024 & 92 & 2.92 & 3.41 & 9.20 & 76 & 6000 & 30 & 34 & -1.03470 & -0.97168 \\
\hline 38 & 96.5 & 167.5 & 65.2 & 53.3 & 2236 & 110 & 3.15 & 3.58 & 9.00 & 86 & 5800 & 27 & 33 & -0.54091 & -0.54248 \\
\hline
\end{tabular}




\begin{tabular}{|c|c|c|c|c|c|c|c|c|c|c|c|c|c|c|c|}
\hline 39 & 96.5 & 167.5 & 65.2 & 53.3 & 2289 & 110 & 3.15 & 3.58 & 9.00 & 86 & 5800 & 27 & 33 & -0.52638 & -0.52814 \\
\hline 40 & 96.5 & 175.4 & 65.2 & 54.1 & 2304 & 110 & 3.15 & 3.58 & 9.00 & 86 & 5800 & 27 & 33 & -0.40729 & -0.42295 \\
\hline 41 & 96.5 & 175.4 & 62.5 & 54.1 & 2372 & 110 & 3.15 & 3.58 & 9.00 & 86 & 5800 & 27 & 33 & -0.53518 & -0.57050 \\
\hline 42 & 96.5 & 175.4 & 65.2 & 54.1 & 2465 & 110 & 3.15 & 3.58 & 9.00 & 101 & 5800 & 24 & 28 & -0.15942 & -0.17945 \\
\hline 43 & 96.5 & 169.1 & 66.0 & 51.0 & 2293 & 110 & 3.15 & 3.58 & 9.10 & 100 & 5500 & 25 & 31 & -0.34342 & -0.36368 \\
\hline 44 & 94.3 & 170.7 & 61.8 & 53.5 & 2337 & 111 & 3.31 & 3.23 & 8.50 & 78 & 4800 & 24 & 29 & -0.45208 & -0.50345 \\
\hline 47 & 96.0 & 172.6 & 65.2 & 51.4 & 2734 & 119 & 3.43 & 3.23 & 9.20 & 90 & 5000 & 24 & 29 & -0.04120 & -0.08108 \\
\hline 48 & 113.0 & 199.6 & 69.6 & 52.8 & 4066 & 258 & 3.63 & 4.17 & 8.10 & 176 & 4750 & 15 & 19 & 2.37985 & 2.41705 \\
\hline 49 & 113.0 & 199.6 & 69.6 & 52.8 & 4066 & 258 & 3.63 & 4.17 & 8.10 & 176 & 4750 & 15 & 19 & 2.37985 & 2.41705 \\
\hline 50 & 102.0 & 191.7 & 70.6 & 47.8 & 3950 & 326 & 3.54 & 2.76 & 11.50 & 262 & 5000 & 13 & 17 & 2.46032 & 2.45538 \\
\hline 51 & 93.1 & 159.1 & 64.2 & 54.1 & 1890 & 91 & 3.03 & 3.15 & 9.00 & 68 & 5000 & 30 & 31 & -1.01497 & -0.98957 \\
\hline 52 & 93.1 & 159.1 & 64.2 & 54.1 & 1900 & 91 & 3.03 & 3.15 & 9.00 & 68 & 5000 & 31 & 38 & -1.16250 & -1.13902 \\
\hline 53 & 93.1 & 159.1 & 64.2 & 54.1 & 1905 & 91 & 3.03 & 3.15 & 9.00 & 68 & 5000 & 31 & 38 & -1.16113 & -1.13767 \\
\hline 54 & 93.1 & 166.8 & 64.2 & 54.1 & 1945 & 91 & 3.03 & 3.15 & 9.00 & 68 & 5000 & 31 & 38 & -1.04544 & -1.04388 \\
\hline 55 & 93.1 & 166.8 & 64.2 & 54.1 & 1950 & 91 & 3.08 & 3.15 & 9.00 & 68 & 5000 & 31 & 38 & -1.02865 & -1.02304 \\
\hline 60 & 98.8 & 177.8 & 66.5 & 53.7 & 2385 & 122 & 3.39 & 3.39 & 8.60 & 84 & 4800 & 26 & 32 & -0.04151 & -0.03510 \\
\hline 61 & 98.8 & 177.8 & 66.5 & 55.5 & 2410 & 122 & 3.39 & 3.39 & 8.60 & 84 & 4800 & 26 & 32 & -0.01773 & 0.00769 \\
\hline 62 & 98.8 & 177.8 & 66.5 & 53.7 & 2385 & 122 & 3.39 & 3.39 & 8.60 & 84 & 4800 & 26 & 32 & -0.04151 & -0.03510 \\
\hline 63 & 98.8 & 177.8 & 66.5 & 55.5 & 2410 & 122 & 3.39 & 3.39 & 8.60 & 84 & 4800 & 26 & 32 & -0.01773 & 0.00769 \\
\hline 64 & 98.8 & 177.8 & 66.5 & 55.5 & 2443 & 122 & 3.39 & 3.39 & 22.70 & 64 & 4650 & 36 & 42 & -0.31207 & -0.39959 \\
\hline 65 & 98.8 & 177.8 & 66.5 & 55.5 & 2425 & 122 & 3.39 & 3.39 & 8.60 & 84 & 4800 & 26 & 32 & -0.01361 & 0.01175 \\
\hline 66 & 104.9 & 175.0 & 66.1 & 54.4 & 2670 & 140 & 3.76 & 3.16 & 8.00 & 120 & 5000 & 19 & 27 & 0.60126 & 0.63041 \\
\hline 67 & 104.9 & 175.0 & 66.1 & 54.4 & 2700 & 134 & 3.43 & 3.64 & 22.00 & 72 & 4200 & 31 & 39 & 0.09529 & -0.00705 \\
\hline 68 & 110.0 & 190.9 & 70.3 & 56.5 & 3515 & 183 & 3.58 & 3.64 & 21.50 & 123 & 4350 & 22 & 25 & 1.66577 & 1.58017 \\
\hline 69 & 110.0 & 190.9 & 70.3 & 58.7 & 3750 & 183 & 3.58 & 3.64 & 21.50 & 123 & 4350 & 22 & 25 & 1.75087 & 1.68780 \\
\hline 70 & 106.7 & 187.5 & 70.3 & 54.9 & 3495 & 183 & 3.58 & 3.64 & 21.50 & 123 & 4350 & 22 & 25 & 1.53925 & 1.44225 \\
\hline 71 & 115.6 & 202.6 & 71.7 & 56.3 & 3770 & 183 & 3.58 & 3.64 & 21.50 & 123 & 4350 & 22 & 25 & 2.07028 & 1.96564 \\
\hline 72 & 115.6 & 202.6 & 71.7 & 56.5 & 3740 & 234 & 3.46 & 3.10 & 8.30 & 155 & 4750 & 16 & 18 & 2.31539 & 2.33506 \\
\hline 73 & 96.6 & 180.3 & 70.5 & 50.8 & 3685 & 234 & 3.46 & 3.10 & 8.30 & 155 & 4750 & 16 & 18 & 1.53429 & 1.52440 \\
\hline 74 & 120.9 & 208.1 & 71.7 & 56.7 & 3900 & 308 & 3.80 & 3.35 & 8.00 & 184 & 4500 & 14 & 16 & 3.03552 & 3.10651 \\
\hline 75 & 112.0 & 199.2 & 72.0 & 55.4 & 3715 & 304 & 3.80 & 3.35 & 8.00 & 184 & 4500 & 14 & 16 & 2.69391 & 2.76848 \\
\hline 76 & 102.7 & 178.4 & 68.0 & 54.8 & 2910 & 140 & 3.78 & 3.12 & 8.00 & 175 & 5000 & 19 & 24 & 0.92468 & 1.04696 \\
\hline 77 & 93.7 & 157.3 & 64.4 & 50.8 & 1918 & 92 & 2.97 & 3.23 & 9.40 & 68 & 5500 & 37 & 41 & -1.46713 & -1.42132 \\
\hline 78 & 93.7 & 157.3 & 64.4 & 50.8 & 1944 & 92 & 2.97 & 3.23 & 9.40 & 68 & 5500 & 31 & 38 & -1.21958 & -1.24025 \\
\hline 79 & 93.7 & 157.3 & 64.4 & 50.8 & 2004 & 92 & 2.97 & 3.23 & 9.40 & 68 & 5500 & 31 & 38 & -1.20313 & -1.22402 \\
\hline 80 & 93.0 & 157.3 & 63.8 & 50.8 & 2145 & 98 & 3.03 & 3.39 & 7.60 & 102 & 5500 & 24 & 30 & -0.78115 & -0.79196 \\
\hline 81 & 96.3 & 173.0 & 65.4 & 49.4 & 2370 & 110 & 3.17 & 3.46 & 7.50 & 116 & 5500 & 23 & 30 & -0.23589 & -0.26859 \\
\hline 82 & 96.3 & 173.0 & 65.4 & 49.4 & 2328 & 122 & 3.35 & 3.46 & 8.50 & 88 & 5000 & 25 & 32 & -0.25259 & -0.29817 \\
\hline 83 & 95.9 & 173.2 & 66.3 & 50.2 & 2833 & 156 & 3.58 & 3.86 & 7.00 & 145 & 5000 & 19 & 24 & 0.52629 & 0.56973 \\
\hline 84 & 95.9 & 173.2 & 66.3 & 50.2 & 2921 & 156 & 3.59 & 3.86 & 7.00 & 145 & 5000 & 19 & 24 & 0.55349 & 0.59744 \\
\hline 85 & 95.9 & 173.2 & 66.3 & 50.2 & 2926 & 156 & 3.59 & 3.86 & 7.00 & 145 & 5000 & 19 & 24 & 0.55486 & 0.59879 \\
\hline 86 & 96.3 & 172.4 & 65.4 & 51.6 & 2365 & 122 & 3.35 & 3.46 & 8.50 & 88 & 5000 & 25 & 32 & -0.22992 & -0.25059 \\
\hline 87 & 96.3 & 172.4 & 65.4 & 51.6 & 2405 & 122 & 3.35 & 3.46 & 8.50 & 88 & 5000 & 25 & 32 & -0.21896 & -0.23976 \\
\hline 88 & 96.3 & 172.4 & 65.4 & 51.6 & 2403 & 110 & 3.17 & 3.46 & 7.50 & 116 & 5500 & 23 & 30 & -0.21431 & -0.22209 \\
\hline 89 & 96.3 & 172.4 & 65.4 & 51.6 & 2403 & 110 & 3.17 & 3.46 & 7.50 & 116 & 5500 & 23 & 30 & -0.21431 & -0.22209 \\
\hline 90 & 94.5 & 165.3 & 63.8 & 54.5 & 1889 & 97 & 3.15 & 3.29 & 9.40 & 69 & 5200 & 31 & 37 & -0.99982 & -0.98214 \\
\hline 91 & 94.5 & 165.3 & 63.8 & 54.5 & 2017 & 103 & 2.99 & 3.47 & 21.90 & 55 & 4800 & 45 & 50 & -1.46867 & -1.49507 \\
\hline 92 & 94.5 & 165.3 & 63.8 & 54.5 & 1918 & 97 & 3.15 & 3.29 & 9.40 & 69 & 5200 & 31 & 37 & -0.99187 & -0.97430 \\
\hline 93 & 94.5 & 165.3 & 63.8 & 54.5 & 1938 & 97 & 3.15 & 3.29 & 9.40 & 69 & 5200 & 31 & 37 & -0.98639 & -0.96888 \\
\hline 94 & 94.5 & 170.2 & 63.8 & 53.5 & 2024 & 97 & 3.15 & 3.29 & 9.40 & 69 & 5200 & 31 & 37 & -0.90557 & -0.91283 \\
\hline 95 & 94.5 & 165.3 & 63.8 & 54.5 & 1951 & 97 & 3.15 & 3.29 & 9.40 & 69 & 5200 & 31 & 37 & -0.98282 & -0.96537 \\
\hline 96 & 94.5 & 165.6 & 63.8 & 53.3 & 2028 & 97 & 3.15 & 3.29 & 9.40 & 69 & 5200 & 31 & 37 & -0.96892 & -0.96532 \\
\hline 97 & 94.5 & 165.3 & 63.8 & 54.5 & 1971 & 97 & 3.15 & 3.29 & 9.40 & 69 & 5200 & 31 & 37 & -0.97734 & -0.95995 \\
\hline 98 & 94.5 & 170.2 & 63.8 & 53.5 & 2037 & 97 & 3.15 & 3.29 & 9.40 & 69 & 5200 & 31 & 37 & -0.90201 & -0.90932 \\
\hline 99 & 95.1 & 162.4 & 63.8 & 53.3 & 2008 & 97 & 3.15 & 3.29 & 9.40 & 69 & 5200 & 31 & 37 & -1.00706 & -0.99360 \\
\hline 100 & 97.2 & 173.4 & 65.2 & 54.7 & 2324 & 120 & 3.33 & 3.47 & 8.50 & 97 & 5200 & 27 & 34 & -0.29921 & -0.26091 \\
\hline 101 & 97.2 & 173.4 & 65.2 & 54.7 & 2302 & 120 & 3.33 & 3.47 & 8.50 & 97 & 5200 & 27 & 34 & -0.30524 & -0.26687 \\
\hline 102 & 100.4 & 181.7 & 66.5 & 55.1 & 3095 & 181 & 3.43 & 3.27 & 9.00 & 152 & 5200 & 17 & 22 & 0.99136 & 0.99365 \\
\hline 103 & 100.4 & 184.6 & 66.5 & 56.1 & 3296 & 181 & 3.43 & 3.27 & 9.00 & 152 & 5200 & 17 & 22 & 1.09530 & 1.09930 \\
\hline 104 & 100.4 & 184.6 & 66.5 & 55.1 & 3060 & 181 & 3.43 & 3.27 & 9.00 & 152 & 5200 & 19 & 25 & 0.90716 & 0.91952 \\
\hline 105 & 91.3 & 170.7 & 67.9 & 49.7 & 3071 & 181 & 3.43 & 3.27 & 9.00 & 160 & 5200 & 19 & 25 & 0.59446 & 0.59946 \\
\hline 106 & 91.3 & 170.7 & 67.9 & 49.7 & 3139 & 181 & 3.43 & 3.27 & 7.80 & 200 & 5200 & 17 & 23 & 0.75720 & 0.81744 \\
\hline 107 & 99.2 & 178.5 & 67.9 & 49.7 & 3139 & 181 & 3.43 & 3.27 & 9.00 & 160 & 5200 & 19 & 25 & 0.86222 & 0.85477 \\
\hline
\end{tabular}




\begin{tabular}{|c|c|c|c|c|c|c|c|c|c|c|c|c|c|c|c|}
\hline 108 & 107.9 & 186.7 & 68.4 & 56.7 & 3020 & 120 & 3.46 & 3.19 & 8.40 & 97 & 5000 & 19 & 24 & 0.92134 & 0.90631 \\
\hline 109 & 107.9 & 186.7 & 68.4 & 56.7 & 3197 & 152 & 3.70 & 3.52 & 21.00 & 95 & 4150 & 28 & 33 & 0.94989 & 0.89724 \\
\hline 110 & 114.2 & 198.9 & 68.4 & 58.7 & 3230 & 120 & 3.46 & 3.19 & 8.40 & 97 & 5000 & 19 & 24 & 1.27771 & 1.25652 \\
\hline 111 & 114.2 & 198.9 & 68.4 & 58.7 & 3430 & 152 & 3.70 & 3.52 & 21.00 & 95 & 4150 & 25 & 25 & 1.54298 & 1.46385 \\
\hline 112 & 107.9 & 186.7 & 68.4 & 56.7 & 3075 & 120 & 3.46 & 2.19 & 8.40 & 95 & 5000 & 19 & 24 & 0.89855 & 0.84578 \\
\hline 113 & 107.9 & 186.7 & 68.4 & 56.7 & 3252 & 152 & 3.70 & 3.52 & 21.00 & 95 & 4150 & 28 & 33 & 0.96497 & 0.91213 \\
\hline 114 & 114.2 & 198.9 & 68.4 & 56.7 & 3285 & 120 & 3.46 & 2.19 & 8.40 & 95 & 5000 & 19 & 24 & 1.23610 & 1.15596 \\
\hline 115 & 114.2 & 198.9 & 68.4 & 58.7 & 3485 & 152 & 3.70 & 3.52 & 21.00 & 95 & 4150 & 25 & 25 & 1.55805 & 1.47873 \\
\hline 116 & 107.9 & 186.7 & 68.4 & 56.7 & 3075 & 120 & 3.46 & 3.19 & 8.40 & 97 & 5000 & 19 & 24 & 0.93642 & 0.92119 \\
\hline 117 & 107.9 & 186.7 & 68.4 & 56.7 & 3252 & 152 & 3.70 & 3.52 & 21.00 & 95 & 4150 & 28 & 33 & 0.96497 & 0.91213 \\
\hline 118 & 108.0 & 186.7 & 68.3 & 56.0 & 3130 & 134 & 3.61 & 3.21 & 7.00 & 142 & 5600 & 18 & 24 & 1.08234 & 1.13327 \\
\hline 119 & 93.7 & 157.3 & 63.8 & 50.8 & 1918 & 90 & 2.97 & 3.23 & 9.40 & 68 & 5500 & 37 & 41 & -1.50608 & -1.46434 \\
\hline 120 & 93.7 & 157.3 & 63.8 & 50.8 & 2128 & 98 & 3.03 & 3.39 & 7.60 & 102 & 5500 & 24 & 30 & -0.77313 & -0.78301 \\
\hline 121 & 93.7 & 157.3 & 63.8 & 50.6 & 1967 & 90 & 2.97 & 3.23 & 9.40 & 68 & 5500 & 31 & 38 & -1.25410 & -1.28105 \\
\hline 122 & 93.7 & 167.3 & 63.8 & 50.8 & 1989 & 90 & 2.97 & 3.23 & 9.40 & 68 & 5500 & 31 & 38 & -1.11018 & -1.16335 \\
\hline 123 & 93.7 & 167.3 & 63.8 & 50.8 & 2191 & 98 & 2.97 & 3.23 & 9.40 & 68 & 5500 & 31 & 38 & -1.02927 & -1.08413 \\
\hline 124 & 103.3 & 174.6 & 64.6 & 59.8 & 2535 & 122 & 3.35 & 3.46 & 8.50 & 88 & 5000 & 24 & 30 & 0.07254 & 0.12696 \\
\hline 125 & 95.9 & 173.2 & 66.3 & 50.2 & 2818 & 156 & 3.59 & 3.86 & 7.00 & 145 & 5000 & 19 & 24 & 0.52526 & 0.56957 \\
\hline 126 & 94.5 & 168.9 & 68.3 & 50.2 & 2778 & 151 & 3.94 & 3.11 & 9.50 & 143 & 5500 & 19 & 27 & 0.55876 & 0.58047 \\
\hline 127 & 89.5 & 168.9 & 65.0 & 51.6 & 2756 & 194 & 3.74 & 2.90 & 9.50 & 207 & 5900 & 17 & 25 & 0.54204 & 0.58841 \\
\hline 128 & 89.5 & 168.9 & 65.0 & 51.6 & 2756 & 194 & 3.74 & 2.90 & 9.50 & 207 & 5900 & 17 & 25 & 0.54204 & 0.58841 \\
\hline 129 & 89.5 & 168.9 & 65.0 & 51.6 & 2800 & 194 & 3.74 & 2.90 & 9.50 & 207 & 5900 & 17 & 25 & 0.55410 & 0.60032 \\
\hline 133 & 99.1 & 186.6 & 66.5 & 56.1 & 2658 & 121 & 3.54 & 3.07 & 9.31 & 110 & 5250 & 21 & 28 & 0.46531 & 0.44228 \\
\hline 134 & 99.1 & 186.6 & 66.5 & 56.1 & 2695 & 121 & 3.54 & 3.07 & 9.30 & 110 & 5250 & 21 & 28 & 0.47531 & 0.45228 \\
\hline 135 & 99.1 & 186.6 & 66.5 & 56.1 & 2707 & 121 & 2.54 & 2.07 & 9.30 & 110 & 5250 & 21 & 28 & 0.13552 & -0.00345 \\
\hline 136 & 99.1 & 186.6 & 66.5 & 56.1 & 2758 & 121 & 3.54 & 3.07 & 9.30 & 110 & 5250 & 21 & 28 & 0.49258 & 0.46932 \\
\hline 137 & 99.1 & 186.6 & 66.5 & 56.1 & 2808 & 121 & 3.54 & 3.07 & 9.00 & 160 & 5500 & 19 & 26 & 0.66533 & 0.69607 \\
\hline 138 & 99.1 & 186.6 & 66.5 & 56.1 & 2847 & 121 & 3.54 & 3.07 & 9.00 & 160 & 5500 & 19 & 26 & 0.67602 & 0.70662 \\
\hline 139 & 93.7 & 156.9 & 63.4 & 53.7 & 2050 & 97 & 3.62 & 2.36 & 9.00 & 69 & 4900 & 31 & 36 & -0.97261 & -0.92551 \\
\hline 140 & 93.7 & 157.9 & 63.6 & 53.7 & 2120 & 108 & 3.62 & 2.64 & 8.70 & 73 & 4400 & 26 & 31 & -0.61069 & -0.58859 \\
\hline 141 & 93.3 & 157.3 & 63.8 & 55.7 & 2240 & 108 & 3.62 & 2.64 & 8.70 & 73 & 4400 & 26 & 31 & -0.56354 & -0.51800 \\
\hline 142 & 97.2 & 172.0 & 65.4 & 52.5 & 2145 & 108 & 3.62 & 2.64 & 9.50 & 82 & 4800 & 32 & 37 & -0.55031 & -0.50726 \\
\hline 143 & 97.2 & 172.0 & 65.4 & 52.5 & 2190 & 108 & 3.62 & 2.64 & 9.50 & 82 & 4400 & 28 & 33 & -0.32087 & -0.31128 \\
\hline 144 & 97.2 & 172.0 & 65.4 & 52.5 & 2340 & 108 & 3.62 & 2.64 & 9.00 & 94 & 5200 & 26 & 32 & -0.23337 & -0.23586 \\
\hline 145 & 97.0 & 172.0 & 65.4 & 54.3 & 2385 & 108 & 3.62 & 2.64 & 9.00 & 82 & 4800 & 24 & 25 & -0.02231 & -0.02723 \\
\hline 146 & 97.0 & 172.0 & 65.4 & 54.3 & 2510 & 108 & 3.62 & 2.64 & 7.70 & 111 & 4800 & 24 & 29 & -0.02806 & 0.01912 \\
\hline 147 & 97.0 & 173.5 & 65.4 & 53.0 & 2290 & 108 & 3.62 & 2.64 & 9.00 & 82 & 4800 & 28 & 32 & -0.28523 & -0.27355 \\
\hline 148 & 97.0 & 173.5 & 65.4 & 53.0 & 2455 & 108 & 3.62 & 2.64 & 9.00 & 94 & 5200 & 25 & 31 & -0.13182 & -0.14396 \\
\hline 149 & 96.9 & 173.6 & 65.4 & 54.9 & 2420 & 108 & 3.62 & 2.64 & 9.00 & 82 & 4800 & 23 & 29 & -0.02334 & -0.04670 \\
\hline 150 & 96.9 & 173.6 & 65.4 & 54.9 & 2650 & 108 & 3.62 & 2.64 & 7.70 & 111 & 4800 & 23 & 23 & 0.16923 & 0.21753 \\
\hline 151 & 95.7 & 158.7 & 63.6 & 54.5 & 1985 & 92 & 3.05 & 3.03 & 9.00 & 62 & 4800 & 35 & 39 & -1.26272 & -1.19711 \\
\hline 152 & 95.7 & 158.7 & 63.6 & 54.5 & 2040 & 92 & 3.05 & 3.03 & 9.00 & 62 & 4800 & 31 & 38 & -1.10431 & -1.08515 \\
\hline 153 & 95.7 & 158.7 & 63.6 & 54.5 & 2015 & 92 & 3.05 & 3.03 & 9.00 & 62 & 4800 & 31 & 38 & -1.11117 & -1.09191 \\
\hline 154 & 95.7 & 169.7 & 63.6 & 59.1 & 2280 & 92 & 3.05 & 3.03 & 9.00 & 62 & 4800 & 31 & 37 & -0.82870 & -0.79066 \\
\hline 155 & 95.7 & 169.7 & 63.6 & 59.1 & 2290 & 92 & 3.05 & 3.03 & 9.00 & 62 & 4800 & 27 & 32 & -0.61481 & -0.61509 \\
\hline 156 & 95.7 & 169.7 & 63.6 & 59.1 & 3110 & 92 & 3.05 & 3.03 & 9.00 & 62 & 4800 & 27 & 32 & -0.39004 & -0.39321 \\
\hline 157 & 95.7 & 166.3 & 64.4 & 53.0 & 2081 & 98 & 3.19 & 3.03 & 9.00 & 70 & 4800 & 30 & 37 & -0.83661 & -0.83670 \\
\hline 158 & 95.7 & 166.3 & 64.4 & 52.8 & 2109 & 98 & 3.19 & 3.03 & 9.00 & 70 & 4800 & 30 & 37 & -0.83081 & -0.83313 \\
\hline 159 & 95.7 & 166.3 & 64.4 & 53.0 & 2275 & 110 & 3.27 & 3.35 & 22.50 & 56 & 4500 & 34 & 36 & -0.62717 & -0.75563 \\
\hline 160 & 95.7 & 166.3 & 64.4 & 52.8 & 2275 & 110 & 3.27 & 3.35 & 22.50 & 56 & 4500 & 38 & 47 & -0.94192 & -1.04617 \\
\hline 161 & 95.7 & 166.3 & 64.4 & 53.0 & 2094 & 98 & 3.19 & 3.03 & 9.00 & 70 & 4800 & 38 & 47 & -1.25534 & -1.17890 \\
\hline 162 & 95.7 & 166.3 & 64.4 & 52.8 & 2122 & 98 & 3.19 & 3.03 & 9.00 & 70 & 4800 & 28 & 34 & -0.71320 & -0.73370 \\
\hline 163 & 95.7 & 166.3 & 64.4 & 52.8 & 2140 & 98 & 3.19 & 3.03 & 9.00 & 70 & 4800 & 28 & 34 & -0.70827 & -0.72883 \\
\hline 164 & 94.5 & 168.7 & 64.0 & 52.6 & 2169 & 98 & 3.19 & 3.03 & 9.00 & 70 & 4800 & 29 & 34 & -0.74458 & -0.76647 \\
\hline 165 & 94.5 & 168.7 & 64.0 & 52.6 & 2204 & 98 & 3.19 & 3.03 & 9.00 & 70 & 4800 & 29 & 34 & -0.73499 & -0.75700 \\
\hline 166 & 94.5 & 168.7 & 64.0 & 52.6 & 2265 & 98 & 3.24 & 3.08 & 9.40 & 112 & 6600 & 26 & 29 & -0.55107 & -0.56765 \\
\hline 167 & 94.5 & 168.7 & 64.0 & 52.6 & 2300 & 98 & 3.24 & 3.08 & 9.40 & 112 & 6600 & 26 & 29 & -0.54147 & -0.55818 \\
\hline 168 & 98.4 & 176.2 & 65.6 & 52.0 & 2540 & 146 & 3.62 & 3.50 & 9.30 & 116 & 4800 & 24 & 30 & 0.21746 & 0.24081 \\
\hline 169 & 98.4 & 176.2 & 65.6 & 52.0 & 2536 & 146 & 3.62 & 3.50 & 9.30 & 116 & 4800 & 24 & 30 & 0.21636 & 0.23973 \\
\hline 170 & 98.4 & 176.2 & 65.6 & 52.0 & 2551 & 146 & 3.62 & 3.50 & 9.30 & 116 & 4800 & 24 & 30 & 0.22047 & 0.24378 \\
\hline 171 & 98.4 & 176.2 & 65.6 & 52.0 & 2679 & 146 & 3.62 & 3.50 & 9.30 & 116 & 4800 & 24 & 30 & 0.25556 & 0.27842 \\
\hline 172 & 98.4 & 176.2 & 65.6 & 52.0 & 2714 & 146 & 3.62 & 3.50 & 9.30 & 116 & 4800 & 24 & 30 & 0.26515 & 0.28789 \\
\hline 173 & $\begin{array}{ll}98.4 \\
\end{array}$ & 176.2 & 65.6 & 53.0 & 2975 & 146 & 3.62 & 3.50 & 9.30 & 116 & 4800 & 24 & 30 & 0.34610 & 0.37853 \\
\hline
\end{tabular}




\begin{tabular}{|c|c|c|c|c|c|c|c|c|c|c|c|c|c|c|c|}
\hline 174 & 102.4 & 175.6 & 66.5 & 54.9 & 2326 & 122 & 3.31 & 3.54 & 8.70 & 92 & 4200 & 29 & 34 & -0.11058 & -0.02856 \\
\hline 175 & 102.4 & 175.6 & 66.5 & 54.9 & 2480 & 110 & 3.27 & 3.35 & 22.50 & 73 & 4500 & 30 & 33 & 0.01331 & -0.11541 \\
\hline 176 & 102.4 & 175.6 & 66.5 & 53.9 & 2414 & 122 & 3.31 & 3.54 & 8.70 & 92 & 4200 & 27 & 32 & 0.00123 & 0.05219 \\
\hline 177 & 102.4 & 175.6 & 66.5 & 54.9 & 2414 & 122 & 3.31 & 3.54 & 8.70 & 92 & 4200 & 27 & 32 & 0.01063 & 0.07221 \\
\hline 178 & 102.4 & 175.6 & 66.5 & 53.9 & 2458 & 122 & 3.31 & 3.54 & 8.70 & 92 & 4200 & 27 & 32 & 0.01329 & 0.06410 \\
\hline 179 & 102.9 & 183.5 & 67.7 & 52.0 & 2976 & 171 & 3.27 & 3.35 & 9.30 & 161 & 5200 & 20 & 24 & 0.87615 & 0.88528 \\
\hline 180 & 102.9 & 183.5 & 67.7 & 52.0 & 3016 & 171 & 3.27 & 3.35 & 9.30 & 161 & 5200 & 19 & 24 & 0.91870 & 0.91564 \\
\hline 181 & 104.5 & 187.8 & 66.5 & 54.1 & 3131 & 171 & 3.27 & 3.35 & 9.20 & 156 & 5200 & 20 & 24 & 0.95119 & 0.95712 \\
\hline 182 & 104.5 & 187.8 & 66.5 & 54.1 & 3151 & 161 & 3.27 & 3.35 & 9.20 & 156 & 5200 & 19 & 24 & 0.95633 & 0.95136 \\
\hline 183 & 97.3 & 171.7 & 65.5 & 55.7 & 2261 & 97 & 3.01 & 3.40 & 23.00 & 52 & 4800 & 37 & 46 & -0.84414 & -0.96862 \\
\hline 184 & 97.3 & 171.7 & 65.5 & 55.7 & 2209 & 109 & 3.19 & 3.40 & 9.00 & 85 & 5250 & 27 & 34 & -0.42201 & -0.40347 \\
\hline 185 & 97.3 & 171.7 & 65.5 & 55.7 & 2264 & 97 & 3.01 & 3.40 & 23.00 & 52 & 4800 & 37 & 46 & -0.84331 & -0.96781 \\
\hline 186 & 97.3 & 171.7 & 65.5 & 55.7 & 2212 & 109 & 3.19 & 3.40 & 9.00 & 85 & 5250 & 27 & 34 & -0.42119 & -0.40266 \\
\hline 187 & 97.3 & 171.7 & 65.5 & 55.7 & 2275 & 109 & 3.19 & 3.40 & 9.00 & 85 & 5250 & 27 & 34 & -0.40392 & -0.38561 \\
\hline 188 & 97.3 & 171.7 & 65.5 & 55.7 & 2319 & 97 & 3.01 & 3.40 & 23.00 & 68 & 4500 & 37 & 42 & -0.71743 & -0.80501 \\
\hline 189 & 97.3 & 171.7 & 65.5 & 55.7 & 2300 & 109 & 3.19 & 3.40 & 10.00 & 100 & 5500 & 26 & 32 & -0.30709 & -0.29211 \\
\hline 190 & 94.5 & 159.3 & 64.2 & 55.6 & 2254 & 109 & 3.19 & 3.40 & 8.50 & 90 & 5500 & 24 & 29 & -0.53451 & -0.51149 \\
\hline 191 & 94.5 & 165.7 & 64.0 & 51.4 & 2221 & 109 & 3.19 & 3.40 & 8.50 & 90 & 5500 & 24 & 29 & -0.50686 & -0.54783 \\
\hline 192 & 100.4 & 180.2 & 66.9 & 55.1 & 2661 & 136 & 3.19 & 3.40 & 8.50 & 110 & 5500 & 19 & 24 & 0.47118 & 0.43137 \\
\hline 193 & 100.4 & 180.2 & 66.9 & 55.1 & 2579 & 97 & 3.01 & 3.40 & 23.00 & 68 & 4500 & 33 & 38 & -0.20990 & -0.35514 \\
\hline 194 & 100.4 & 183.1 & 66.9 & 55.1 & 2563 & 109 & 3.19 & 3.40 & 9.00 & 88 & 5500 & 25 & 31 & 0.06111 & 0.03572 \\
\hline 195 & 104.3 & 188.8 & 67.2 & 56.2 & 2912 & 141 & 3.78 & 3.15 & 9.50 & 114 & 5400 & 23 & 28 & 0.77604 & 0.80326 \\
\hline 196 & 104.3 & 188.8 & 67.2 & 57.5 & 3034 & 141 & 3.78 & 3.15 & 9.50 & 114 & 5400 & 23 & 28 & 0.82171 & 0.86229 \\
\hline 197 & 104.3 & 188.8 & 67.2 & 56.2 & 2935 & 141 & 3.78 & 3.15 & 9.50 & 114 & 5400 & 24 & 28 & 0.75075 & 0.78995 \\
\hline 198 & 104.3 & 188.8 & 67.2 & 57.5 & 3042 & 141 & 3.78 & 3.15 & 9.50 & 114 & 5400 & 24 & 28 & 0.79230 & 0.84493 \\
\hline 199 & 104.3 & 188.8 & 67.2 & 56.2 & 3045 & 130 & 3.62 & 3.15 & 7.50 & 162 & 5100 & 17 & 22 & 1.08472 & 1.14278 \\
\hline 200 & 104.3 & 188.8 & 67.2 & 57.5 & 3157 & 130 & 3.62 & 3.15 & 7.50 & 162 & 5100 & 17 & 22 & 1.12765 & 1.19911 \\
\hline 201 & 109.1 & 188.8 & 68.9 & 55.5 & 2952 & 141 & 3.78 & 3.15 & 9.50 & 114 & 5400 & 23 & 28 & 0.95958 & 0.99744 \\
\hline 202 & 109.1 & 188.8 & 68.8 & 55.5 & 3049 & 141 & 3.78 & 3.15 & 8.70 & 160 & 5300 & 19 & 25 & 1.22622 & 1.30180 \\
\hline 203 & 109.1 & 188.8 & 68.9 & 55.5 & 3012 & 173 & 3.58 & 2.87 & 8.80 & 134 & 5500 & 18 & 23 & 1.26588 & 1.26068 \\
\hline 204 & 109.1 & 188.8 & 68.9 & 55.5 & 3217 & 145 & 3.01 & 3.40 & 23.00 & 106 & 4800 & 26 & 27 & 0.95680 & 0.79760 \\
\hline 205 & 109.1 & 188.8 & 68.9 & 55.5 & 3062 & 141 & 3.78 & 3.15 & 9.50 & 114 & 5400 & 19 & 25 & 1.16697 & 1.16217 \\
\hline
\end{tabular}

\begin{tabular}{|c|c|c|c|c|c|c|c|c|c|c|c|}
\hline \multicolumn{12}{|c|}{ Table.A3. Sinusoidal Dataset } \\
\hline $\mathrm{SI}$ & $\mathrm{X}_{1}$ & $X_{2}$ & $X_{3}$ & $\mathrm{X}_{4}$ & $X_{5}$ & $\mathrm{X}_{6}$ & $\mathrm{X}_{7}$ & $\mathrm{X}_{8}$ & $X_{9}$ & Score(Brown) & Score(Pearson) \\
\hline 1 & 2.0837 & 4.2353 & 4.3292 & 4.0904 & 4.1422 & 3.9829 & 4.7411 & 4.5986 & 3.9351 & -0.337441 & -0.311286 \\
\hline 2 & 1.8541 & 4.1915 & 3.2582 & 4.1899 & 4.3320 & 3.8189 & 4.3377 & 4.4643 & 3.8473 & -0.538507 & -0.218996 \\
\hline 3 & 1.9994 & 3.6198 & 4.3375 & 4.1483 & 3.7891 & 4.6002 & 3.3976 & 3.7702 & 4.6008 & 0.061252 & -0.334053 \\
\hline 4 & 1.3837 & 3.3781 & 4.3133 & 4.7420 & 3.7048 & 4.4836 & 3.4238 & 3.4706 & 3.8691 & 0.364762 & 0.407034 \\
\hline 5 & 1.9511 & 4.5662 & 4.0955 & 4.3636 & 4.3368 & 4.1238 & 3.5894 & 4.8252 & 4.0103 & 0.609176 & 0.510047 \\
\hline 6 & 2.5612 & 4.5431 & 4.6683 & 4.5552 & 3.4883 & 3.7691 & 3.9627 & 4.1986 & 3.8160 & 1.352704 & 1.618107 \\
\hline 7 & 2.1086 & 4.6512 & 4.1957 & 4.7175 & 3.7525 & 4.0692 & 4.0314 & 3.5325 & 3.7539 & 1.453773 & 1.677951 \\
\hline 8 & 1.7348 & 4.0675 & 3.5432 & 4.3068 & 4.1192 & 3.8883 & 3.3629 & 3.9518 & 4.2416 & -0.033888 & 0.080931 \\
\hline 9 & 1.5065 & 3.7316 & 3.9810 & 4.3329 & 3.2210 & 3.7644 & 4.1856 & 3.5475 & 4.0060 & -0.610669 & -0.214704 \\
\hline 10 & 1.2573 & 3.3584 & 3.7540 & 3.7481 & 3.1882 & 4.1226 & 4.3259 & 4.5405 & 4.2041 & -1.990575 & -1.923801 \\
\hline 11 & 1.7246 & 4.1046 & 3.6241 & 4.6056 & 3.6256 & 3.7500 & 4.1309 & 4.1175 & 4.0622 & -0.407947 & 0.130207 \\
\hline 12 & 2.6322 & 4.7450 & 3.7855 & 4.1694 & 3.4801 & 4.3316 & 3.8871 & 3.6584 & 4.1042 & 1.441995 & 1.381882 \\
\hline 13 & 2.0621 & 4.3156 & 4.3592 & 3.8445 & 4.0382 & 4.5804 & 3.4367 & 3.8129 & 4.0146 & 1.184961 & 0.563772 \\
\hline 14 & 1.8791 & 4.2367 & 3.2403 & 4.6382 & 3.6257 & 4.0495 & 4.0247 & 4.8212 & 3.6610 & 0.050395 & 0.609045 \\
\hline 15 & 1.5112 & 3.4910 & 3.8038 & 3.9307 & 4.1306 & 3.9202 & 4.2733 & 4.8377 & 4.4899 & -2.072868 & -2.019629 \\
\hline 16 & 1.6518 & 3.5881 & 4.3199 & 4.6517 & 4.4673 & 4.6639 & 4.7464 & 3.5748 & 4.0936 & -0.406312 & -0.457361 \\
\hline 17 & 1.7610 & 3.9197 & 3.4747 & 3.9237 & 3.8715 & 4.0219 & 3.4690 & 3.8142 & 4.1663 & -0.173838 & -0.220847 \\
\hline 18 & 2.0136 & 4.4562 & 4.4243 & 4.4978 & 4.0509 & 4.7200 & 3.7309 & 3.7082 & 3.9769 & 1.469388 & 1.128241 \\
\hline 19 & 2.2197 & 4.5856 & 4.4887 & 4.2467 & 4.3618 & 4.3798 & 3.6868 & 4.1732 & 4.1462 & 1.154814 & 0.762270 \\
\hline 20 & 2.5207 & 3.6700 & 3.4058 & 4.8536 & 3.9622 & 3.9076 & 4.0618 & 3.7211 & 4.0655 & 0.168860 & 0.844616 \\
\hline 21 & 1.3715 & 3.6554 & 3.8140 & 4.1879 & 4.1889 & 3.9913 & 4.2248 & 3.8971 & 4.3366 & -1.289759 & -1.213762 \\
\hline 22 & 1.9048 & 3.6063 & 4.0161 & 4.6047 & 4.2792 & 4.2978 & 3.8869 & 3.3820 & 3.9040 & 0.405438 & 0.502145 \\
\hline 23 & 1.5089 & 4.1864 & 4.2004 & 4.0401 & 4.2139 & 4.4783 & 3.7998 & 4.6189 & 4.7220 & -0.774427 & -1.235220 \\
\hline 24 & 2.4648 & 3.9409 & 3.7769 & 3.9755 & 3.9379 & 4.2695 & 4.0705 & 4.8825 & 4.1152 & -0.199345 & -0.232100 \\
\hline
\end{tabular}




\begin{tabular}{|c|c|c|c|c|c|c|c|c|c|c|c|}
\hline 25 & 2.6104 & 4.0564 & 4.4911 & 4.0244 & 4.6120 & 4.5664 & 4.0326 & 3.7293 & 4.4612 & 0.640811 & 0.102681 \\
\hline 26 & 2.2400 & 3.9058 & 3.4525 & 4.2232 & 3.6707 & 4.2454 & 3.9085 & 3.2905 & 3.7562 & 0.750211 & 0.915919 \\
\hline 27 & 2.3430 & 4.3348 & 3.9327 & 4.1118 & 3.9066 & 4.6888 & 3.6346 & 3.5922 & 3.8081 & 1.596170 & 1.251684 \\
\hline 28 & 1.8607 & 3.1990 & 4.1295 & 3.8114 & 4.0561 & 3.9393 & 4.1108 & 4.7483 & 4.6985 & -2.028398 & -2.099501 \\
\hline 29 & 2.1214 & 3.2734 & 3.9152 & 3.9105 & 3.8588 & 4.3526 & 3.6619 & 4.3791 & 3.8977 & -0.248547 & -0.370087 \\
\hline 30 & 2.2698 & 3.8770 & 3.3021 & 4.2093 & 3.7168 & 4.6214 & 4.2444 & 3.2473 & 4.2505 & 0.151837 & 0.173487 \\
\hline 31 & 2.1173 & 4.0114 & 4.0465 & 4.1677 & 3.2163 & 3.9461 & 4.2888 & 3.6079 & 4.3656 & -0.286422 & -0.088996 \\
\hline 32 & 2.0616 & 3.8351 & 4.0729 & 4.6203 & 3.2402 & 4.0584 & 3.3906 & 4.1492 & 4.4709 & 0.049310 & 0.317923 \\
\hline 33 & 1.6516 & 3.7818 & 4.0430 & 4.6904 & 4.1050 & 3.7441 & 3.6889 & 3.9700 & 3.7097 & 0.183634 & 0.578401 \\
\hline 34 & 1.3956 & 4.0700 & 3.7404 & 3.9725 & 3.7471 & 4.1872 & 4.4494 & 4.0215 & 4.7488 & -1.553858 & -1.639446 \\
\hline 35 & 1.7059 & 3.3272 & 4.5193 & 4.0814 & 3.7378 & 4.0890 & 4.1434 & 3.8772 & 3.9771 & -0.615917 & -0.648026 \\
\hline 36 & 1.4636 & 4.1047 & 3.2159 & 4.5279 & 3.7705 & 4.0785 & 3.9561 & 3.8587 & 4.1870 & -0.49 & -0.141531 \\
\hline 37 & 2.1891 & 4.3371 & 3.8465 & 4.3971 & 4.2060 & 3.9199 & 3.3812 & 4.5791 & 3.6793 & 687 & 814 \\
\hline 38 & 2.4384 & 4.8442 & 3.8776 & 4.3019 & 3.9639 & 3.9791 & 3.3013 & 4.0922 & 3.9668 & 1.651053 & 1.630686 \\
\hline 39 & 2.4249 & 3.6340 & 3.8810 & 4.3401 & 3.9354 & 3.8813 & 3.8557 & 3.4267 & 4.0039 & 0.377956 & 0.643057 \\
\hline 40 & 1.3428 & 3.8686 & 4.4143 & 4.0009 & 4.7477 & 4.4126 & 4.8444 & 4.0901 & 4.7466 & -1.712407 & -2.145952 \\
\hline 41 & 1.4547 & 3.1468 & 4.0471 & 4.5406 & 4.8227 & 4.5071 & 3.9225 & 4.6013 & 3.9690 & -0.895527 & -0.948567 \\
\hline 42 & 1.6920 & 3.7372 & 3.6634 & 3.8872 & 4.3905 & 3.8158 & 3.8826 & 4.7977 & 4.0939 & -1.109418 & -1.085991 \\
\hline 43 & 1.7749 & 3.9428 & 3.9479 & 4.3180 & 4.4757 & 4.3852 & 3.5086 & 3.4772 & 4.3180 & 0.330109 & 0.070397 \\
\hline 44 & 2.4863 & 4.7421 & 4.6521 & 4.0632 & 4.6023 & 4.0975 & 4.2879 & 3.1249 & 3.6476 & 1.898624 & 1.5 \\
\hline 45 & 2.5014 & 4.1742 & 3.5020 & 4.3939 & 4.0202 & 4.1966 & 4.1206 & 4.1394 & 4.3147 & 0.13 & 0.339895 \\
\hline 46 & 1.5804 & 4.2400 & 4.0922 & 4.0834 & 4.5901 & 4.4423 & 3.5738 & 4.8312 & 3.9163 & 0.20 & -0.209040 \\
\hline 47 & 1.5751 & 3.7389 & 4.7221 & 4.1356 & 3.9224 & 4.1362 & 3.9769 & 4.2264 & 4.3136 & -0.620030 & -0.836694 \\
\hline 48 & 2.2233 & 4.1546 & 4.4104 & 3.8274 & 3.7488 & 4.5009 & 3.8050 & 3.9350 & 4.1471 & 0.673622 & 0.200528 \\
\hline 49 & 1.9518 & 3.6631 & 3.2961 & 4.1534 & 3.6438 & 3.9252 & 4.6823 & 3.6540 & 4.4967 & -1.447854 & -1.050840 \\
\hline 50 & 1.8075 & 4.4237 & 4.4625 & 4.5947 & 3.3065 & 4.3341 & 3.9091 & 4.3481 & 4.1868 & 0.470457 & 0.506216 \\
\hline
\end{tabular}

\begin{tabular}{|c|c|c|c|c|c|c|c|c|c|}
\hline \multicolumn{10}{|c|}{ Table.A4. Crime Incidents in India - 2011 Dataset } \\
\hline State/UT & $\begin{array}{l}\text { Murder } \\
\text { (Sec. } \\
302 \\
\text { IPC) }\end{array}$ & $\begin{array}{l}\text { Attempt } \\
\text { to } \\
\text { Commit } \\
\text { Murder } \\
\text { (Sec. } 307 \\
\text { IPC) }\end{array}$ & $\begin{array}{l}\text { C.H. Not } \\
\text { Amount- } \\
\text { ing } \\
\text { to Murder } \\
\text { (Sec. } 304 \text {, } \\
308 \text { IPC) }\end{array}$ & $\begin{array}{l}\text { Rape } \\
\text { (Sec. } \\
376 \\
\text { IPC) }\end{array}$ & $\begin{array}{l}\text { Kidnapping } \\
\& \\
\text { Abduction } \\
\text { (Sec. 363- } \\
\text { 310, 371- } \\
\text { 373 IPC) }\end{array}$ & $\begin{array}{l}\text { Dacoity } \\
\text { (Sec.395- } \\
398 \\
\text { IPC) }\end{array}$ & $\begin{array}{l}\text { Preparation } \\
\& \\
\text { Assembly } \\
\text { For Dacoity } \\
\text { (Sec.399- } \\
402 \\
\text { IPC) }\end{array}$ & $\begin{array}{l}\text { Score } \\
\text { (Brown) }\end{array}$ & $\begin{array}{l}\text { Score } \\
\text { (Pearson) }\end{array}$ \\
\hline 1.Andhra Pr. & 2808 & 2229 & 171 & 1442 & 2154 & 126 & 7 & 0.749764 & 0.794320 \\
\hline 2.Arunachal Pr. & 65 & 29 & 2 & 42 & 93 & 13 & 0 & -0.735533 & -0.777157 \\
\hline 3.Assam & 1303 & 504 & 48 & 1700 & 3764 & 305 & 4 & 0.367099 & 0.529381 \\
\hline 4.Bihar & 3198 & 3327 & 348 & 934 & 4268 & 556 & 105 & 1.626906 & 1.712828 \\
\hline 5.Chhattisgarh & 1110 & 747 & 28 & 1053 & 472 & 68 & 7 & -0.198115 & -0.154705 \\
\hline 6.Goa & 48 & 22 & 6 & 29 & 28 & 2 & 0 & -0.748896 & -0.797532 \\
\hline 7.Gujarat & 1126 & 478 & 43 & 439 & 1614 & 221 & 24 & -0.070253 & -0.055458 \\
\hline 8. Haryana & 1062 & 851 & 60 & 733 & 959 & 167 & 176 & 0.020274 & 0.042718 \\
\hline 9.Himachal P. & 130 & 50 & 6 & 168 & 212 & 1 & 0 & -0.694342 & -0.731526 \\
\hline 10.J.\&Kashmir & 169 & 494 & 29 & 277 & 1077 & 14 & 0 & -0.514322 & -0.509559 \\
\hline 11.Jharkhand & 1747 & 718 & 83 & 784 & 941 & 309 & 40 & 0.192686 & 0.207980 \\
\hline 12.Karnataka & 1820 & 1837 & 85 & 636 & 1395 & 214 & 399 & 0.523504 & 0.552124 \\
\hline 13.Kerala & 365 & 521 & 105 & 1132 & 299 & 71 & 245 & -0.130657 & -0.131914 \\
\hline 14.Madhya Pr. & 2511 & 2340 & 139 & 3406 & 1288 & 118 & 117 & 0.887699 & 1.116751 \\
\hline 15.Maharashtra & 2818 & 2105 & 144 & 1701 & 1669 & 773 & 291 & 1.276130 & 1.485005 \\
\hline 16.Manipur & 78 & 245 & 4 & 53 & 169 & 1 & 154 & -0.605028 & -0.648949 \\
\hline 17.Meghalaya & 170 & 51 & 3 & 130 & 87 & 49 & 0 & -0.676070 & -0.705606 \\
\hline 18.Mizoram & 26 & 24 & 8 & 77 & 6 & 1 & 0 & -0.747646 & -0.792724 \\
\hline 19.Nagaland & 46 & 43 & 11 & 23 & 34 & 7 & 0 & -0.737980 & -0.787135 \\
\hline 20.Odisha & 1477 & 1621 & 51 & 1112 & 1139 & 417 & 84 & 0.327749 & 0.502767 \\
\hline 21.Punjab & 842 & 997 & 112 & 479 & 681 & 28 & 143 & -0.110480 & -0.155850 \\
\hline 22.Rajasthan & 1461 & 1566 & 100 & 1800 & 3204 & 28 & 72 & 0.411694 & 0.535415 \\
\hline 23.Sikkim & 14 & 7 & 8 & 16 & 10 & 0 & 0 & -0.759842 & -0.810890 \\
\hline
\end{tabular}




\begin{tabular}{|c|c|c|c|c|c|c|c|c|c|}
\hline 24.Tamil Nadu & 1877 & 2962 & 28 & 677 & 1984 & 101 & 11 & 0.295429 & 0.466029 \\
\hline 25.Tripura & 163 & 75 & 0 & 205 & 154 & 11 & 0 & -0.686939 & -0.715228 \\
\hline 26.Uttar Pr. & 4951 & 4653 & 1454 & 2042 & 8500 & 379 & 39 & 3.973624 & 3.473496 \\
\hline 27.Uttarakhand & 178 & 189 & 54 & 129 & 314 & 13 & 1 & -0.594947 & -0.653215 \\
\hline 28.West Bengal & 2109 & 2242 & 486 & 2363 & 4285 & 236 & 939 & 2.007857 & 1.930806 \\
\hline 29.A\&N Islands & 14 & 6 & 2 & 13 & 15 & 1 & 0 & -0.767162 & -0.814402 \\
\hline 30.Chandigarh & 24 & 40 & 6 & 27 & 58 & 6 & 2 & -0.746446 & -0.791264 \\
\hline 31.D\&N Haveli & 14 & 2 & 0 & 4 & 9 & 7 & 0 & -0.768208 & -0.813733 \\
\hline 32.Daman\&Diu & 6 & 1 & 0 & 1 & 3 & 4 & 0 & -0.772847 & -0.819133 \\
\hline 33.Delhi & 543 & 386 & 71 & 572 & 3767 & 33 & 25 & -0.077412 & -0.065369 \\
\hline 34.Lakshadweep & 0 & 1 & 0 & 0 & 0 & 0 & 0 & -0.777023 & -0.824161 \\
\hline 35.Puducherry & 32 & 22 & 12 & 7 & 12 & 5 & 10 & -0.740266 & -0.794110 \\
\hline
\end{tabular}

\begin{tabular}{|c|c|c|c|c|c|c|c|c|c|}
\hline \multicolumn{10}{|c|}{ Table.A5. Dataset with Outliers } \\
\hline SI & $X_{1}$ & $x_{2}$ & $x_{3}$ & $X_{4}$ & $x_{5}$ & $x_{6}$ & $x_{7}$ & $\begin{array}{c}\text { Score } \\
\text { (Brown) }\end{array}$ & $\begin{array}{c}\text { Score } \\
\text { (Pearson) }\end{array}$ \\
\hline 1 & 1.077682 & 1.140908 & 1.208296 & 1.151883 & 0.822192 & 0.719490 & 0.983262 & -1.228140 & -1.588607 \\
\hline 2 & 1.923077 & 1.960607 & 2.226456 & 2.064075 & 2.156102 & 1.499589 & 2.572422 & -1.168314 & -1.515159 \\
\hline 3 & 2.962812 & 2.829700 & 3.264841 & 3.159331 & 3.180563 & 3.304192 & 3.687762 & -1.103764 & -1.432080 \\
\hline 4 & 4.080219 & 4.049193 & 4.255646 & 4.326654 & 3.500006 & 3.490373 & 3.570235 & -1.060687 & -1.357769 \\
\hline 5 & 49.411562 & 5.081494 & 4.893908 & 5.136103 & 4.832139 & 5.258435 & 4.505863 & 0.183137 & 0.163046 \\
\hline 6 & 6.008522 & 5.842828 & 5.809820 & 5.803793 & 6.141950 & 6.424315 & 6.008884 & -0.936988 & -1.203804 \\
\hline 7 & 7.041500 & 6.817300 & 6.944475 & 7.044302 & 6.599157 & 6.589016 & 7.422431 & -0.879339 & -1.127030 \\
\hline 8 & 8.011244 & 8.141910 & 8.036765 & 7.671292 & 8.035854 & 8.502820 & 7.912820 & -0.819698 & -1.041212 \\
\hline 9 & 8.944017 & 9.117921 & 9.079594 & 9.334909 & 8.894629 & 9.480762 & 9.496862 & -0.755880 & -0.959126 \\
\hline 10 & 9.922213 & 98.398512 & 9.922357 & 9.824893 & 10.208457 & 9.663454 & 10.018876 & -0.212391 & 0.565465 \\
\hline 11 & 11.021235 & 10.850046 & 10.744802 & 11.283774 & 10.635725 & 11.326977 & 11.170139 & -0.645498 & -0.810919 \\
\hline 12 & 12.031965 & 12.182981 & 11.750493 & 11.901474 & 12.011181 & 12.594397 & 11.498643 & -0.590484 & -0.728639 \\
\hline 13 & 13.092702 & 12.939893 & 12.746827 & 12.795517 & 13.291158 & 12.972235 & 12.468223 & -0.534694 & -0.654560 \\
\hline 14 & 13.917489 & 14.077809 & 13.899319 & 13.931400 & 14.223924 & 13.951558 & 14.087580 & -0.473131 & -0.574977 \\
\hline 15 & 15.097872 & 14.995657 & 149.899473 & 15.149472 & 14.965230 & 15.175330 & 14.348062 & -0.080067 & 0.703821 \\
\hline 16 & 16.060008 & 15.803115 & 15.813045 & 16.030555 & 16.200695 & 15.875041 & 15.391044 & -0.362741 & -0.421715 \\
\hline 17 & 17.055419 & 17.070173 & 17.271701 & 17.126990 & 17.077891 & 16.969294 & 16.917957 & -0.295905 & -0.332128 \\
\hline 18 & 18.036488 & 17.925449 & 18.217657 & 17.917049 & 17.600922 & 17.946274 & 18.584179 & -0.234437 & -0.257982 \\
\hline 19 & 18.911146 & 19.022213 & 19.276058 & 19.211489 & 19.273300 & 18.893385 & 19.342020 & -0.178161 & -0.177531 \\
\hline 20 & 19.906232 & 20.063513 & 19.952000 & 202.968212 & 20.438697 & 19.711310 & 19.381258 & 0.315949 & 0.998294 \\
\hline 21 & 21.004311 & 21.043895 & 21.034252 & 21.030676 & 21.315756 & 20.841754 & 20.816167 & -0.066159 & -0.022824 \\
\hline 22 & 22.051297 & 22.097930 & 21.888662 & 21.817636 & 22.451371 & 22.490388 & 22.098432 & -0.000058 & 0.060622 \\
\hline 23 & 23.050831 & 22.938382 & 22.939871 & 22.726158 & 23.135141 & 23.220819 & 22.438843 & 0.046916 & 0.130427 \\
\hline 24 & 24.065438 & 23.807062 & 23.742039 & 23.977633 & 24.035376 & 23.860401 & 23.904998 & 0.107762 & 0.206821 \\
\hline 25 & 25.006791 & 25.170981 & 24.815775 & 25.000573 & 249.327053 & 24.556066 & 24.377850 & 1.157007 & 1.454063 \\
\hline 26 & 26.008554 & 25.985657 & 26.049708 & 25.918773 & 25.802752 & 26.403516 & 25.432177 & 0.220856 & 0.367000 \\
\hline 27 & 26.946083 & 26.926664 & 26.922245 & 26.812549 & 27.137024 & 26.973472 & 27.314238 & 0.285576 & 0.443887 \\
\hline 28 & 27.948304 & 27.967381 & 27.735514 & 28.322362 & 28.173216 & 28.196977 & 27.404016 & 0.336006 & 0.521695 \\
\hline 29 & 29.099590 & 28.839757 & 29.216105 & 29.378184 & 29.298987 & 28.957820 & 29.540645 & 0.410901 & 0.612222 \\
\hline 30 & 30.022379 & 29.830491 & 30.127099 & 29.891538 & 29.751847 & 295.333455 & 29.816559 & 1.867513 & 1.964431 \\
\hline 31 & 31.047042 & 30.964575 & 30.995462 & 30.852886 & 30.564621 & 31.161013 & 30.753473 & 0.513778 & 0.758011 \\
\hline 32 & 32.074665 & 31.858398 & 32.068824 & 32.223393 & 31.552488 & 31.889945 & 31.847920 & 0.572783 & 0.837578 \\
\hline 33 & 33.037495 & 32.948731 & 33.029843 & 33.269463 & 32.813184 & 33.046659 & 32.497468 & 0.628593 & 0.916808 \\
\hline 34 & 34.002371 & 34.185251 & 34.171760 & 34.078895 & 34.363046 & 34.016002 & 33.538122 & 0.689824 & 1.001054 \\
\hline 35 & 35.010063 & 34.838184 & 34.994360 & 35.161942 & 35.158680 & 35.264930 & 350.696077 & 4.289935 & 2.501275 \\
\hline
\end{tabular}

\begin{tabular}{|c|c|c|c|c|c|c|c|c|c|}
\hline \multicolumn{10}{|c|}{ Table.A6. Lévy Distributed Probability Density Function Dataset } \\
\hline $\mathrm{SI}$ & $\mathrm{X}_{1}$ & $\mathrm{X}_{2}$ & $\mathrm{X}_{3}$ & $\mathrm{X}_{4}$ & $\mathrm{X}_{5}$ & $\mathrm{X}_{6}$ & $\mathrm{X}_{7}$ & $\begin{array}{c}\text { Score } \\
\text { (Brown) }\end{array}$ & $\begin{array}{c}\text { Score } \\
\text { (Pearson) }\end{array}$ \\
\hline 1 & 0.5906 & 0.0000 & 0.0000 & 0.0000 & 0.0000 & 0.0000 & 0.0000 & 4.178488 & 1.695382 \\
\hline 2 & 0.1591 & 0.2938 & 0.0000 & 0.0000 & 0.0000 & 0.0000 & 0.0000 & 2.589793 & 2.421982 \\
\hline 3 & 0.0645 & 0.1855 & 0.0000 & 0.0000 & 0.0000 & 0.0000 & 0.0000 & 1.467566 & 1.646117 \\
\hline 4 & 0.0360 & 0.1054 & 0.1448 & 0.0000 & 0.0000 & 0.0000 & 0.0000 & 1.602804 & 2.298040 \\
\hline
\end{tabular}




\begin{tabular}{|c|c|c|c|c|c|c|c|c|c|}
\hline 5 & 0.0237 & 0.0688 & 0.1425 & 0.0000 & 0.0000 & 0.0000 & 0.0000 & 1.345085 & 2.057081 \\
\hline 6 & 0.0168 & 0.0492 & 0.1024 & 0.0000 & 0.0000 & 0.0000 & 0.0000 & 1.020808 & 1.620680 \\
\hline 7 & 0.0128 & 0.0369 & 0.0771 & 0.0879 & 0.0000 & 0.0000 & 0.0000 & 0.998423 & 1.603635 \\
\hline 8 & 0.0100 & 0.0292 & 0.0610 & 0.1044 & 0.0000 & 0.0000 & 0.0000 & 0.902487 & 1.477564 \\
\hline 9 & 0.0082 & 0.0239 & 0.0496 & 0.0856 & 0.0000 & 0.0000 & 0.0000 & 0.774206 & 1.300282 \\
\hline 10 & 0.0068 & 0.0195 & 0.0411 & 0.0713 & 0.0115 & 0.0000 & 0.0000 & 0.676237 & 1.061663 \\
\hline 11 & 0.0056 & 0.0167 & 0.0352 & 0.0597 & 0.0827 & 0.0000 & 0.0000 & 0.608008 & 0.325490 \\
\hline 12 & 0.0049 & 0.0143 & 0.0298 & 0.0520 & 0.0793 & 0.0000 & 0.0000 & 0.551036 & 0.276416 \\
\hline 13 & 0.0044 & 0.0123 & 0.0260 & 0.0447 & 0.0696 & 0.0000 & 0.0000 & 0.505242 & 0.300167 \\
\hline 14 & 0.0038 & 0.0108 & 0.0229 & 0.0394 & 0.0606 & 0.0146 & 0.0000 & 0.076050 & 0.070464 \\
\hline 15 & 0.0033 & 0.0096 & 0.0199 & 0.0347 & 0.0540 & 0.0711 & 0.0000 & -1.475440 & -0.925603 \\
\hline 16 & 0.0031 & 0.0088 & 0.0182 & 0.0312 & 0.0482 & 0.0688 & 0.0000 & -1.434086 & -0.860886 \\
\hline 17 & 0.0027 & 0.0078 & 0.0164 & 0.0283 & 0.0435 & 0.0621 & 0.0000 & -1.275902 & -0.727867 \\
\hline 18 & 0.0024 & 0.0071 & 0.0150 & 0.0253 & 0.0397 & 0.0567 & 0.0218 & -1.179105 & -0.998228 \\
\hline 19 & 0.0023 & 0.0067 & 0.0135 & 0.0235 & 0.0359 & 0.0514 & 0.0665 & -1.112057 & -1.661399 \\
\hline 20 & 0.0021 & 0.0060 & 0.0124 & 0.0214 & 0.0330 & 0.0470 & 0.0633 & -1.003513 & -1.520444 \\
\hline 21 & 0.0019 & 0.0054 & 0.0114 & 0.0194 & 0.0303 & 0.0434 & 0.0587 & -0.913393 & -1.369768 \\
\hline 22 & 0.0018 & 0.0049 & 0.0104 & 0.0184 & 0.0281 & 0.0400 & 0.0545 & -0.826010 & -1.230395 \\
\hline 23 & 0.0016 & 0.0047 & 0.0096 & 0.0169 & 0.0260 & 0.0372 & 0.0503 & -0.754151 & -1.101107 \\
\hline 24 & 0.0015 & 0.0044 & 0.0090 & 0.0158 & 0.0238 & 0.0346 & 0.0468 & -0.686653 & -0.984189 \\
\hline 25 & 0.0014 & 0.0041 & 0.0084 & 0.0147 & 0.0224 & 0.0322 & 0.0436 & -0.624901 & -0.883202 \\
\hline 26 & 0.0012 & 0.0038 & 0.0078 & 0.0135 & 0.0211 & 0.0298 & 0.0410 & -0.564852 & -0.793973 \\
\hline 27 & 0.0012 & 0.0036 & 0.0076 & 0.0127 & 0.0200 & 0.0287 & 0.0380 & -0.534670 & -0.717601 \\
\hline 28 & 0.0011 & 0.0034 & 0.0071 & 0.0120 & 0.0187 & 0.0263 & 0.0363 & -0.473252 & -0.640932 \\
\hline 29 & 0.0011 & 0.0032 & 0.0065 & 0.0114 & 0.0174 & 0.0251 & 0.0340 & -0.442851 & -0.575648 \\
\hline 30 & 0.0010 & 0.0029 & 0.0062 & 0.0107 & 0.0164 & 0.0236 & 0.0318 & -0.404412 & -0.508083 \\
\hline 31 & 0.0010 & 0.0028 & 0.0059 & 0.0100 & 0.0155 & 0.0223 & 0.0301 & -0.370467 & -0.452349 \\
\hline 32 & 0.0009 & 0.0025 & 0.0057 & 0.0095 & 0.0147 & 0.0211 & 0.0288 & -0.340445 & -0.406121 \\
\hline 33 & 0.0009 & 0.0026 & 0.0053 & 0.0089 & 0.0139 & 0.0200 & 0.0271 & -0.311243 & -0.354273 \\
\hline 34 & 0.0008 & 0.0025 & 0.0050 & 0.0087 & 0.0137 & 0.0191 & 0.0258 & -0.288214 & -0.317614 \\
\hline 35 & 0.0008 & 0.0023 & 0.0047 & 0.0081 & 0.0127 & 0.0181 & 0.0247 & -0.263413 & -0.276967 \\
\hline 36 & 0.0007 & 0.0022 & 0.0046 & 0.0078 & 0.0120 & 0.0174 & 0.0235 & -0.245184 & -0.239846 \\
\hline 37 & 0.0007 & 0.0021 & 0.0042 & 0.0076 & 0.0115 & 0.0165 & 0.0223 & -0.222112 & -0.202816 \\
\hline 38 & 0.0007 & 0.0020 & 0.0041 & 0.0072 & 0.0110 & 0.0159 & 0.0215 & -0.206645 & -0.176282 \\
\hline 39 & 0.0007 & 0.0019 & 0.0040 & 0.0068 & 0.0105 & 0.0150 & 0.0206 & -0.182976 & -0.142655 \\
\hline 40 & 0.0006 & 0.0019 & 0.0039 & 0.0067 & 0.0101 & 0.0143 & 0.0200 & -0.164704 & -0.117466 \\
\hline 41 & 0.0006 & 0.0018 & 0.0036 & 0.0065 & 0.0097 & 0.0138 & 0.0188 & -0.151904 & -0.087695 \\
\hline 42 & 0.0006 & 0.0017 & 0.0035 & 0.0060 & 0.0094 & 0.0135 & 0.0182 & -0.144969 & -0.072067 \\
\hline 43 & 0.0005 & 0.0016 & 0.0033 & 0.0059 & 0.0088 & 0.0127 & 0.0173 & -0.124528 & -0.039443 \\
\hline 44 & 0.0006 & 0.0015 & 0.0033 & 0.0056 & 0.0086 & 0.0124 & 0.0167 & -0.116032 & -0.023136 \\
\hline 45 & 0.0005 & 0.0015 & 0.0031 & 0.0055 & 0.0082 & 0.0117 & 0.0161 & -0.098235 & 0.001264 \\
\hline 46 & 0.0005 & 0.0014 & 0.0030 & 0.0052 & 0.0079 & 0.0116 & 0.0154 & -0.096129 & 0.015630 \\
\hline 47 & 0.0005 & 0.0014 & 0.0028 & 0.0049 & 0.0077 & 0.0110 & 0.0149 & -0.080882 & 0.034336 \\
\hline 48 & 0.0005 & 0.0014 & 0.0027 & 0.0047 & 0.0073 & 0.0108 & 0.0147 & -0.076134 & 0.043579 \\
\hline 49 & 0.0005 & 0.0013 & 0.0028 & 0.0047 & 0.0073 & 0.0104 & 0.0138 & -0.064110 & 0.066534 \\
\hline 50 & 0.0013 & 0.0015 & 0.0039 & 0.0055 & 0.0070 & 0.0101 & 0.0136 & -0.042659 & 0.091750 \\
\hline
\end{tabular}




\begin{tabular}{|c|c|c|c|c|c|c|}
\hline \multicolumn{7}{|c|}{ Table.B1. Transformed Iris Flower Dataset } \\
\hline SI no. & Sepal length & Sepal width & Petal length & Petal width & Score(Brown) & Score(Pearson) \\
\hline 1 & -1.247908 & -0.409229 & -1.402788 & -1.385778 & -1.325658 & -1.32123 \\
\hline 2 & -0.629788 & -1.242008 & -1.297983 & -1.175388 & -1.218104 & -1.21404 \\
\hline 3 & -1.128450 & -1.154195 & -1.339647 & -1.261441 & -1.383916 & -1.37930 \\
\hline 4 & -1.048737 & -1.354322 & -1.190768 & -1.235037 & -1.345959 & -1.34147 \\
\hline 5 & -1.494989 & -0.361034 & -1.394747 & -1.432252 & -1.398909 & -1.39424 \\
\hline 6 & -1.648892 & 0.434334 & -1.314571 & -1.303563 & -1.214984 & -1.21093 \\
\hline 7 & -1.551650 & -0.948060 & -1.272623 & -1.224736 & -1.430628 & -1.42585 \\
\hline 8 & -1.172695 & -0.617934 & -1.311653 & -1.352479 & -1.307011 & -1.30265 \\
\hline 9 & -0.911809 & -1.797463 & -1.181732 & -1.147754 & -1.366597 & -1.36203 \\
\hline 10 & -0.762465 & -1.117316 & -1.266827 & -1.359024 & -1.278610 & -1.27434 \\
\hline 11 & -1.296653 & 0.118455 & -1.432539 & -1.469921 & -1.268063 & -1.26383 \\
\hline 12 & -1.344563 & -0.778443 & -1.212478 & -1.365654 & -1.361615 & -1.35707 \\
\hline 13 & -0.696251 & -1.343175 & -1.291182 & -1.311936 & -1.298584 & -1.29425 \\
\hline 14 & -1.150667 & -1.791623 & -1.360839 & -1.306952 & -1.541302 & -1.53616 \\
\hline 15 & -1.434109 & 0.829112 & -1.726658 & -1.566679 & -1.287047 & -1.28275 \\
\hline 16 & -2.187827 & 1.334502 & -1.555581 & -1.497024 & -1.324202 & -1.31978 \\
\hline 17 & -1.666889 & 0.400025 & -1.545550 & -1.275984 & -1.292225 & -1.28791 \\
\hline 18 & -1.269630 & -0.392605 & -1.388874 & -1.252370 & -1.282135 & -1.27785 \\
\hline 19 & -1.203722 & 0.538602 & -1.377956 & -1.384216 & -1.111341 & -1.10763 \\
\hline 20 & -1.741823 & 0.014187 & -1.369154 & -1.389267 & -1.371706 & -1.36713 \\
\hline 21 & -0.810962 & -0.262606 & -1.279025 & -1.353708 & -1.120561 & -1.11682 \\
\hline 22 & -1.604647 & -0.101927 & -1.342565 & -1.212525 & -1.291889 & -1.28758 \\
\hline 23 & -1.865721 & -0.733516 & -1.542865 & -1.417234 & -1.623980 & -1.61856 \\
\hline 24 & -0.981780 & -0.599102 & -1.162463 & -0.919570 & -1.064570 & -1.06102 \\
\hline 25 & -1.331065 & -0.752711 & -1.039244 & -1.386338 & -1.303684 & -1.29933 \\
\hline 26 & -0.532606 & -1.140310 & -1.203209 & -1.186037 & -1.142526 & -1.13871 \\
\hline 27 & -1.211639 & -0.576108 & -1.226081 & -1.092558 & -1.200654 & -1.19665 \\
\hline 28 & -1.155225 & -0.316109 & -1.365758 & -1.389533 & -1.269390 & -1.26515 \\
\hline 29 & -1.000827 & -0.457424 & -1.410828 & -1.339304 & -1.252407 & -1.24823 \\
\hline 30 & -1.114952 & -1.128463 & -1.166413 & -1.282126 & -1.325985 & -1.32156 \\
\hline 31 & -0.867871 & -1.176658 & -1.174453 & -1.235651 & -1.252734 & -1.24855 \\
\hline 32 & -0.863404 & -0.246512 & -1.366687 & -1.073103 & -1.072136 & -1.06856 \\
\hline 33 & -2.086888 & 0.463698 & -1.455721 & -1.782946 & -1.530676 & -1.52557 \\
\hline 34 & -2.007456 & 0.858113 & -1.574373 & -1.676557 & -1.431885 & -1.42710 \\
\hline 35 & -0.784187 & -1.100692 & -1.252913 & -1.225617 & -1.235087 & -1.23096 \\
\hline 36 & -0.868398 & -0.909142 & -1.459537 & -1.245126 & -1.292355 & -1.28804 \\
\hline 37 & -0.899673 & -0.079633 & -1.543393 & -1.366323 & -1.197139 & -1.19314 \\
\hline 38 & -1.561452 & -0.462201 & -1.387946 & -1.568800 & -1.479390 & -1.47445 \\
\hline 39 & -1.075206 & -1.673301 & -1.252152 & -1.184193 & -1.422201 & -1.41745 \\
\hline 40 & -1.084512 & -0.533390 & -1.332368 & -1.349339 & -1.270054 & -1.26581 \\
\hline 41 & -1.362313 & -0.485725 & -1.425904 & -1.248616 & -1.338403 & -1.33393 \\
\hline 42 & 0.103538 & -2.501303 & -1.170229 & -0.744306 & -1.087664 & -1.08403 \\
\hline 43 & -1.393001 & -1.407824 & -1.277501 & -1.270862 & -1.494788 & -1.48980 \\
\hline 44 & -1.413979 & -0.410122 & -1.210928 & -0.869076 & -1.149902 & -1.14606 \\
\hline
\end{tabular}




\begin{tabular}{|c|c|c|c|c|c|c|}
\hline 45 & -1.745547 & 0.065120 & -1.124261 & -1.283439 & -1.250941 & -1.24676 \\
\hline 46 & -0.739694 & -1.309927 & -1.263354 & -1.045120 & -1.211538 & -1.20749 \\
\hline 47 & -1.715602 & 0.006141 & -1.325323 & -1.529570 & -1.395919 & -1.39126 \\
\hline 48 & -1.212134 & -1.230161 & -1.261187 & -1.271476 & -1.401563 & -1.39688 \\
\hline 49 & -1.384837 & 0.033912 & -1.411823 & -1.473061 & -1.305021 & -1.30066 \\
\hline 50 & -1.018297 & -0.759249 & -1.356723 & -1.302250 & -1.290028 & -1.28572 \\
\hline 51 & 0.792093 & 1.281413 & 0.314186 & 0.177253 & 0.644935 & 0.64278 \\
\hline 52 & 0.232271 & 0.773623 & 0.336902 & 0.305610 & 0.428093 & 0.42666 \\
\hline 53 & 0.850084 & 1.097910 & 0.476979 & 0.337066 & 0.726415 & 0.72399 \\
\hline 54 & 0.889641 & -1.258046 & 0.320862 & 0.435015 & 0.238523 & 0.23773 \\
\hline 55 & 0.960543 & 0.335790 & 0.424631 & 0.475192 & 0.629536 & 0.62743 \\
\hline 56 & 0.294018 & -0.382381 & 0.504780 & 0.190150 & 0.227521 & 0.22676 \\
\hline 57 & -0.027533 & 0.855597 & 0.474345 & 0.378755 & 0.436986 & 0.43553 \\
\hline 58 & 0.235311 & -1.742480 & -0.013476 & 0.020880 & -0.285257 & -0.28431 \\
\hline 59 & 0.933273 & 0.519824 & 0.363413 & 0.168182 & 0.543153 & 0.54134 \\
\hline 60 & -0.036720 & -0.972675 & 0.288477 & 0.392561 & 0.006688 & 0.00667 \\
\hline 61 & 0.968083 & -2.171736 & 0.131998 & 0.183567 & -0.064504 & -0.06429 \\
\hline 62 & 0.095650 & 0.059699 & 0.292594 & 0.397263 & 0.257963 & 0.25710 \\
\hline 63 & 1.554621 & -1.017940 & 0.188219 & 0.093826 & 0.329034 & 0.32794 \\
\hline 64 & 0.475132 & 0.122309 & 0.538648 & 0.278995 & 0.421200 & 0.41979 \\
\hline 65 & 0.006443 & -0.411381 & -0.006881 & 0.205729 & -0.019524 & -0.01946 \\
\hline 66 & 0.672941 & 0.869314 & 0.215772 & 0.231852 & 0.512425 & 0.51071 \\
\hline 67 & -0.155403 & -0.168200 & 0.527973 & 0.367158 & 0.205022 & 0.20434 \\
\hline 68 & 0.588266 & -0.514757 & 0.224020 & -0.136020 & 0.092960 & 0.09265 \\
\hline 69 & 1.644878 & -0.722847 & 0.505081 & 0.732672 & 0.717116 & 0.71472 \\
\hline 70 & 0.698974 & -0.949851 & 0.189225 & 0.091566 & 0.096536 & 0.09621 \\
\hline 71 & -0.260313 & 0.426511 & 0.655453 & 0.669449 & 0.431807 & 0.43037 \\
\hline 72 & 0.624256 & -0.087094 & 0.133196 & 0.237185 & 0.278798 & 0.27787 \\
\hline 73 & 1.274366 & -0.205780 & 0.677320 & 0.578230 & 0.722434 & 0.72002 \\
\hline 74 & 0.677473 & -0.043678 & 0.523495 & 0.055513 & 0.370448 & 0.36921 \\
\hline 75 & 0.743407 & 0.325006 & 0.231609 & 0.182586 & 0.411307 & 0.40993 \\
\hline 76 & 0.743655 & 0.652032 & 0.249163 & 0.272046 & 0.511762 & 0.51005 \\
\hline 77 & 1.255814 & 0.589950 & 0.464060 & 0.337415 & 0.735506 & 0.73305 \\
\hline 78 & 0.793670 & 0.837910 & 0.616656 & 0.634041 & 0.795151 & 0.79250 \\
\hline 79 & 0.356229 & 0.037235 & 0.457787 & 0.423052 & 0.389145 & 0.38785 \\
\hline 80 & 0.631984 & -0.783502 & -0.089058 & -0.054457 & -0.023566 & -0.02349 \\
\hline 81 & 0.765188 & -1.175710 & 0.164870 & 0.138654 & 0.076562 & 0.07631 \\
\hline 82 & 0.782410 & -1.200911 & 0.093212 & 0.012141 & 0.013728 & 0.01368 \\
\hline 83 & 0.535825 & -0.498664 & 0.136358 & 0.144585 & 0.141386 & 0.14091 \\
\hline 84 & 0.679298 & -0.160155 & 0.843519 & 0.601760 & 0.621118 & 0.61905 \\
\hline 85 & -0.331770 & -0.337286 & 0.569404 & 0.360878 & 0.131107 & 0.13067 \\
\hline 86 & -0.459980 & 0.717551 & 0.408327 & 0.339790 & 0.251199 & 0.25036 \\
\hline 87 & 0.664718 & 0.911669 & 0.402920 & 0.344575 & 0.613880 & 0.61183 \\
\hline 88 & 1.613108 & -0.547391 & 0.386118 & 0.432556 & 0.611423 & 0.60938 \\
\hline 89 & -0.129958 & -0.235757 & 0.269167 & 0.127921 & 0.040734 & 0.04060 \\
\hline 90 & 0.571847 & -0.992569 & 0.295512 & 0.348347 & 0.165935 & 0.16538 \\
\hline
\end{tabular}




\begin{tabular}{|c|c|c|c|c|c|c|}
\hline 91 & 0.452668 & -0.842146 & 0.499902 & 0.144025 & 0.163360 & 0.16281 \\
\hline 92 & 0.311736 & 0.246470 & 0.468228 & 0.242556 & 0.365596 & 0.36438 \\
\hline 93 & 0.699221 & -0.622825 & 0.206778 & 0.181025 & 0.196990 & 0.19633 \\
\hline 94 & 0.482393 & -1.790675 & -0.021516 & 0.067354 & -0.212006 & -0.21130 \\
\hline 95 & 0.351234 & -0.625395 & 0.364936 & 0.251029 & 0.168926 & 0.16836 \\
\hline 96 & -0.015553 & -0.159260 & 0.292283 & -0.009241 & 0.053479 & 0.05330 \\
\hline 97 & 0.121623 & -0.275375 & 0.318872 & 0.167501 & 0.133296 & 0.13285 \\
\hline 98 & 0.567040 & 0.155919 & 0.273040 & 0.176306 & 0.337393 & 0.33627 \\
\hline 99 & 0.217562 & -1.449762 & -0.226901 & 0.137918 & -0.262045 & -0.26117 \\
\hline 100 & 0.276021 & -0.416690 & 0.273802 & 0.217730 & 0.150279 & 0.14978 \\
\hline 101 & -0.164535 & 1.116716 & 1.350249 & 1.489794 & 1.079730 & 1.07613 \\
\hline 102 & 0.437766 & -0.279369 & 0.926690 & 0.995704 & 0.677773 & 0.67551 \\
\hline 103 & 1.100013 & 1.319774 & 1.109152 & 1.118180 & 1.290867 & 1.28656 \\
\hline 104 & 0.605108 & 0.435086 & 1.072574 & 0.756854 & 0.843001 & 0.84019 \\
\hline 105 & 0.544690 & 0.820561 & 1.189613 & 1.239642 & 1.093336 & 1.08969 \\
\hline 106 & 1.572426 & 1.802531 & 1.409789 & 1.085617 & 1.610826 & 1.60545 \\
\hline 107 & -0.021644 & -1.390447 & 0.764182 & 0.828664 & 0.214836 & 0.21412 \\
\hline 108 & 1.518439 & 1.340559 & 1.269634 & 0.739991 & 1.347747 & 1.34325 \\
\hline 109 & 1.602430 & 0.259460 & 1.155902 & 0.928961 & 1.174627 & 1.17071 \\
\hline 110 & 0.156925 & 2.284399 & 1.183532 & 1.381157 & 1.322775 & 1.31836 \\
\hline 111 & 0.238843 & 0.992750 & 0.732223 & 0.934421 & 0.798529 & 0.79586 \\
\hline 112 & 0.975867 & 0.245045 & 0.917888 & 1.000755 & 0.938138 & 0.93501 \\
\hline 113 & 0.817465 & 1.031836 & 0.940319 & 1.136339 & 1.102753 & 1.09907 \\
\hline 114 & 0.641157 & -0.621343 & 0.928924 & 1.219534 & 0.737616 & 0.73515 \\
\hline 115 & 0.170262 & -0.063511 & 0.983584 & 1.619409 & 0.859095 & 0.85623 \\
\hline 116 & 0.094494 & 0.975233 & 0.910169 & 1.317716 & 0.930762 & 0.92765 \\
\hline 117 & 0.618078 & 0.728334 & 0.960724 & 0.726695 & 0.861312 & 0.85844 \\
\hline 118 & 0.372208 & 2.974183 & 1.359333 & 0.868597 & 1.420267 & 1.41553 \\
\hline 119 & 2.266254 & 1.415100 & 1.640835 & 1.508225 & 1.937937 & 1.93147 \\
\hline 120 & 1.491007 & -0.849048 & 0.835235 & 0.691918 & 0.739754 & 0.73728 \\
\hline 121 & 0.553409 & 1.432258 & 1.037571 & 1.305837 & 1.192790 & 1.18881 \\
\hline 122 & 0.071782 & -0.316248 & 0.853870 & 1.093287 & 0.572467 & 0.57056 \\
\hline 123 & 2.004625 & 1.613550 & 1.458254 & 1.035123 & 1.696159 & 1.69050 \\
\hline 124 & 0.891407 & 0.109569 & 0.693711 & 0.891786 & 0.780416 & 0.77781 \\
\hline 125 & 0.261587 & 1.362662 & 1.038500 & 0.989407 & 0.995535 & 0.99221 \\
\hline 126 & 0.940065 & 1.628499 & 1.079091 & 0.627533 & 1.143977 & 1.14016 \\
\hline 127 & 0.639827 & 0.149187 & 0.644007 & 0.852206 & 0.687854 & 0.68556 \\
\hline 128 & 0.238348 & 0.338697 & 0.697117 & 0.755503 & 0.597620 & 0.59562 \\
\hline 129 & 0.787024 & 0.436763 & 1.106275 & 1.203552 & 1.046822 & 1.04333 \\
\hline 130 & 1.292304 & 1.312620 & 0.961124 & 0.461175 & 1.090898 & 1.08726 \\
\hline 131 & 1.734800 & 1.291834 & 1.160018 & 0.933663 & 1.425901 & 1.42114 \\
\hline 132 & 0.578520 & 3.084290 & 1.116841 & 0.628746 & 1.349204 & 1.34470 \\
\hline 133 & 0.765303 & 0.453387 & 1.120189 & 1.336960 & 1.090345 & 1.08671 \\
\hline 134 & 0.806673 & 0.209589 & 0.754784 & 0.434438 & 0.652173 & 0.65000 \\
\hline 135 & 0.992318 & -0.198712 & 1.096374 & 0.346945 & 0.703875 & 0.70153 \\
\hline 136 & 1.594670 & 1.877436 & 1.128178 & 1.390047 & 1.638278 & 1.63281 \\
\hline
\end{tabular}




\begin{tabular}{|r|r|r|r|r|r|l|}
\hline 137 & -0.319708 & 1.198522 & 1.092682 & 1.340631 & 0.922671 & 0.91959 \\
\hline 138 & 0.370997 & 0.776529 & 0.968765 & 0.680221 & 0.788061 & 0.78543 \\
\hline 139 & 0.145665 & 0.245577 & 0.660088 & 0.759258 & 0.541352 & 0.53955 \\
\hline 140 & 0.742252 & 1.240540 & 0.849185 & 1.103039 & 1.084106 & 1.08049 \\
\hline 141 & 0.509719 & 1.138480 & 1.047846 & 1.483194 & 1.179382 & 1.17544 \\
\hline 142 & 0.685311 & 1.248057 & 0.703778 & 1.390540 & 1.113221 & 1.10950 \\
\hline 143 & 0.437766 & -0.279369 & 0.926690 & 0.995704 & 0.677773 & 0.67551 \\
\hline 144 & 0.474224 & 1.364869 & 1.173776 & 1.288907 & 1.194454 & 1.19047 \\
\hline 145 & 0.174702 & 1.429158 & 1.094154 & 1.523038 & 1.169628 & 1.16572 \\
\hline 146 & 0.672340 & 0.954809 & 0.815628 & 1.420699 & 1.094911 & 1.09126 \\
\hline 147 & 1.191980 & -0.130707 & 0.790719 & 1.104967 & 0.915837 & 0.91278 \\
\hline 148 & 0.561137 & 0.735850 & 0.815317 & 1.014195 & 0.890427 & 0.88745 \\
\hline 149 & -0.395169 & 1.080200 & 0.983994 & 1.217872 & 0.803570 & 0.80089 \\
\hline 150 & 0.070979 & 0.186765 & 0.854037 & 0.735433 & 0.562326 & 0.56045 \\
\hline
\end{tabular}

Table.B2. Transformed Motor Car Dataset

\begin{tabular}{|c|c|c|c|c|c|c|c|c|c|c|c|c|c|c|c|}
\hline $\mathrm{SI}$ & $\mathrm{X}_{1}$ & $X_{2}$ & $X_{3}$ & $\mathrm{X}_{4}$ & $X_{5}$ & $X_{6}$ & $X_{7}$ & $X_{8}$ & $X_{9}$ & $\mathrm{X}_{10}$ & $\mathrm{X}_{11}$ & $\mathrm{X}_{12}$ & $\mathrm{X}_{13}$ & BScore(Br.) & Score(Pear) \\
\hline$T$ & -0.557695 & -0.560356 & -0.144644 & -0.513944 & -0.271215 & $\begin{array}{c}-0.560962 \\
\end{array}$ & -0.716676 & -2.515760 & -0.766157 & 0.038160 & 0.037223 & 1.014680 & 1.071615 & -0.2631 & -0.26243 \\
\hline 2 & -0.557695 & $\begin{array}{r}-0.560356 \\
\end{array}$ & -0.144644 & -0.513944 & -0.271215 & $\begin{array}{r}-0.560962 \\
\end{array}$ & -0.716676 & -2.515760 & -0.766157 & 0.038160 & 0.037223 & 1.014680 & 1.071615 & -0.2631 & -0.26243 \\
\hline 3 & -1.702349 & $\begin{array}{r}-0.353443 \\
\end{array}$ & $\begin{array}{r}-1.326105 \\
\end{array}$ & 0.556531 & 0.118531 & 0.682443 & 0.142128 & 0.967187 & -1.290366 & 1.225774 & 0.436121 & 0.920523 & 0.940506 & 0.116321 & 0.11602 \\
\hline 4 & -0.034923 & 0.004314 & -0.076952 & -0.436433 & 0.276623 & $\begin{array}{r}-0.245663 \\
\end{array}$ & 0.363586 & 0.760022 & -0.663253 & $\begin{array}{r}-0.232803 \\
\end{array}$ & $\begin{array}{r}-0.188415 \\
\end{array}$ & -0.290734 & -0.140092 & -0.08297 & -0.08275 \\
\hline 5 & 0.360787 & 0.367434 & 0.295826 & -0.072228 & 0.128460 & 0.405459 & 0.386871 & 0.934705 & -1.203826 & 0.727066 & $\begin{array}{r}-0.280634 \\
\end{array}$ & 0.726382 & 0.713997 & 0.443999 & 0.44286 \\
\hline 6 & 0.065997 & -0.037735 & 0.183077 & -0.363431 & 0.328979 & -0.137232 & 0.601966 & 0.714285 & -0.908658 & 0.616997 & -0.332011 & 0.371801 & 0.646684 & 0.251627 & 0.25098 \\
\hline 7 & 1.553952 & 0.771444 & 0.056945 & 0.528315 & 1.143640 & 0.695724 & 2.478081 & 1.449389 & -0.494838 & $\begin{array}{r}-0.095138 \\
\end{array}$ & -0.124468 & 0.422554 & 1.011014 & 0.992257 & 0.98971 \\
\hline 8 & 1.532572 & 0.848256 & 0.110853 & 0.558834 & 1.013546 & 0.828738 & 2.496417 & 1.450577 & -0.491502 & -0.125295 & $\begin{array}{l}-0.075438 \\
\end{array}$ & 0.482009 & 1.070722 & 1.022098 & 1.01947 \\
\hline 9 & 1.327226 & 1.453378 & -0.030926 & 0.659246 & 1.447420 & 1.104633 & 2.386295 & 1.640640 & -0.971537 & 0.239847 & 0.061555 & 1.140484 & 1.070862 & 1.250403 & 1.24719 \\
\hline 11 & 0.430393 & 0.631928 & 1.113071 & -0.394716 & 0.282851 & $\begin{array}{l}-0.344997 \\
\end{array}$ & 0.256405 & -1.041600 & -1.266510 & $\begin{array}{r}-0.280734 \\
\end{array}$ & $\begin{array}{r}-0.446037 \\
\end{array}$ & -0.613559 & -0.415629 & -0.03642 & -0.03633 \\
\hline 12 & 0.430393 & 0.631928 & 1.113071 & -0.394716 & 0.282851 & $\begin{array}{r}-0.344997 \\
\end{array}$ & 0.256405 & -1.041600 & -1.266510 & $\begin{array}{r}-0.280734 \\
-1\end{array}$ & $\begin{array}{r}-0.446037 \\
\end{array}$ & -0.613559 & -0.415629 & $\begin{array}{r}-0.03642 \\
\end{array}$ & -0.03633 \\
\hline 13 & -0.368389 & 0.176148 & 0.159339 & 1.610256 & 0.417397 & -0.033479 & -0.672669 & -0.035542 & 0.592004 & 1.234471 & -0.016149 & 0.580446 & 0.725268 & 0.4111061 & 0.41001 \\
\hline 14 & -0.379080 & 0.214554 & 0.186293 & 1.625515 & 0.352350 & 0.033028 & -0.663501 & -0.034948 & 0.593671 & 1.219393 & 0.008365 & 0.610174 & 0.755122 & 0.425982 & 0.42489 \\
\hline 15 & 0.409043 & 0.572734 & 0.497705 & 2.231281 & 0.836145 & 0.508228 & 0.133331 & 0.451383 & 0.523809 & 0.816597 & 0.211362 & 1.081888 & 1.086608 & 0.915134 & 0.91278 \\
\hline 16 & 0.760499 & 0.943253 & 1.729543 & 0.220742 & 1.822076 & 2.223173 & 0.612326 & 0.563207 & -0.119260 & 1.965203 & 0.102607 & 0.946156 & 1.023879 & 1.47394 & 1.47016 \\
\hline 17 & 0.594588 & 0.857620 & 1.728060 & 0.014870 & 1.818585 & 2.195011 & 1.337321 & 0.357907 & 0.133324 & 1.655549 & 0.216570 & 1.418002 & 1.501052 & 1.587969 & 1.58389 \\
\hline 18 & 1.758461 & 1.832991 & 1.576790 & 0.659549 & 2.230335 & 2.480441 & 2.339062 & 1.015154 & 0.269002 & 1.791689 & 0.214643 & 1.274930 & 1.407654 & 2.077163 & 2.07183 \\
\hline 19 & -2.622087 & $\begin{array}{r}-2.104943 \\
\end{array}$ & -2.2322206 & -0.607458 & -2.600052 & -1.233905 & -2.150355 & -1.470440 & 0.045160 & $\begin{array}{l}-1.990992 \\
\end{array}$ & $\begin{array}{l}-0.858584 \\
\end{array}$ & -2.679429 & -3.279284 & -2.61264 & -2.60594 \\
\hline 20 & -1.544582 & -1.263436 & -1.342662 & -0.826671 & -1.500749 & -0.936355 & -0.296587 & -0.930151 & $\begin{array}{l}-0.169597 \\
\end{array}$ & -1.162784 & -0.555760 & -1.474160 & -1.902203 & -1.49634 & -1.49250 \\
\hline 21 & -1.565157 & -1.316016 & -1.204309 & $\begin{array}{c}-0.752922 \\
\end{array}$ & -1.414402 & -0.887118 & -0.232027 & -0.900620 & -0.174551 & -1.286956 & $\begin{array}{l}-0.520424 \\
\end{array}$ & -1.410159 & -1.834469 & -1.45552 & -1.45179 \\
\hline 22 & -1.682534 & -1.512533 & -1.382533 & -1.164816 & -1.548141 & $\begin{array}{r}-1.083434 \\
\end{array}$ & -0.037601 & -0.652415 & $\begin{array}{r}-0.305078 \\
\end{array}$ & $\begin{array}{l}-1.142572 \\
-1.14\end{array}$ & $\begin{array}{l}-0.586321 \\
\end{array}$ & -1.074929 & -1.629268 & $\begin{array}{l}-1.47949 \\
\end{array}$ & -1.47566 \\
\hline 23 & -1.453624 & -1.263193 & -1.286024 & -1.134582 & -1.380365 & -1.335070 & -0.191764 & -0.478660 & -0.708933 & $\begin{array}{r}-0.721048 \\
\end{array}$ & -0.575229 & -1.022082 & -0.908668 & -1.30502 & -1.30167 \\
\hline 24 & -1.363881 & $\begin{array}{r}-0.504815 \\
\end{array}$ & -1.067620 & -1.235340 & -0.845434 & $\begin{array}{r}-0.880535 \\
\end{array}$ & -0.524068 & 0.074907 & -1.077092 & 0.215260 & $\begin{array}{r}-0.821793 \\
\end{array}$ & -0.053132 & -0.145879 & $\begin{array}{r}-0.78503 \\
\end{array}$ & -0.78301 \\
\hline 25 & -1.507881 & -1.211416 & -1.243906 & -1.142081 & -1.499273 & -1.253987 & -0.144458 & $\begin{array}{c}-0.504523 \\
\end{array}$ & $\begin{array}{l}-0.688587 \\
\end{array}$ & $\begin{array}{r}-0.746803 \\
\end{array}$ & $\begin{array}{r}-0.534546 \\
\end{array}$ & -0.944630 & -0.836588 & -1.28435 & -1.28105 \\
\hline 26 & -1.512157 & $\begin{array}{l}-1.196054 \\
\end{array}$ & -1.233124 & -1.135978 & -1.525292 & -1.227385 & -0.140790 & $\begin{array}{l}-0.504285 \\
\end{array}$ & -0.687920 & $\begin{array}{r}-0.752834 \\
\end{array}$ & $\begin{array}{l}-0.524740 \\
\end{array}$ & -0.932739 & -0.824646 & -1.27838 & -1.27510 \\
\hline 27 & -1.512157 & $\begin{array}{l}-1.196054 \\
-1965\end{array}$ & -1.233124 & -1.135978 & -1.525292 & -1.227385 & -0.140790 & -0.504285 & $\begin{array}{c}-0.687920 \\
\end{array}$ & $\begin{array}{r}-0.752834 \\
\end{array}$ & $\begin{array}{r}-0.524740 \\
\end{array}$ & -0.932739 & -0.824646 & -1.27838 & -1.27510 \\
\hline 28 & -1.412695 & $\begin{array}{r}-0.472590 \\
\end{array}$ & -1.039224 & -1.250608 & -0.931227 & -0.833310 & -0.481429 & 0.048742 & -1.057596 & 0.197182 & $\begin{array}{r}-0.793590 \\
\end{array}$ & 0.009186 & -0.088996 & -0.77195 & -0.76997 \\
\hline 29 & 0.787291 & 0.537792 & 0.648418 & 1.127574 & 0.037310 & 0.315102 & -1.169035 & 1.512119 & -0.184960 & 0.314456 & $\begin{array}{r}-0.649716 \\
\end{array}$ & -0.844463 & -0.603022 & 0.123381 & 0.12306 \\
\hline 30 & $\begin{array}{l}-0.330109 \\
\end{array}$ & 0.021607 & 0.148231 & -1.448367 & 0.516732 & 0.618132 & -0.320772 & 0.890763 & 1.072761 & 1.1351111 & $\begin{array}{r}-0.735686 \\
\end{array}$ & 1.759630 & 1.498438 & 0.575817 & 0.57434 \\
\hline 31 & -2.431211 & $\begin{array}{r}-2.717191 \\
\end{array}$ & -3.147280 & -1.004002 & -2.428449 & $\begin{array}{r}-0.554136 \\
\end{array}$ & -1.022624 & $\begin{array}{c}-0.956788 \\
\end{array}$ & 1.474394 & $\begin{array}{l}-1.977741 \\
-1\end{array}$ & $\begin{array}{r}-0.643962 \\
\end{array}$ & -1.702238 & -2.449139 & -2.25766 & -2.25186 \\
\hline 32 & -1.333460 & $\begin{array}{r}-1.736437 \\
\end{array}$ & $\begin{array}{c}-2.067928 \\
\end{array}$ & $\begin{array}{c}-2.379819 \\
\end{array}$ & -1.849800 & -0.653175 & -0.653242 & $\begin{array}{l}-0.268089 \\
\end{array}$ & -1.406510 & -0.568129 & -0.6171112 & -1.236045 & -1.071346 & -1.60687 & -1.60274 \\
\hline 33 & -1.314798 & -1.176916 & -1.849856 & -0.839204 & -1.897927 & $\begin{array}{r}-1.079276 \\
\end{array}$ & -0.295117 & -0.819169 & $\begin{array}{l}-0.670701 \\
\end{array}$ & \begin{tabular}{|c|}
-1.187351 \\
\end{tabular} & $\begin{array}{l}-0.457577 \\
-1\end{array}$ & -1.624616 & -2.107107 & -1.655143 & -1.64719 \\
\hline 34 & -0.964436 & -0.949425 & -1.354124 & -1.716258 & -1.581441 & $\begin{array}{c}-0.779694 \\
\end{array}$ & -0.267691 & 0.324891 & -1.522369 & -0.200572 & $\begin{array}{r}-0.6509999 \\
\end{array}$ & -1.099886 & -1.389030 & -1.24012 & -1.23694 \\
\hline 35 & -0.967546 & $\begin{array}{c}-0.938252 \\
\end{array}$ & -1.346283 & -1.711819 & -1.600364 & $\begin{array}{r}-0.760347 \\
\end{array}$ & -0.265024 & 0.325064 & -1.521884 & $\begin{array}{r}-0.204959 \\
\end{array}$ & $\begin{array}{r}-0.643868 \\
\end{array}$ & -1.091238 & -1.380345 & -1.23578 & -1.23261 \\
\hline 36 & -0.756168 & $\begin{array}{c}-0.887741 \\
\end{array}$ & -0.590635 & -1.012775 & -0.964894 & -0.545484 & -0.061013 & 0.790006 & -1.600640 & $\begin{array}{r}-0.583137 \\
\end{array}$ & -0.582622 & -1.203534 & -1.449833 & -0.98393 & -0.98140 \\
\hline 37 & -0.042460 & 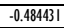 & -0.758765 & -0.538176 & -1.046066 & 0.001974 & -0.836016 & 1.224681 & -1.911762 & $\begin{array}{r}-0.317829 \\
\end{array}$ & $\begin{array}{r}-0.628626 \\
\end{array}$ & -1.833382 & -1.986606 & -0.97418 & -0.97168 \\
\hline 38 & $\begin{array}{l}-0.392320 \\
\end{array}$ & $\begin{array}{r}-0.738298 \\
\end{array}$ & $\begin{array}{c}-0.301055 \\
\end{array}$ & -1.332068 & -0.610205 & $\begin{array}{l}-0.194391 \\
\end{array}$ & 0.089928 & 0.860108 & $\begin{array}{l}-0.675827 \\
\end{array}$ & $\begin{array}{r}-0.326380 \\
\end{array}$ & $\begin{array}{r}-0.588848 \\
\end{array}$ & -0.627800 & -0.490163 & -0.54388 & -0.54248 \\
\hline 39 & $\begin{array}{l}-0.402622 \\
\end{array}$ & $\begin{array}{c}-0.701289 \\
\end{array}$ & $\begin{array}{l}-0.275082 \\
\end{array}$ & -1.317364 & -0.672887 & $\begin{array}{c}-0.130302 \\
\end{array}$ & 0.098763 & 0.860680 & $\begin{array}{l}-0.674219 \\
\end{array}$ & $\begin{array}{r}-0.340910 \\
\end{array}$ & -0.565224 & -0.599153 & -0.461395 & -0.5295 & -0.52814 \\
\hline 40 & -0.296778 & -0.853558 & 0.072354 & -1.007762 & -0.297506 & 0.022498 & 0.132695 & 1.047640 & -0.760495 & -0.653921 & -0.505264 & -0.581298 & $-0.41|23|$ & -0.42404 & -0.42295 \\
\hline 41 & $\begin{array}{l}-0.989669 \\
\end{array}$ & $\begin{array}{c}-0.953983 \\
\end{array}$ & 0.782869 & $\begin{array}{c}-0.918664 \\
\end{array}$ & -0.581298 & $\begin{array}{r}-0.080429 \\
\end{array}$ & -0.615806 & 1.012503 & $\begin{array}{r}-0.980189 \\
\end{array}$ & $\begin{array}{r}-0.481343 \\
\end{array}$ & -0.510627 & $\begin{array}{l}-0.634970 \\
\end{array}$ & -0.612540 & -0.57197 & -0.57050 \\
\hline 42 & -0.217556 & -0.401422 & 0.159594 & $\begin{array}{c}-0.971997 \\
\end{array}$ & -0.108898 & 0.149244 & 0.020034 & 1.181416 & -1.140585 & $\begin{array}{l}-0.259475 \\
\end{array}$ & -0.373360 & 0.014463 & -0.156107 & -0.17991 & -0.17945 \\
\hline 43 & $\begin{array}{l}-0.748321 \\
\end{array}$ & -0.542415 & $\begin{array}{c}-0.657635 \\
\end{array}$ & -1.332374 & -0.321038 & $\begin{array}{r}-0.494353 \\
\end{array}$ & $0.41 \mid 467$ & 0.616620 & -0.270645 & $\begin{array}{l}-0.156691 \\
\end{array}$ & $\begin{array}{r}-0.458174 \\
\end{array}$ & 0.134702 & 0.167519 & -0.36461 & -0.36368 \\
\hline 44 & -0.709793 & $\begin{array}{c}-0.684243 \\
\end{array}$ & 0.399037 & 0.338670 & -0.617936 & -0.920020 & -1.846562 & -0.145497 & -0.410688 & -0.026810 & -0.578819 & 0.176360 & 0.052960 & -0.50475 & -0.50345 \\
\hline 47 & -0.211301 & $\begin{array}{r}-0.137680 \\
\end{array}$ & 0.174064 & -0.374192 & -0.598231 & $\begin{array}{r}-0.324652 \\
\end{array}$ & -0.275691 & -0.481634 & 0.143505 & $\begin{array}{r}-0.212338 \\
-.03\end{array}$ & $\begin{array}{r}-0.226199 \\
\end{array}$ & 0.687668 & 0.643002 & -0.08128 & -0.08108 \\
\hline 48 & 0.553716 & 1.091670 & 2.257205 & 0.496643 & 1.359107 & 2.598631 & 2.271005 & 2.502860 & 2.332255 & 2.905605 & 0.282285 & 2.694193 & 2.480347 & 2.423267 & 2.41705 \\
\hline 49 & 0.553716 & 1.091670 & 2.257205 & 0.496643 & 1.359107 & 2.598631 & 2.271005 & 2.502860 & 2.332255 & 2.905605 & 0.282285 & 2.694193 & 2.480347 & 2.423267 & 2.41705 \\
\hline 50 & 0.025952 & 0.638085 & 0.947218 & 0.422923 & 2.560033 & 3.278379 & 3.353122 & -2.324844 & 0.374811 & 4.053547 & 2.245557 & 3.119142 & 2.659708 & 2.461696 & 2.45538 \\
\hline 51 & $\begin{array}{r}-0.364764 \\
\end{array}$ & -0.898675 & -1.402760 & 0.121864 & -0.908825 & -1.229774 & -1.115543 & -0.153285 & -0.829074 & -0.443407 & $\begin{array}{c}-0.604981 \\
\end{array}$ & -0.334431 & -1.086048 & -0.99212 & -0.98957 \\
\hline 52 & -0.744123 & -1.010445 & -1.499923 & 0.085738 & -1.007594 & -0.967930 & -1.018094 & -0.323784 & -0.424933 & -0.780126 & -0.615763 & -1.145960 & -0.970859 & -1.14196 & -1.13902 \\
\hline 53 & -0.745095 & -1.006954 & -1.497472 & 0.087125 & -1.013508 & -0.961884 & -1.017261 & -0.323730 & -0.424781 & -0.781497 & -0.613535 & -1.143257 & -0.968145 & -1.1406 & -1.13767 \\
\hline 54 & -0.789438 & $\begin{array}{l}-1.183524 \\
-.18\end{array}$ & -1.156060 & 0.268258 & -0.721641 & -0.895156 & -0.854665 & -0.245894 & -0.439540 & $\begin{array}{r}-1.096685 \\
\end{array}$ & $\begin{array}{r}-0.543302 \\
\end{array}$ & -1.001935 & -0.817029 & -1.04657 & -1.04388 \\
\hline 55 & -0.706057 & -1.139500 & -1.072996 & 0.194825 & -0.697464 & $\begin{array}{c}-0.877944 \\
\end{array}$ & -0.908928 & -0.300274 & $\begin{array}{r}-0.350729 \\
\end{array}$ & $\begin{array}{l}-1.108887 \\
-1.08\end{array}$ & -0.569672 & -0.994608 & -0.807557 & -1.02567 & -1.02304 \\
\hline 60 & 0.245707 & $\begin{array}{r}-0.365480 \\
\end{array}$ & -0.141018 & 0.232500 & 0.080554 & $\begin{array}{c}-0.390177 \\
\end{array}$ & -0.087822 & 0.315070 & 0.725740 & -0.379385 & -0.572396 & 0.115885 & 0.287655 & -0.03519 & -0.03510 \\
\hline 61 & 0.569970 & -0.242114 & -0.106454 & 0.534161 & 0.152547 & -0.099338 & -0.372885 & 0.556952 & 0.568224 & $\begin{array}{c}-0.378982 \\
\end{array}$ & -0.562355 & -0.124996 & 0.097055 & 0.007712 & 0.00769 \\
\hline 62 & 0.245707 & $\begin{array}{r}-0.365480 \\
\end{array}$ & -0.141018 & 0.232500 & 0.080554 & $\begin{array}{c}-0.390177 \\
\end{array}$ & -0.087822 & 0.315070 & 0.725740 & -0.379385 & -0.572396 & 0.115885 & 0.287655 & -0.03519 & -0.03510 \\
\hline 63 & 0.569970 & -0.242114 & -0.106454 & 0.534161 & 0.152547 & $\begin{array}{r}-0.099338 \\
\end{array}$ & -0.372885 & 0.556952 & 0.568224 & $\begin{array}{r}-0.378982 \\
\end{array}$ & -0.562355 & -0.124996 & 0.097055 & 0.007712 & 0.00769 \\
\hline 64 & 0.323928 & $\begin{array}{r}-0.817898 \\
\end{array}$ & $\begin{array}{c}-0.218498 \\
\end{array}$ & -0.185780 & -0.310545 & $\begin{array}{r}-0.426726 \\
\end{array}$ & -0.264847 & 0.215727 & 1.533040 & $\begin{array}{l}-1.209974 \\
\end{array}$ & 2.634111 & -1.171579 & -1.035382 & -0.40062 & -0.39959 \\
\hline 65 & 0.567054 & $\begin{array}{r}-0.231639 \\
\end{array}$ & $\begin{array}{c}-0.099103 \\
\end{array}$ & 0.538323 & 0.134807 & -0.081199 & -0.370385 & 0.557114 & 0.568679 & $\begin{array}{r}-0.383094 \\
\end{array}$ & -0.555669 & -0.116888 & 0.105198 & 0.011781 & 0.01175 \\
\hline 66 & 0.825465 & 1.328309 & 1.046636 & 0.053219 & 0.674236 & 0.007734 & -0.128539 & -0.334144 & 0.582954 & 0.917233 & $\begin{array}{l}-0.670948 \\
\end{array}$ & 0.124658 & 0.597006 & 0.632034 & 0.63041 \\
\hline 67 & -0.113788 & -0.000913 & 0.061150 & 0.126812 & -0.475047 & $\begin{array}{r}-0.783974 \\
\end{array}$ & -0.309057 & 0.883808 & 2.390660 & $\begin{array}{r}-0.063077 \\
-\end{array}$ & 2.416507 & -0.619835 & -0.242545 & -0.00707 & -0.00705 \\
\hline 68 & 1.704729 & 1.425058 & 0.905687 & 0.828395 & 1.001216 & 0.922768 & 1.182472 & 1.593783 & 1.917203 & 1.156747 & 2.983202 & 1.065601 & 0.937137 & 1.584241 & 1.58017 \\
\hline 69 & 2.061313 & 1.718601 & 1.048124 & 1.253814 & 0.847416 & 1.525457 & 0.868142 & 1.891626 & 1.730884 & 1.101191 & 3.086599 & 0.881694 & 0.815155 & 1.692145 & 1.68780 \\
\hline 70 & 1.505159 & 1.104478 & 0.562354 & 0.394969 & 0.782610 & 0.844416 & 1.097543 & 1.256677 & 1.929429 & 1.103435 & 3.014422 & 1.323845 & $\frac{.1193880}{1.17480}$ & 1.445958 & 1.44225 \\
\hline
\end{tabular}




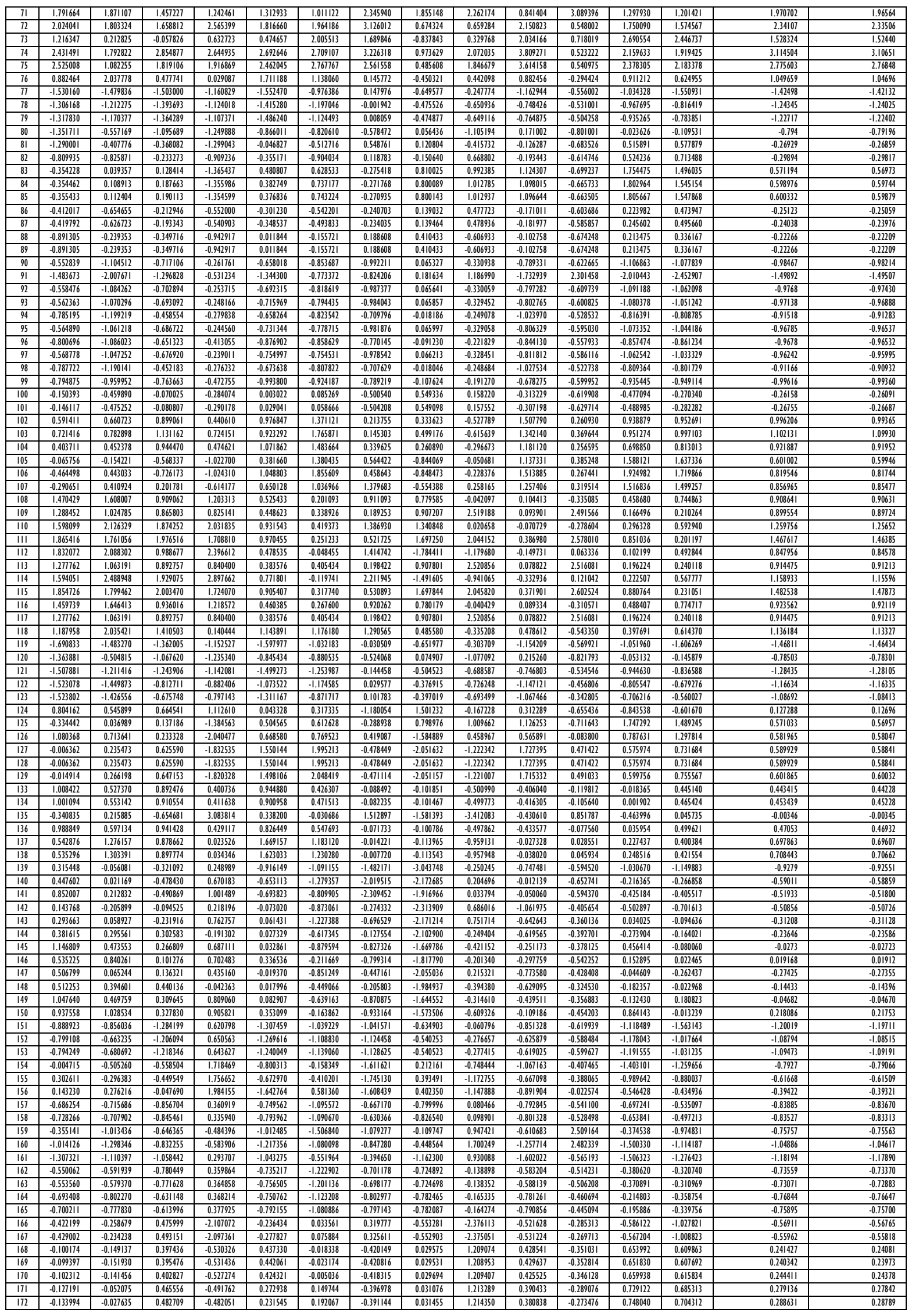




\begin{tabular}{|c|c|c|c|c|c|c|c|c|c|c|c|c|c|c|c|}
\hline 173 & $\begin{array}{c}-0.001878 \\
\end{array}$ & 0.213458 & 0.623013 & -0.245003 & -0.020711 & 0.652456 & -0.508319 & 0.168503 & 1.134336 & 0.313316 & -0.157755 & 0.74782 & 0.732556 & 0.379507 & 0.37853 \\
\hline 174 & -0.166103 & -0.054364 & -0.670702 & 1.113619 & 0.207337 & -0.506443 & -0.415663 & 0.881683 & 1.680952 & -0.096329 & -0.034577 & 0.102695 & -0.145763 & -0.02863 & -0.02856 \\
\hline 175 & 0.282103 & 0.098988 & -0.332100 & 0.196077 & -0.155956 & -1.201881 & -0.164782 & 0.549818 & 0.800553 & -0.0377509 & 2.627504 & -0.2988448 & -0.630044 & -0.11571 & $\begin{array}{c}-0.11544 \\
\end{array}$ \\
\hline 176 & -0.237513 & 0.043258 & -0.594557 & 0.989389 & 0.111889 & -0.660807 & -0.302508 & 0.828120 & 1.585129 & 0.056632 & -0.588270 & 0.433449 & 0.220206 & 0.052327 & 0.05211 \\
\hline 177 & -0.054668 & 0.102096 & $\begin{array}{l}-0.582161 \\
\end{array}$ & 1.153125 & 0.168311 & -0.516024 & -0.4631922 & 0.96349 & 1.497199 & 0.06664 & -0.58888 & 0.292111 & 0.106778 & 0.072396 & 0.07212 \\
\hline 178 & -0.24066 & 0.017393 & -0.572993 & 1.001596 & 0.059851 & -0.067601 & -0.0295174 & 0.82896 & 1.586463 & 0.044569 & -0.568658 & 0.45731 & 0.244899 & 0.064264 & 0.06410 \\
\hline 179 & 0.0308469 & 0.598169 & 0.29873 & 0.024744 & 1.086296 & 0.868952 & 1.424996 & 0.30845 & -0.063699 & 1.221321 & 0.311661 & 1268072 & 0.87875 & 0.87758 & 0.085510 \\
\hline 180 & -0.304165 & 0.661730 & 0.321957 & 0.038162 & 1006244 & 0.0891284 & 1.410845 & 0.362652 & -0.103925 & 1.260344 & 0.330675 & 1.236289 & 1.038333 & 0 & $\begin{array}{l}0.002510 \\
0.91564\end{array}$ \\
\hline $\mid 181$ & -0.251618 & 0.73831 & 0.98644 & 0,60260 & 1032161 & 1146388 & 1002213 & 0.672149 & -0.284164 & 1.16301 & 0.323939 & 1022195 & 0.654122 & 0.99982 & 0.995712 \\
\hline 182 & -0.291600 & 0.935129 & 0.958767 & 0.573505 & 1.030393 & 1.071277 & 0.937062 & 0.718290 & -0.358276 & 1.038805 & 0.304132 & 0.991915 & 0.790721 & 0.953811 & 0.95136 \\
\hline 183 & -0.589371 & -1.144597 & -1.0 .16661 & -0.088482 & -0.049248 & -0.881418 & -0.366571 & 0.561649 & 0.716678 & .15772946 & 2.683640 & .059986 & 1380183 & 0.07111 & -0.96862 \\
\hline 184 & 0.039733 & -0.470921 & $\begin{array}{l}-0.472095 \\
0\end{array}$ & $\frac{0.004426}{0}$ & $=0.01486811$ & -0.0167583 & -0433166 & 0702959 & 0.0323544 & -0.46856 & -0.530247 & -0.805696 & -0481353 & .040451 & $\begin{array}{r}-0.090000 \\
-0.4037\end{array}$ \\
\hline 185 & -0.589820 & -1.142502 & -1.015491 & -0.084010 & -0.952796 & -0.807790 & -0.366072 & 0.561681 & 0.716769 & .15731699 & 2.684977 & -1.957564 & -1.378555 & -0.9703 & \\
\hline 186 & 0.0302169 & $\begin{array}{l}-0.4680497 \\
\end{array}$ & $\begin{array}{l}-0.425625 \\
\end{array}$ & -0.003593 & -0.152229 & -0.00163956 & $\frac{0.05001}{-0.432666}$ & 0.00702992 & 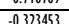 & 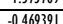 & 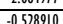 & -0.804074 & 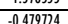 & 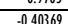 & $\begin{array}{l}-0.991818 \\
-0.40266\end{array}$ \\
\hline $\begin{array}{l}187 \\
1\end{array}$ & 0.02624 & -0.42505 & -0.394751 & 0.018855 & $\begin{array}{c}-0.2263717 \\
\end{array}$ & -0.087775 & -0.422164 & 0.703671 & -0.321542 & -0.48662 & -0.500830 & -0.770023 & -0.445527 & -0.3866 & $\begin{array}{l}-0.4 .42600 \\
-0.3856\end{array}$ \\
\hline 188 & -0.6646955 & -0.839050 & -1.215321 & 0.283780 & 0.0657527 & 0 & 0.065286 & 0.603332 & 0.837317 & $\frac{0.40002}{.128309}$ & 2776413 & $\frac{1.1020408}{-1.20848}$ & $\frac{0.040311}{-1.43671}$ & -0.000709 & $\begin{array}{l}-0.083500 \\
.080501\end{array}$ \\
\hline 189 & 0.026926 & -0.194867 & -0.270868 & -0.385759 & 0.028972 & 0.086535 & -0.302698 & 0.746794 & $\frac{0.0750348}{2}$ & .03087819 & $=0.213831$ & -0.683815 & 0.0561837 & 2.0 .29886 & $\begin{array}{l}-0.0 .035011 \\
-0.2291\end{array}$ \\
\hline$\frac{197}{190}$ & $\begin{array}{l}0.00052769 \\
0.0959\end{array}$ & $\begin{array}{r}-0.154001 \\
-0.250108\end{array}$ & $\begin{array}{l}.0 .52000 \\
-0.52515\end{array}$ & $\frac{0.0538733}{-0.588}$ & $\frac{0.020412}{-0.69426}$ & $\begin{array}{l}-0.0000307 \\
-0.13643\end{array}$ & $\frac{0.030270}{-1.183262}$ & 0.0636248 & $\frac{0.01700400}{-1.161140}$ & $\begin{array}{l}-5.507017 \\
0.274199\end{array}$ & $\begin{array}{l}-0.075011 \\
-0.653482\end{array}$ & $\begin{array}{l}-0.005013 \\
-0.574705\end{array}$ & $=0.05010170$ & 0.0 .071280 & $\begin{array}{l}-0.1511149 \\
.051 / 49\end{array}$ \\
\hline 191 & -0.7746309 & $\begin{array}{l}-0.2500100 \\
-0.071204\end{array}$ & -0.275168 & -1.138451 & $\begin{array}{l}-0.0644200 \\
-0.025326\end{array}$ & -0.782910 & $\begin{array}{l}-1.0 .102021 \\
-0.040574\end{array}$ & 0.133809 & -0.822537 & $\begin{array}{l}0.02761616 \\
0.0216\end{array}$ & $\begin{array}{l}-0.0350202 \\
-0.624704\end{array}$ & $\begin{array}{l}-0.091403 \\
0.09387\end{array}$ & 0.003654 & $\begin{aligned}-0.01701 \\
-0.54924\end{aligned}$ & $\begin{array}{l}-0.551149 \\
.054783\end{array}$ \\
\hline$\frac{171}{192}$ & 0.557949 & 0.0 .110251 & 0.298480 & $\frac{1.15007917}{0.076937}$ & 0.0 .4252090 & 0.0320909 & 0.057212129 & $\frac{0.050907}{1.059312}$ & $\frac{.1063826}{.15}$ & $\frac{0.027010}{0.500281}$ & $\frac{-0.04704}{-0.246257}$ & $\begin{array}{l}0.053001 \\
0.344476\end{array}$ & 0.000503490 & 0.432787 & $\begin{array}{r}-0.548133 \\
0.3137\end{array}$ \\
\hline 193 & -0.324330 & 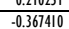 & -0.839201 & 0.524456 & $\begin{array}{l}0.0 .486879 \\
-0.3862\end{array}$ & -0.882916 & 0.179670 & 0.871696 & $\begin{array}{c}0.10000202 \\
\end{array}$ & $\frac{0.500201}{-1.2540900}$ & 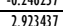 & $\frac{-5.5414030}{-0.610309}$ & $\begin{array}{c}-0.06408677 \\
-0.067\end{array}$ & $\begin{array}{l}0.40247605 \\
.03560\end{array}$ & $\begin{array}{l}0.43151 \\
0.035514\end{array}$ \\
\hline 194 & 0.295915 & -0.085894 & 0.2232377 & -0.005579 & 0.099285 & 0.118969 & 0.713488 & 0.948108 & -0.553768 & -0.746787 & -0.324596 & $\begin{array}{l}-0.0262826 \\
-\end{array}$ & 0.021406 & 0.035812 & 0.03572 \\
\hline 195 & 1.467143 & 0.990596 & 1.736490 & 0.065030 & 0.951390 & 0.887178 & 0.543940 & -0.064866 & 0.263357 & -0.114631 & -0.139070 & 0.067960 & 0.186161 & 0.805326 & 0.80326 \\
\hline 196 & 1.681130 & 1.152277 & 1.812393 & 0.311735 & 0.880453 & 1.222920 & 0.355389 & 0.110949 & 0.152748 & -0.142837 & -0.085488 & -0.048827 & 0.104927 & 0.864513 & 0.86229 \\
\hline 197 & 1.450594 & 0.971026 & 1.738281 & 0.060991 & 0.900733 & 0.941027 & 0.568093 & -0.082684 & 0.305494 & -0.170926 & -0.0130053 & 0.133795 & 0.060900 & 0.791983 & 0.78995 \\
\hline 198 & 1.667496 & 1.122233 & 1.806832 & 0.311635 & 0.847536 & 1.258631 & 0.377041 & 0.092970 & 0.194430 & -0.195019 & -0.083157 & 0.007900 & -0.028476 & 0.8471 & 0.84493 \\
\hline 199 & 0.805699 & 1.975312 & 1.153060 & 0.715851 & 1.744261 & 1.087860 & 0.213005 & 0.264938 & -0.270964 & 0.543386 & -0.0307851 & 0.940740 & 0.787852 & 1.145717 & 1.14278 \\
\hline 200 & 1.021629 & 2.130010 & 1.224062 & 0.959781 & 1.685151 & 1.441510 & 0.022786 & 0.440646 & -0.381877 & 0.5179222 & -0.258726 & 0.817548 & 0.701190 & 1.202191 & 1.19911 \\
\hline 201 & 1.653212 & 1.510865 & 1.570640 & 0.049392 & 0.995863 & 0.680826 & 1.533992 & -0.007887 & 0.66 & 0.022710 & -0.0188961 & 0.106126 & 0.251294 & 1.000005 & 0.99744 \\
\hline 202 & 1.206150 & 2.288839 & 1.389427 & 0.151501 & 1.803415 & 1.105412 & 1.263708 & 0.028488 & 0.44 & 0.595488 & -0.176185 & 0.538251 & 0.588613 & 1.305152 & 1.30180 \\
\hline 203 & 1.643151 & 1.503297 & 1.498251 & 0.71 & 1.312 & & & -0.43 & -0.47 & 1.067241 & 0.067021 & 0.353518 & 0.604862 & 1.263926 & 1.26068 \\
\hline 204 & 0.385903 & 0.861476 & 0.197533 & 0.910516 & 0.311850 & -0.004168 & 1.807066 & 1.443688 & 0.203213 & 0.354933 & 3.410973 & 0.5090222 & -0.054757 & 0.799648 & 0.79760 \\
\hline 205 & $\begin{array}{l}.833619 \\
19\end{array}$ & 1.765822 & 1.702150 & 0.108869 & 0.986798 & 0.613815 & 1.438713 & 0.130941 & 0.344239 & 0.314221 & -0.128989 & 0.324968 & 0.755911 & 1.165163 & $\begin{array}{l}1.16217 \\
\end{array}$ \\
\hline
\end{tabular}

\section{Table.B3. Transformed Sinusoidal Dataset}

\begin{tabular}{|c|c|c|c|c|c|c|c|c|c|c|c|}
\hline SI & $X_{1}$ & $x_{2}$ & $x_{3}$ & $X_{4}$ & $X_{5}$ & $X_{6}$ & $X_{7}$ & $X_{8}$ & $X_{9}$ & Score(Brown) & Score(Pearson) \\
\hline 1 & 0.379768 & 0.591644 & 0.864886 & -0.583739 & 0.437819 & -0.706206 & 2.086528 & 1.164571 & -0.655893 & -0.314447 & -0.311286 \\
\hline 2 & -0.222814 & 0.487962 & -1.770506 & -0.231000 & 0.910600 & -1.291688 & 1.026590 & 0.887420 & -0.958380 & -0.221219 & -0.218996 \\
\hline 3 & 0.158524 & -0.865345 & 0.885310 & -0.378477 & -0.441734 & 1.497563 & -1.443534 & -0.544974 & 1.637562 & -0.337445 & -0.334053 \\
\hline 4 & -1.457372 & -1.437488 & 0.825761 & 1.726260 & -0.651721 & 1.081300 & -1.374693 & -1.163250 & -0.883275 & 0.411166 & 0.407034 \\
\hline 5 & 0.031762 & 1.374938 & 0.289824 & 0.384787 & 0.922557 & -0.203191 & -0.939577 & 1.632199 & -0.396816 & 0.515225 & 0.510047 \\
\hline 6 & 1.632960 & 1.320257 & 1.699304 & 1.064032 & -1.191011 & -1.469474 & 0.041273 & 0.339102 & -1.066214 & 1.634535 & 1.618107 \\
\hline 7 & 0.445118 & 1.576147 & 0.536385 & 1.639405 & -0.532903 & -0.398114 & 0.221783 & -1.035509 & -1.280159 & 1.694987 & 1.677951 \\
\hline 8 & -0.535915 & 0.194434 & -1.069211 & 0.183424 & 0.380527 & -1.043929 & -1.534709 & -0.170212 & 0.400054 & 0.081753 & 0.080931 \\
\hline 9 & -1.135085 & -0.600696 & 0.008076 & 0.275952 & -1.856840 & -1.486253 & 0.626945 & -1.004554 & -0.411630 & -0.216884 & -0.214704 \\
\hline 10 & -1.789107 & -1.484121 & -0.550499 & -1.797233 & -1.938543 & -0.207475 & 0.995585 & 1.044672 & 0.270860 & -1.943332 & -1.923801 \\
\hline 11 & -0.562685 & 0.282256 & -0.870142 & 1.242706 & -0.849004 & -1.537662 & 0.483220 & 0.171739 & -0.218011 & 0.131529 & 0.130207 \\
\hline 12 & 1.819299 & 1.798187 & -0.472988 & -0.303675 & -1.211436 & 0.538658 & -0.157367 & -0.775693 & -0.073313 & 1.395912 & 1.381882 \\
\hline 13 & 0.323079 & 0.781727 & 0.938706 & -1.455484 & 0.178760 & 1.426877 & -1.340798 & -0.456856 & -0.382001 & 0.569496 & 0.563772 \\
\hline 14 & -0.157201 & 0.594958 & -1.814552 & 1.358277 & -0.848755 & -0.468443 & 0.204179 & 1.623944 & -1.600217 & 0.615228 & 0.609045 \\
\hline 15 & -1.122750 & -1.170236 & -0.427957 & -1.149895 & 0.408924 & -0.930045 & 0.857378 & 1.657995 & 1.255492 & -2.040133 & -2.019629 \\
\hline 16 & -0.753747 & -0.940384 & 0.842002 & 1.406136 & 1.247625 & 1.724973 & 2.100454 & -0.948216 & -0.109832 & -0.462004 & -0.457361 \\
\hline 17 & -0.467153 & -0.155433 & -1.237768 & -1.174710 & -0.236480 & -0.566975 & -1.255930 & -0.454173 & 0.140632 & -0.223089 & -0.220847 \\
\hline 18 & 0.195792 & 1.114550 & 1.098897 & 0.860542 & 0.210395 & 1.925251 & -0.567784 & -0.672922 & -0.511885 & 1.139696 & 1.128241 \\
\hline 19 & 0.736698 & 1.420861 & 1.257365 & -0.029637 & 0.984830 & 0.710732 & -0.683658 & 0.286685 & 0.071384 & 0.770009 & 0.762270 \\
\hline 20 & 1.526669 & -0.746513 & -1.407309 & 2.121895 & -0.010552 & -0.975028 & 0.301659 & -0.646301 & -0.206642 & 0.853191 & 0.844616 \\
\hline 21 & -1.489391 & -0.781074 & -0.402858 & -0.238090 & 0.554146 & -0.676218 & 0.729944 & -0.283094 & 0.727346 & -1.226084 & -1.213762 \\
\hline 22 & -0.089752 & -0.897302 & 0.094446 & 1.239515 & 0.779078 & 0.417991 & -0.157892 & -1.346092 & -0.763038 & 0.507243 & 0.502145 \\
\hline 23 & -1.128786 & 0.475890 & 0.547950 & -0.762059 & 0.616419 & 1.062379 & -0.386749 & 1.206464 & 2.055118 & -1.247761 & -1.235220 \\
\hline 24 & 1.379960 & -0.105249 & -0.494150 & -0.991073 & -0.071082 & 0.316960 & 0.324519 & 1.750447 & -0.035416 & -0.234457 & -0.232100 \\
\hline 25 & 1.762085 & 0.168159 & 1.263271 & -0.817717 & 1.608065 & 1.376897 & 0.224936 & -0.629378 & 1.156615 & 0.103724 & 0.102681 \\
\hline 26 & 0.789976 & -0.188336 & -1.292395 & -0.112947 & -0.736662 & 0.230923 & -0.101138 & -1.534917 & -1.272236 & 0.925218 & 0.915919 \\
\hline 27 & 1.060298 & 0.827177 & -0.110775 & -0.507874 & -0.149048 & 1.813866 & -0.820814 & -0.912308 & -1.093431 & 1.264391 & 1.251684 \\
\hline 28 & -0.205492 & -1.861447 & 0.373487 & -1.572827 & 0.223348 & -0.861858 & 0.430407 & 1.473503 & 1.974156 & -2.120817 & -2.099501 \\
\hline 29 & 0.478711 & -1.685330 & -0.153837 & -1.221506 & -0.268115 & 0.613628 & -0.749083 & 0.711595 & -0.784743 & -0.373844 & -0.370087 \\
\hline 30 & 0.868185 & -0.256511 & -1.662482 & -0.162225 & -0.621830 & 1.573247 & 0.781443 & -1.624068 & 0.430716 & 0.175248 & 0.173487 \\
\hline 31 & 0.467951 & 0.061636 & 0.169251 & -0.309702 & -1.868548 & -0.837582 & 0.898105 & -0.879908 & 0.827256 & -0.089899 & -0.088996 \\
\hline 32 & 0.321767 & -0.355695 & 0.234213 & 1.294819 & -1.809014 & -0.436670 & -1.461927 & 0.237157 & 1.190034 & 0.321151 & 0.317923 \\
\hline 33 & -0.754272 & -0.481864 & 0.160638 & 1.543332 & 0.345155 & -1.558725 & -0.678140 & -0.132653 & -1.432436 & 0.584273 & 0.578401 \\
\hline 34 & -1.426140 & 0.200352 & -0.583964 & -1.001709 & -0.546354 & 0.023148 & 1.320083 & -0.026374 & 2.147449 & -1.656090 & -1.639446 \\
\hline 35 & -0.611762 & -1.557977 & 1.332662 & -0.615645 & -0.569520 & -0.327427 & 0.516064 & -0.324161 & -0.511196 & -0.654606 & -0.648026 \\
\hline 36 & -1.247675 & 0.282493 & -1.874593 & 0.967250 & -0.488066 & -0.364912 & 0.023931 & -0.362339 & 0.211947 & -0.142968 & -0.141531 \\
\hline 37 & 0.656389 & 0.832621 & -0.322886 & 0.503549 & 0.596741 & -0.931116 & -1.486625 & 1.124329 & -1.537170 & 1.163508 & 1.151814 \\
\hline 38 & 1.310674 & 2.033010 & -0.246359 & 0.166053 & -0.006317 & -0.719772 & -1.696563 & 0.119528 & -0.546681 & 1.647242 & 1.630686 \\
\hline 39 & 1.275243 & -0.831731 & -0.237992 & 0.301477 & -0.077309 & -1.068919 & -0.239871 & -1.253845 & -0.418865 & 0.649586 & 0.643057 \\
\hline 40 & -1.564713 & -0.276395 & 1.074290 & -0.901027 & 1.946086 & 0.827829 & 2.357950 & 0.115194 & 2.139869 & -2.167739 & -2.145952 \\
\hline 41 & -1.271033 & -1.985013 & 0.170727 & 1.012273 & 2.132907 & 1.165195 & -0.064353 & 1.170143 & -0.539102 & -0.958198 & -0.948567 \\
\hline 42 & -0.648243 & -0.587440 & -0.773437 & -1.304107 & 1.056320 & -1.302755 & -0.169191 & 1.575448 & -0.108799 & -1.097017 & -1.085991 \\
\hline 43 & -0.430673 & -0.100751 & -0.073373 & 0.223130 & 1.268549 & 0.730010 & -1.151880 & -1.149630 & 0.663266 & 0.071111 & 0.070397 \\
\hline 44 & 1.436386 & 1.791322 & 1.659441 & -0.680166 & 1.583903 & -0.297082 & 0.895740 & -1.876661 & -1.646382 & 1.563204 & 1.547493 \\
\hline 45 & 1.476016 & 0.447010 & -1.170591 & 0.492204 & 0.133923 & 0.056706 & 0.456157 & 0.216933 & 0.651897 & 0.343345 & 0.339895 \\
\hline 46 & -0.941135 & 0.602770 & 0.281704 & -0.608555 & 1.553513 & 0.933858 & -0.980566 & 1.644581 & -0.720662 & -0.211162 & -0.209040 \\
\hline 47 & -0.955045 & -0.583416 & 1.831688 & -0.423500 & -0.109691 & -0.158923 & 0.078584 & 0.396473 & 0.648107 & -0.845189 & -0.836694 \\
\hline 48 & 0.746147 & 0.400614 & 1.064693 & -1.516105 & -0.542119 & 1.143061 & -0.373086 & -0.204881 & 0.074485 & 0.202564 & 0.200528 \\
\hline 49 & 0.033599 & -0.762847 & -1.677246 & -0.360397 & -0.803669 & -0.912195 & 1.932031 & -0.784773 & 1.278919 & -1.061508 & -1.050840 \\
\hline 50 & -0.345115 & 1.037618 & 1.192895 & 1.204064 & -1.643865 & 0.547583 & -0.099562 & 0.647621 & 0.211258 & 0.511356 & 0.506216 \\
\hline
\end{tabular}




\begin{tabular}{|c|c|c|c|c|c|c|c|c|c|}
\hline State/UT & $\begin{array}{l}\text { Murder } \\
\text { (Sec. } \\
302 \\
\text { IPC) }\end{array}$ & $\begin{array}{l}\text { Attempt } \\
\text { to } \\
\text { Commit } \\
\text { Murder } \\
\text { (Sec. } 307 \\
\text { IPC) }\end{array}$ & $\begin{array}{l}\text { C.H. Not } \\
\text { Amount- } \\
\text { ing } \\
\text { to Murder } \\
\text { (Sec. 304, } \\
308 \text { IPC) }\end{array}$ & $\begin{array}{l}\text { Rape } \\
\text { (Sec. } \\
376 \\
\text { IPC) }\end{array}$ & $\begin{array}{l}\text { Kidnapping } \\
\& \\
\text { Abduction } \\
\text { (Sec. 363- } \\
\text { 310, 371- } \\
\text { 373 IPC) }\end{array}$ & $\begin{array}{l}\text { Dacoity } \\
\text { (Sec.395- } \\
398 \\
\text { IPC) }\end{array}$ & $\begin{array}{l}\text { Preparation } \\
\& \\
\text { Assembly } \\
\text { For Dacoity } \\
\text { (Sec.399- } \\
402 \\
\text { IPC) }\end{array}$ & $\begin{array}{l}\text { BScore } \\
\text { (Brown) }\end{array}$ & $\begin{array}{l}\text { Score } \\
\text { (Pearson) }\end{array}$ \\
\hline 1.Andhra Pr. & 1.171231 & 0.482465 & 1.318533 & -0.128862 & 0.270452 & 0.821229 & 1.039301 & 0.805917 & 0.794320 \\
\hline 2.Arunachal Pr. & \begin{tabular}{|l}
-0.750762 \\
\end{tabular} & -0.661604 & -0.846638 & -0.656380 & -0.738678 & -0.693263 & -0.336640 & -0.788503 & -0.777157 \\
\hline 3.Assam & -0.264487 & -0.817900 & 0.864876 & 1.071947 & 1.416584 & 0.552980 & 0.618254 & 0.537109 & 0.529381 \\
\hline 4.Bihar & 1.390559 & 1.820915 & 2.305963 & 2.036492 & 1.027998 & 0.313572 & 1.590260 & 1.737834 & 1.712828 \\
\hline 5.Chhattisgarh & -0.104895 & -0.274076 & 0.081390 & -0.743013 & 0.090017 & 0.039608 & 0.036394 & -0.156964 & -0.154705 \\
\hline 6.Goa & -0.749061 & -0.656879 & -0.891573 & -0.702397 & -0.776297 & -0.686393 & -0.346624 & -0.809175 & -0.797532 \\
\hline 7.Gujarat & -0.077701 & -0.435856 & 0.138155 & 0.276441 & 0.169928 & -0.556590 & 0.214459 & -0.056268 & -0.055458 \\
\hline 8.Haryana & 0.224880 & 0.103735 & 0.097829 & 0.063892 & 0.185974 & -0.132932 & -0.431277 & 0.043342 & 0.042718 \\
\hline 9. Himachal P. & \begin{tabular}{|c|}
-0.703013 \\
\end{tabular} & -0.693452 & -0.804186 & -0.665783 & -0.675543 & -0.549860 & -0.303938 & -0.742205 & -0.731526 \\
\hline 10.J.\&Kashmir & -0.729443 & -0.527548 & -0.473990 & -0.255750 & -0.708693 & -0.191283 & -0.119081 & -0.516998 & -0.509559 \\
\hline 11.Jharkhand & 0.354355 & 0.021602 & 0.449090 & 0.009123 & 0.761657 & -0.652195 & 0.338407 & 0.211017 & 0.207980 \\
\hline 12.Karnataka & 1.308983 & 0.934878 & 0.726878 & 0.669966 & 0.027256 & 0.135052 & -0.886119 & 0.560185 & 0.552124 \\
\hline 13.Kerala & \begin{tabular}{|l}
-0.110937 \\
\end{tabular} & 0.168662 & -0.530231 & -0.313733 & 0.385811 & 0.314335 & -0.942805 & -0.133840 & -0.131914 \\
\hline 14.Madhya Pr. & 0.860182 & 0.844624 & 1.638571 & -0.812338 & 1.826214 & 2.129052 & 0.328536 & 1.133055 & 1.116751 \\
\hline 15.Maharashtra & 1.182805 & 1.743989 & 2.159915 & 1.375505 & 2.690144 & -0.534550 & 0.107552 & 1.506685 & 1.485005 \\
\hline 16.Manipur & -0.372511 & -0.372251 & -0.823242 & -0.390072 & -0.795137 & -0.465671 & -0.883949 & -0.658423 & -0.648949 \\
\hline 17.Meghalaya & -0.712146 & -0.605090 & -0.736752 & -0.622008 & -0.550537 & -0.728277 & -0.295741 & -0.715907 & -0.705606 \\
\hline 18.Mizoram & -0.773320 & -0.644402 & -0.894496 & -0.722637 & -0.739072 & -0.651214 & -0.353582 & -0.804297 & -0.792724 \\
\hline 19.Nagaland & -0.753809 & -0.625552 & -0.886253 & -0.685710 & -0.767385 & -0.692372 & -0.334633 & -0.798627 & -0.787135 \\
\hline 20.Odisha & -0.028687 & 0.768130 & 1.152367 & 0.368328 & 0.984336 & -0.376163 & 0.144444 & 0.510107 & 0.502767 \\
\hline 21.Punjab & 0.153344 & 0.163959 & -0.293102 & -0.292145 & -0.479566 & 0.047504 & -0.350439 & -0.158125 & -0.155850 \\
\hline 22.Rajasthan & 0.234362 & -0.224500 & 0.822155 & 0.344045 & 0.318566 & 1.524207 & 0.371383 & 0.543231 & 0.535415 \\
\hline 23.Sikkim & -0.771499 & -0.656483 & -0.920927 & -0.706256 & -0.786977 & -0.692904 & -0.355633 & -0.822729 & -0.810890 \\
\hline 24.Tamil Nadu & 0.382014 & 0.812126 & 1.555037 & 0.058794 & -0.954678 & 0.512483 & 0.548781 & 0.472833 & 0.466029 \\
\hline 25.Tripura & -0.696118 & -0.666377 & -0.752213 & -0.687200 & -0.626010 & -0.563404 & -0.309351 & -0.725669 & -0.715228 \\
\hline 26.Uttar Pr. & 3.240298 & 3.535300 & 1.345790 & 3.299056 & 2.201805 & 3.321114 & 4.754557 & 3.524207 & 3.473496 \\
\hline 27.Uttarakhand & -0.650280 & -0.507686 & -0.813120 & -0.573944 & -0.662581 & -0.518848 & -0.185434 & -0.662752 & -0.653215 \\
\hline 28.West Bengal & 2.765764 & 2.027622 & 0.552783 & 2.587753 & 1.987720 & 2.679472 & -1.751979 & 1.958995 & 1.930806 \\
\hline
\end{tabular}




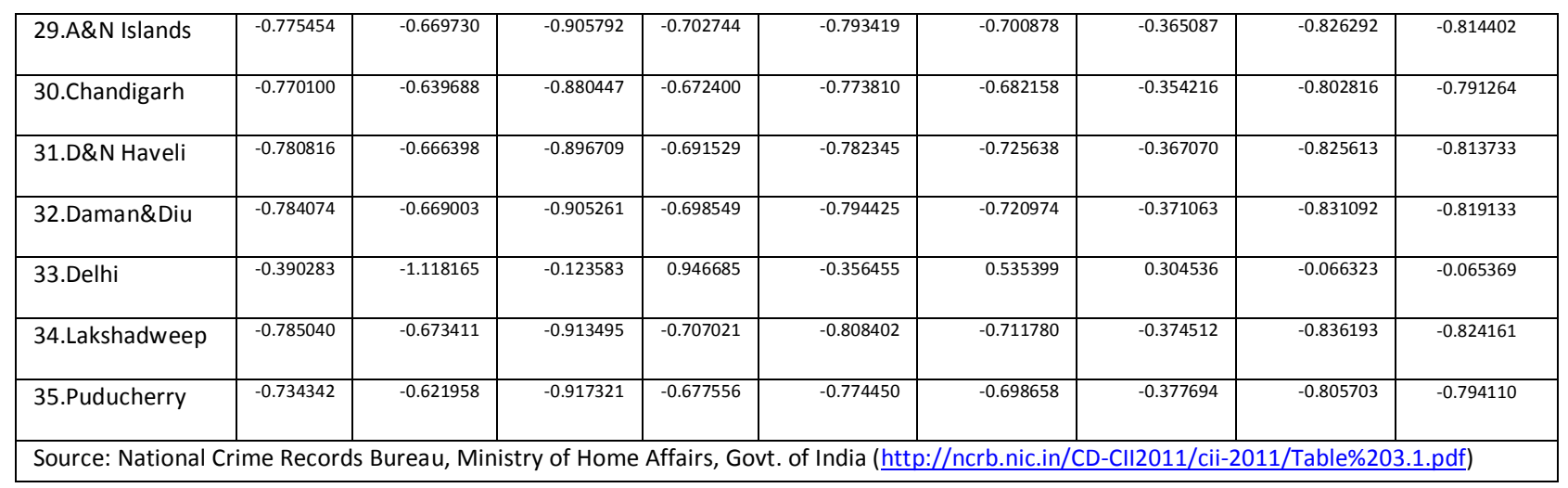

\begin{tabular}{|c|c|c|c|c|c|c|c|c|c|}
\hline \multicolumn{10}{|c|}{ Table.B5. Transformed Dataset with Outliers } \\
\hline SI & $x_{1}$ & $x_{2}$ & $x_{3}$ & $X_{4}$ & $x_{5}$ & $x_{6}$ & $x_{7}$ & $\begin{array}{l}\text { BScore } \\
\text { (Brown) }\end{array}$ & $\begin{array}{c}\text { Score } \\
\text { (Pearson) }\end{array}$ \\
\hline 1 & -1.688774 & -1.122541 & -1.540757 & -1.289075 & -1.225625 & -1.173593 & -1.194511 & -1.611800 & -1.588607 \\
\hline 2 & -1.610575 & -1.069114 & -1.471953 & -1.236476 & -1.168420 & -1.115488 & -1.135166 & -1.537280 & -1.515159 \\
\hline 3 & -1.515834 & -1.008167 & -1.393443 & -1.165169 & -1.106919 & -1.056048 & -1.080525 & -1.452988 & -1.432080 \\
\hline 4 & -1.422986 & -0.979006 & -1.312597 & -1.103745 & -1.043808 & -1.008427 & -1.023617 & -1.377592 & -1.357769 \\
\hline 5 & 1.809941 & -0.465374 & -0.612031 & 0.038771 & 0.035582 & 0.072951 & -0.044589 & 0.165426 & 0.163046 \\
\hline 6 & -1.251766 & -0.872067 & -1.176587 & -0.970833 & -0.934509 & -0.882798 & -0.910338 & -1.221379 & -1.203804 \\
\hline 7 & -1.161819 & -0.827339 & -1.100730 & -0.917648 & -0.861722 & -0.832385 & -0.850828 & -1.143483 & -1.127030 \\
\hline 8 & -1.073033 & -0.774236 & -1.012924 & -0.837809 & -0.804857 & -0.756646 & -0.793584 & -1.056413 & -1.041212 \\
\hline 9 & -0.985753 & -0.715628 & -0.932479 & -0.772734 & -0.733590 & -0.707899 & -0.728112 & -0.973128 & -0.959126 \\
\hline 10 & -0.916948 & -1.261919 & 1.163508 & 1.604958 & 1.140223 & 1.172300 & 0.789530 & 0.573720 & 0.565465 \\
\hline 11 & -0.806870 & -0.624372 & -0.794515 & -0.651084 & -0.619182 & -0.602533 & -0.617285 & -0.822758 & -0.810919 \\
\hline 12 & -0.718021 & -0.579947 & -0.710454 & -0.577530 & -0.563189 & -0.530311 & -0.556799 & -0.739277 & -0.728639 \\
\hline 13 & -0.626614 & -0.533294 & -0.641331 & -0.526752 & -0.508703 & -0.473786 & -0.495207 & -0.664116 & -0.654560 \\
\hline 14 & -0.548210 & -0.479475 & -0.560875 & -0.464142 & -0.439409 & -0.414386 & -0.435494 & -0.583371 & -0.574977 \\
\hline 15 & 0.600157 & 1.165771 & 2.762316 & -1.477752 & 0.710969 & 1.099341 & -1.026790 & 0.714097 & 0.703821 \\
\hline 16 & -0.361730 & -0.383471 & -0.412965 & -0.340983 & -0.326334 & -0.306546 & -0.321145 & -0.427872 & -0.421715 \\
\hline 17 & -0.268910 & -0.325476 & -0.319738 & -0.272324 & -0.248758 & -0.237275 & -0.259520 & -0.336977 & -0.332128 \\
\hline 18 & -0.183303 & -0.276518 & -0.253346 & -0.214718 & -0.182006 & -0.181016 & -0.210438 & -0.261748 & -0.257982 \\
\hline 19 & -0.100674 & -0.222816 & -0.169863 & -0.149823 & -0.126889 & -0.122156 & -0.140439 & -0.180123 & -0.177531 \\
\hline 20 & 0.759513 & 1.458132 & 1.637894 & 1.100581 & 1.136662 & -2.738609 & 2.296270 & 1.012868 & 0.998294 \\
\hline 21 & 0.080238 & -0.131592 & -0.022215 & -0.020083 & -0.010659 & -0.005317 & -0.023628 & -0.023157 & -0.022824 \\
\hline 22 & 0.172679 & -0.076124 & 0.052815 & 0.054138 & 0.052195 & 0.061982 & 0.034189 & 0.061507 & 0.060622 \\
\hline 23 & 0.259359 & -0.035796 & 0.124775 & 0.108169 & 0.105516 & 0.111450 & 0.082854 & 0.132331 & 0.130427 \\
\hline 24 & 0.347860 & 0.013966 & 0.193305 & 0.167496 & 0.170210 & 0.161807 & 0.145999 & 0.209840 & 0.206821 \\
\hline 25 & 0.920426 & 1.764478 & 1.070762 & 0.633021 & -1.498657 & 2.387700 & 3.436665 & 1.475291 & 1.454063 \\
\hline 26 & 0.524033 & 0.114247 & 0.357951 & 0.300975 & 0.294147 & 0.282423 & 0.254287 & 0.371892 & 0.367000 \\
\hline 27 & 0.607207 & 0.166146 & 0.425874 & 0.357644 & 0.357770 & 0.344600 & 0.320300 & 0.450367 & 0.443887 \\
\hline 28 & 0.696707 & 0.213324 & 0.506012 & 0.429336 & 0.412011 & 0.390808 & 0.382717 & 0.529312 & 0.521695 \\
\hline 29 & 0.800780 & 0.278733 & 0.591069 & 0.487639 & 0.489435 & 0.460725 & 0.448204 & 0.621161 & 0.612222 \\
\hline 30 & 1.639476 & 2.876129 & 1.652693 & 3.795192 & 0.540994 & 1.494253 & -0.940401 & 1.993110 & 1.964431 \\
\hline 31 & 0.968842 & 0.359472 & 0.734928 & 0.615767 & 0.605556 & 0.573674 & 0.545529 & 0.769077 & 0.758011 \\
\hline 32 & 1.060980 & 0.412190 & 0.813170 & 0.675688 & 0.669467 & 0.625270 & 0.608920 & 0.849806 & 0.837578 \\
\hline 33 & 1.147662 & 0.461530 & 0.892581 & 0.743473 & 0.726089 & 0.684825 & 0.670400 & 0.930193 & 0.916808 \\
\hline 34 & 1.235314 & 0.513308 & 0.977105 & 0.810634 & 0.787551 & 0.757005 & 0.737107 & 1.015669 & 1.001054 \\
\hline 35 & 1.610647 & 2.966845 & 0.482047 & 1.065198 & 4.168860 & 2.464106 & 2.035446 & 2.537792 & 2.501275 \\
\hline
\end{tabular}

\begin{tabular}{|c|c|c|c|c|c|c|c|c|c|}
\hline \multicolumn{10}{|c|}{ Table.B6. Transformed Lévy Distributed Probability Density Function Dataset } \\
\hline $\mathrm{SI}$ & $\mathrm{X}_{1}$ & $\mathrm{X}_{2}$ & $\mathrm{X}_{3}$ & $\mathrm{X}_{4}$ & $\mathrm{X}_{5}$ & $\mathrm{X}_{6}$ & $\mathrm{X}_{7}$ & $\begin{array}{c}\text { BScore } \\
\text { (Brown) }\end{array}$ & $\begin{array}{c}\text { Score } \\
\text { (Pearson) }\end{array}$ \\
\hline 1 & 5.039421 & -0.284487 & -1.161836 & 1.163818 & 1.906479 & 1.726509 & 1.854936 & 1.712594 & 1.695382 \\
\hline 2 & 1.680129 & 4.134063 & 0.857482 & -0.268956 & 0.876800 & 2.626207 & 3.335717 & 2.446571 & 2.421982 \\
\hline 3 & 1.089211 & 2.960932 & 0.914043 & -0.138148 & 0.766572 & 1.804884 & 1.607625 & 1.662829 & 1.646117 \\
\hline
\end{tabular}




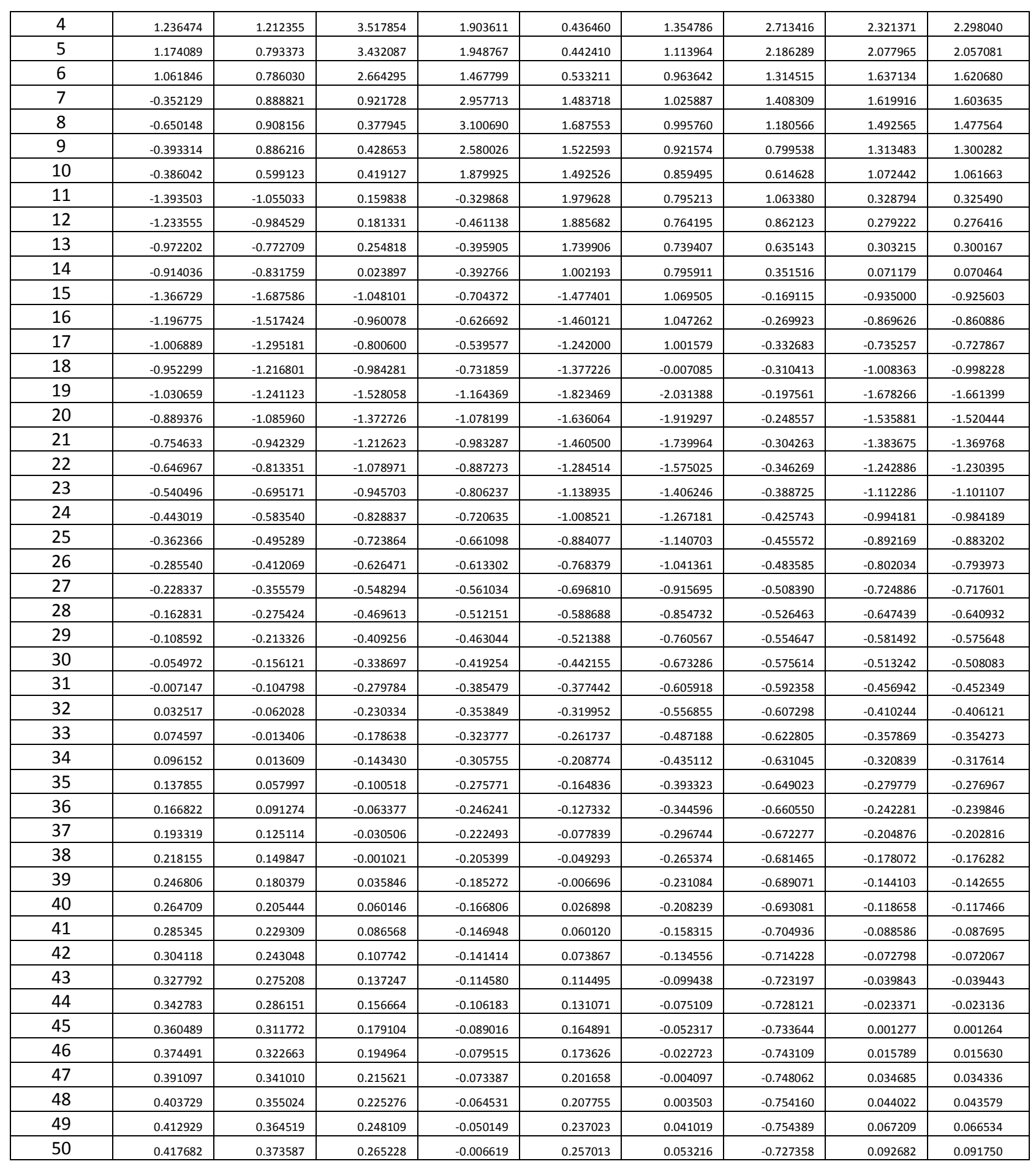

